\title{
Analysis of option returns in perfect and imperfect markets
}

\author{
Dissertation \\ zur Erlangung des Doktorgrades \\ der Wirtschaftswissenschaftlichen Fakultät \\ der Georg-August-Universität Göttingen
}

vorgelegt von

Dipl.-Wi.-Ing. David Salazar Volkmann, M.Sc.

Göttingen, 2020 


\section{Thesis Committee:}

Prof. Dr. Olaf Korn

Prof. Dr. Marliese Uhrig-Homburg

Prof. Dr. Helmut Herwartz 


\section{Contents}

List of Tables $\quad$ iii

List of Figures $\quad$ iv

1 Introduction 1

2 Explaining S\&P500 option returns: an implied risk-adjusted approach 4

2.1 Introduction . . . . . . . . . . . . . . . . . . . 5

2.2 Implied Risk-Adjusted Expected Option Return . . . . . . . . . . . . 7

2.3 Realized option returns . . . . . . . . . . . . . . . . . . 13

2.4 Option Return Prediction Test . . . . . . . . . . . . . . . . . 16

2.5 Conclusion . . . . . . . . . . . . . . . . . . . 30

3 Option Return Volatility 31

3.1 Introduction . . . . . . . . . . . . . . . . . 32

3.2 Option Volatility . . . . . . . . . . . . . . . . . 33

3.3 Cross-Section of Option Volatilities . . . . . . . . . . . . . . 36

3.4 Empirical study on S\&P500 Option Volatilities . . . . . . . . . . . . 44

3.5 Conclusion . . . . . . . . . . . . . . . . . . 54

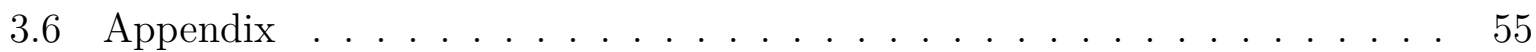

3.6 .1 Option volatility held to maturity . . . . . . . . . . . . . 55

3.6.2 Option volatility over finite holding periods . . . . . . . . . . 59

3.6.3 Option volatility over infinitesimal holding period . . . . . . . . . 61

4 A New Look at the Low-Volatility Effect 63

4.1 Introduction . . . . . . . . . . . . . . . . . . . . . . 64

4.2 Volatility and Imperfect Markets: The Conditional Low-Volatility Effect . 67

4.3 Data and Data Processing . . . . . . . . . . . . . . . . 69 
4.4 The Conditional Low-Volatility Effect: Empirical Evidence . . . . . . . . . 73

4.5 Benefits for Investors . . . . . . . . . . . . . . . . . . . . 75

4.6 Conclusions . . . . . . . . . . . . . . . . . . . . . . . . 79

$\begin{array}{lll}5 & \text { Conclusion } & 90\end{array}$

$\begin{array}{ll}\text { Bibliography } & 93\end{array}$

$\begin{array}{ll}\text { Declaration } & 98\end{array}$ 


\section{List of Tables}

2.1 Average 1-month S\&P500 put returns and S\&P500 index returns over different time periods. . . . . . . . . . . . . . . . . 15

2.2 Average 1-month S\&P500 call returns and S\&P500 index returns over different time periods. . . . . . . . . . . . . . . . . . 15

2.3 S\&P500 option return prediction test. . . . . . . . . . . . 26

2.4 Mean absolute prediction error differences of the Implied-CRRA model against the benchmark models. . . . . . . . . . . . . . . . . . . 28

3.1 S\&P500 Option Volatility Test . . . . . . . . . . . . . . . . . . . . . 48

3.2 S\&P500 Dynamic Option Volatility Test . . . . . . . . . . . . 53

4.1 Summary Statistics of Options and Stock Data . . . . . . . . . . . . . 81

4.2 Average Returns of Options Sorted by Stock Volatility and Expensiveness: One-factor Model . . . . . . . . . . . . . . . . . . . . . . 82

4.3 Average Returns of Options Sorted by Stock Volatility and Expensiveness: Three-factor Model . . . . . . . . . . . . . . . . . . . . . 84

4.4 Regressions of Average Returns of Long-Short (1-5) Portfolios When Expensiveness is High (5-high) on Different Combinations of Factors . . . . . 86

4.5 Average Returns and Alphas of Long-Short (1-5) Portfolios When Expensiveness is High (5-high) for Different Periods . . . . . . . . . . . . 88

4.6 Effect of Transaction Costs on Average Returns and Alphas of Long-Short (1-5) Portfolios When Expensiveness is High (5-high) . . . . . . . . . . . . 89 


\section{List of Figures}

2.1 Impact of the option strike on expected option payoffs and returns in the Implied-CRRA model. . . . . . . . . . . . . . . . . . . . 11

(a) Implied-CRRA discounted risk-neutral and physical expected call and put payoffs for different option strikes. . . . . . . . . . . . . . . 11

(b) Implied-CRRA hold-to-expiration expected call and put returns for different option strikes. . . . . . . . . . . . . . . . . . . . . . . 11

2.2 Impact of risk-aversion in the Implied-CRRA model. . . . . . . . . . . . . 12

(a) Implied-CRRA discounted risk-neutral and physical expected call and put option payoffs for varying risk-aversion. . . . . . . . . . . 12

(b) Implied-CRRA expected call and put returns for varying risk-aversion. 12

2.3 Monthly realized S\&P500 European option returns from 01/1996 - 08/2015. 16

2.4 Estimated CRRA risk aversion. . . . . . . . . . . . . . . . 18

2.5 Estimated Implied-CRRA risk aversion, Lognormal-CRRA risk aversion, Lognormal-CRRA volatility. . . . . . . . . . . . . . . . . . . 21

(a) Monthly estimated risk aversion and S\&P500 index prices. . . . . . . 21

(b) Monthly estimated Lognormal-CRRA volatility, realized volatility, and S\&P500 index prices. . . . . . . . . . . . . . . . . . 21

2.6 Monthly annualized risk-free rate . . . . . . . . . . . . . . 22

2.7 Forecasted and realized S\&P500 option returns. . . . . . . . . . . . 23

2.8 S\&P500 pricing kernel. . . . . . . . . . . . . . . . . . . . . . . . . . . . . . . 29

3.1 Impact of time to maturity and moneyness on option volatility. . . . . . . 38

(a) Option volatility for varying $T(h=T) \ldots \ldots \ldots$

(b) Option volatility for varying $T(h=0.5 T) \ldots \ldots \ldots \ldots$

(c) Option volatility for varying $T(h \rightarrow 0) \ldots \ldots \ldots$

(d) Option volatility for varying $K / S(h=T) \ldots \ldots \ldots$

(e) Option volatility for varying $K / S(h=0.5 T) \ldots \ldots \ldots \ldots$ 
(f) Option volatility for varying $K / S(h \rightarrow 0) \ldots \ldots \ldots$

3.2 Impact of underlying volatility and physical drift rate on option volatility. . 41

(a) Option volatility for varying $\sigma(h=T) \ldots \ldots \ldots \ldots$. . . . . . . 41

(b) Option volatility for varying $\sigma(h=0.5 T) \ldots \ldots \ldots$. . . . . . . 41

(c) Option volatility for varying $\sigma(h \rightarrow 0) \ldots \ldots \ldots \ldots \ldots$. . . . . . . 41

(d) Option volatility for varying $\mu(h=T) \ldots \ldots \ldots \ldots$. . . . . . . 41

(e) Option volatility for varying $\mu(h=0.5 T) . \ldots \ldots \ldots . \ldots . \ldots . \ldots 4$

(f) Option volatility for varying $\mu(h \rightarrow 0) \ldots \ldots \ldots$. . . . . . . . 41

3.3 Impact of risk-free rate and dividend yield on option volatility. . . . . . . . 43

(a) Option volatility for varying $r(h=T) \ldots \ldots \ldots . \ldots . \ldots 43$

(b) Option volatility for varying $r(h=0.5 T) \ldots \ldots \ldots . \ldots . \ldots . \ldots 43$

(c) Option volatility for varying $r(h \rightarrow 0) \ldots \ldots \ldots . \ldots . \ldots . \ldots 43$

(d) Option volatility for varying $d(h=T) \ldots \ldots \ldots$. . . . . . . . 43

(e) Option volatility for varying $d(h=0.5 T) \ldots \ldots \ldots . \ldots . \ldots . \ldots 43$

(f) Option volatility for varying $d(h \rightarrow 0) \ldots \ldots \ldots$. . . . . . . . 43

3.4 Simulated, predicted and realized S\&P500 option volatilities. . . . . . . . . 46

3.5 Simulated, predicted and realized $z$-score volatilities. . . . . . . . . . 51 


\section{Introduction}

This thesis studies option returns in perfect and imperfect markets to explain different parts of the option mispricing puzzle.

The option mispricing puzzle refers to a number of option pricing anomalies such as extreme realized index put returns (Bondarenko 2014; Chambers et al. 2014), too high implied volatilities (Goyal and Saretto 2009), and negative delta-hedged option returns (Bakshi et al. 2003).

Perfect markets contain the assumptions of informational efficiency, market completeness and frictionless trading, such that option mispricing cannot exist as option payoffs are perfectly replicable. Since options imply leveraged positions in the underlying, the occurrence of extreme returns is expected. However, it remains to show the coherence of a perfect option return model with the observed empirical option return series, as presented in chapter 2 of this thesis.

In imperfect markets, the existence of market frictions allows arbitrage-free deviations of option prices from fair value (Figlewski 1989) resulting in option return premiums over the risk-free rate. Such market frictions can include stock illiquidity, taxes, leverage restrictions, funding costs, transaction costs, market incompleteness, and indivisibility ${ }^{1}$. However, while market frictions may explain the potential magnitude of option mispricing, the direction (over- or underpriced) is controlled by net end-user option demand (Garleanu et al. 2009), as market makers adjust their quotes to net demand pressure to optimize and hedge their positions. While many studies focused on the explanation of index option mispricing, where the market maker's position is empirically documented, only few works yet discovered the relevant frictions with respect to individual equity options, where comprehensive data on net end-user demand is however usually unavailable.

\footnotetext{
${ }^{1}$ Bollen and Whaley (2004); Cao and Han (2013); Christoffersen et al. (2014); Figlewski (1989); Garleanu et al. (2009); Goyenko et al. (2014); Huang and Shaliastovich (2014); Karakaya (2014); Schürhoff and Ziegler (2011); Santa-Clara and Saretto (2009); Black (1975).
} 
In perfect markets, the thesis explains expected S\&P500 index option returns via an option-implied risk-adjusted return model based on a representative investor in chapter 2 . Further the properties of S\&P500 option return volatility are investigated in a Black-Scholes setting of chapter 3 . In imperfect markets, chapter 4 analyzes the conditional low-volatility effect in option markets expressing a relation between delta-hedged equity option returns and underlying volatility conditional on a proxy for option market makers' position.

Chapter 2 applies the approach by Brinkmann and Korn (2018) to explain S\&P500 index option returns in perfect markets. This option-implied risk-adjusted approach captures the risk-aversion of a representative investor through a utility function to infer the physical measure from the risk-neutral measure. The risk-neutral moments are implied from option market prices. The ratio of the expected physical option payoff over the option market price yields the expected option return. The option-implied risk-adjusted approach offers various benefits compared to standard option pricing models. The approach is forwardlooking and dynamic as it extracts current market expectations from option prices and continuously adjusts to changes in option prices, rather than using historical estimates and constant parameter assumptions. It does not impose a stochastic process or model option prices over market option prices when forecasting option returns. The approach is highly flexible as it allows to incorporate any risk-averse utility function to capture investor risk preferences. Compared to other model-free approaches, moments are obtained without explicit construction of the risk-neutral density, avoiding severe numerical problems. As a drawback, the approach requires an infinite set of current option market prices as input, as well as an explicit choice for the representative investor's utility function and its calibration. The utility function can only be risk-averse, which limits its ability to generate so-called U-shaped pricing kernels. An empirical study following the test in Broadie et al. (2009) investigates the hypothesis that the implied risk-adjusted option return model explains realized S\&P500 index option returns compared to the Black-Scholes and risk-neutral benchmark models.

Chapter 3 presents a study on option return volatility in a Black-Scholes world. While much research exists on expected option and underlying returns, little is known about option return volatility. Option volatility can far exceed underlying volatility due to the 
high implied leverage and represents an important measure for option risk. Options can reflect both long and short positions in the underlying as well as combinations thereof. I study theoretical and empirical properties of call and put volatilities over finite and instantaneous holding periods in a Black-Scholes setting. The study derives and illustrates properties and sensitivities of option volatility with respect to maturity, physical drift rate, dividend yield, moneyness, underlying volatility, and the risk-free rate over different holding horizons. While theoretical option volatility is found to behave similarly for hold to maturity or selling prior to maturity horizons, significant differences exist comparing to instantaneous holding periods with respect to the physical drift rate and maturity. In a further empirical test, I compare realized S\&P500 put volatilities with Black-Scholes model predictions to investigate whether the first are explainable by the latter.

Chapter 4 investigates the conditional low-volatility effect in delta-hedged equity option returns. The empirically negative relation between volatility and future returns called the low-volatility effect is well documented with respect to equity returns. Cao and Han (2013) confirm the same effect for delta-hedged option returns decreasing with higher idiosyncratic volatility of the underlying stock returns due to higher hedging costs. This paper further explores this effect as to be conditional on market makers being net short in the respective equity option. If market makers are net long in options, there can be a converse relation, leading to a high-volatility effect. Since the market maker's position is not directly observable, we use the difference between historical and implied volatility as a proxy. The conditional low-volatility effects stress the importance of market imperfections and the reaction of market makers in explaining the anomaly, which is important for investors because it is three to four times stronger than the unconditional effect. We further verify that the conditional low-volatility effect cannot be explained by common factor risks or market inefficiencies. 


\title{
2 Explaining S\&P500 option returns: an implied risk-adjusted approach
}

Accepted for publication in the Central European Journal of Operations Research, S.I. :

Modelling and Management of Commodities and Financial Markets (forthcoming)

\begin{abstract}
The option mispricing puzzle states that realized option returns are inconsistent with option pricing models in perfect markets. This paper applies the approach by Brinkmann and Korn (2018) to forecast S\&P500 option returns via option-implied expectations of a risk-averse representative investor. The approach is able to explain S\&P500 put returns and achieves superior prediction results over standard option pricing models. However, none of the tested option pricing models can explain the highly negative mean realized S\&P500 out-of-the-money call returns due to the empirically U-shaped pricing kernel.
\end{abstract}

Acknowledgment: I would like to thank Olaf Korn and Niklas Trappe for their helpful comments and suggestions. This work was supported by the Deutsche Forschungsgemeinschaft [UH 107/4-1, KO $2285 / 3-1]$.

Acknowledgment: Earlier versions of this article have been presented at the 61st Meeting of EURO Working Group for Commodities and Financial Modelling 2018, Kaunas, and the research colloquium of Georg-August-Universität Göttingen 2018. We are grateful to the discussants and participants of each seminar for their helpful comments and suggestions. 


\section{$2.1 \quad$ Introduction}

The U.S. equity option market represents one of the largest equity derivative markets in the world with $\$ 1.5$ trillion trading volume in 2012 (Karakaya 2014). However, empirical option prices and returns can not be fully described by standard option pricing models under perfect market assumptions, known as the option mispricing puzzle (Christoffersen et al. 2013). Standard option models could not explain the highly negative realized S\&P500 put returns, overshooting and skewed option-implied volatilities, and negative delta-hedged option returns ${ }^{1}$.

Two strings of literature aim to explain realized option returns in either perfect or imperfect markets. In imperfect markets, market frictions allow arbitrage-free deviations of option prices from their theoretical fair value (Figlewski 1989) resulting in apparent return premiums. These premiums are however not exploitable via arbitrage strategies due to market frictions. Market frictions may include hedging costs such as stock illiquidity, funding costs, transaction costs, leverage restrictions and market incompleteness ${ }^{2}$. Garleanu et al. (2009) and Bollen and Whaley (2004) state that within such arbitrage-free boundaries induced by market frictions, net end-user option demand determines the direction of option over- or underpricing.

In perfect markets with full informational efficiency, market completeness and frictionless trading, an option mispricing cannot exist as all European contingent claims are perfectly replicable via a portfolio of the underlying and risk-free asset. Any deviation of option market prices from their theoretical value would be immediately arbitraged away. However, it remains to show the existence of an option pricing model in perfect markets consistent with the observed realized option- and underlying price and return distributions. This paper studies an approach to achieve such result.

Various articles studied realized option returns in perfect markets. Bondarenko (2014) tests a model-independent approach to find that S\&P500 put returns could not be explained.

\footnotetext{
${ }^{1}$ Bondarenko (2014); Chambers et al. (2014); Goyal and Saretto (2009); Bates (2000); Bakshi et al. (2003)

${ }^{2}$ Bollen and Whaley (2004); Cao and Han (2013); Christoffersen et al. (2014); Figlewski (1989); Goyenko et al. (2014); Karakaya (2014); Schürhoff and Ziegler (2011); Santa-Clara and Saretto (2009); Black (1975).
} 
Broadie et al. (2009) applied standard option pricing models including the Black-Scholes model, Heston model and Bates model revealing that realized S\&P500 put returns did not deviate significantly from perfect option pricing models given certain market, volatility and jump risk premiums. However, their in-sample simulations were based on restrictive assumptions such as constant parameters over 18 years time, conversion of American to European implied volatilities, and rather arbitrary choices of premium adjustments. In a related study, Chambers et al. (2014) also find that S\&P500 puts were not mispriced given certain risk premiums, but were again unable to infer the required risk premiums from the realized index returns, as they state: "The determination of a reasonable estimate of the wedge between P-measures and Q-measures based on the Broadie et al. (2009) data is difficult however, as the risk adjustments rely on somewhat arbitrary choices of a risk aversion parameter.".

This paper hereby connects through the application of an implied risk-adjusted approach, which explains realized option returns via option-implied expectations of a representative investor with risk-averse preferences. The approach extracts investor's risk aversion consistent with option market prices without requiring "arbitrary choices". The estimates of expected option returns are also conditioned on the option market prices, such that no model option prices are imposed, which can deviate significantly from option market prices. Expected option returns are further forecasted in a dynamic setting with time-varying parameters. This study analyzes call and put returns together, whereas many previous research focused on puts only due to their extreme negative returns ${ }^{3}$. We find that put returns can be well explained by the presented approach, while the observed negative mean realized call returns were unexplainable due to the empirically U-shaped pricing kernel; therefore the often cited put option puzzle switches to a call option puzzle.

The study is presented as follows. Section 2.2 introduces the option-implied risk-adjusted approach. Section 2.3 presents the S\&P500 option return sample. Section 2.4 performs a prediction test on the approach and a set of benchmark models. Section 2.5 concludes.

\footnotetext{
${ }^{3}$ Bondarenko (2014); Broadie et al. (2009); Chambers et al. (2014).
} 


\subsection{Implied Risk-Adjusted Expected Option Return}

Expected option return in perfect markets is determined by the ratio of the expected option payoff under the physical measure over the option market price under the risk-neutral measure (Broadie et al. 2009):

$$
E\left(R_{t, T}^{H}\right)=\frac{E^{P}\left(H_{T}\right)}{e^{-r \tau} E^{Q}\left(H_{T}\right)}-1
$$

Where $E\left(R_{t, T}^{H}\right)$ denotes the expected return of a European contingent claim at time $t$ with, expiration date $T$, time to maturity $\tau=T-t$, risk-free rate $r$, payoff function $H_{T} \in C^{2}$. The expected physical option payoff is denoted as $E^{P}\left(H_{T}\right)$ and the discounted risk-neutral expected option payoff, i.e. option market price, $e^{-r \tau} E^{Q}\left(H_{T}\right)$.

When option market prices are observable, expected option returns are determined solely by the physical expected option payoff. The option-implied risk-adjusted moments framework derived in Brinkmann and Korn (2018) presents a model-free approach to infer the expected physical payoffs of European contingent claims from current option market prices representing the investor's believe and a utility function $(U)$ to model investor's taste of risk. The approach is based on the general relationship between the risk-neutral $(q)$ and physical density $(p)$ given by

$$
p\left(S_{T}\right)=\frac{q\left(S_{T}\right)}{c \cdot U^{\prime}\left(S_{T}\right)}, \quad \text { with } \quad c \equiv \int \frac{q(x)}{U^{\prime}(x)} d x
$$

Assuming that the representative investor holds the market portfolio, the discounted expected physical call $C^{P}(t, \tau, K):=e^{r \tau} E^{P}\left[\left(S_{T}-K\right)^{+}\right]$, and put $P^{P}(t, \tau, K):=e^{r \tau} E^{P}[(K-$ $\left.S_{T}\right)^{+}$] payoffs in equations $(2.3),(2.4)$ were determined such that the investor is indifferent between holding the index or index options to maturity:

$$
C^{P}(t, \tau, K)=\frac{C(t, \tau, K)}{c \cdot U^{\prime}(K)}+\int_{K}^{\infty} \frac{-U^{\prime \prime}(x)}{c \cdot U^{\prime}(x)^{2}}\{C(t, \tau, x)+(x-K) D(t, \tau, x)\} d x
$$




$$
\begin{gathered}
P^{P}(t, \tau, K)=\frac{P(t, \tau, K)}{c \cdot U^{\prime}(K)}-\int_{0}^{K} \frac{-U^{\prime \prime}(x)}{c \cdot U^{\prime}(x)^{2}}\left\{P(t, \tau, x)+(K-x)\left(e^{-r \tau}-D(t, \tau, x)\right)\right\} d x, \\
\text { with } c:=\int_{0}^{\infty} \frac{-U^{\prime \prime}(x)}{U^{\prime}(x)^{2}} e^{r \tau} D(t, \tau, x) d x+\frac{1}{U^{\prime}(0)}
\end{gathered}
$$

where $C(t, \tau, K), P(t, \tau, K)$ represent European call and put option market prices with strike $K, D(t, \tau, K)$ the price of a digital call paying $\mathbf{1}_{\left(S_{T}>K\right)}$ at time $T$. The representative investor's utility function $U(x) \in C^{2}$ is assumed to be risk-averse with $U^{\prime}(x)>0, U^{\prime \prime}(x)<0$ $\forall x>0$. The integrals in equations (2.3), (2.4) are calculated by the method in Brinkmann and Korn $(2018)^{4}$.

The option-implied risk-adjusted approach is forward-looking and dynamic as it extracts current market expectations from option prices and continuously adjusts to changes in option prices, rather than using historical estimates and constant parameter assumptions. The approach does not impose a stochastic process or model option prices over market option prices when forecasting option return. The approach is highly flexible as it allows for any risk-averse utility function to capture investor preferences. Compared to other modelfree approaches, moments are obtained without explicit construction of the risk-neutral density, avoiding severe numerical problems (Brinkmann and Korn 2018).

As a drawback, the approach requires an infinite set of current option market prices as input, as well as an explicit choice for the representative investor's utility function and its calibration. The utility function can only be risk-averse, which limits its ability to generate so-called U-shaped pricing kernels, as discussed later in section 2.4.

The expected returns on European call and put options under the approach follow from equation (2.1) as

$$
E\left(R_{t, T}^{C}\right)=\frac{e^{r \tau} C^{P}(t, \tau, K)}{C(t, \tau, K)}-1,
$$

\footnotetext{
${ }^{4}$ Each month $t$, a 1,500 step grid was spanned over the interval $K \in\left[0.001,3 S_{t}\right]$ to integrate the expected physical option payoffs via trapezoidal integration. The required set of option market prices was obtained via a quadratic fit over the Black-Scholes sample implied volatility curve; for strikes below or above the available option sample strikes, implied volatility was extrapolated flat. The resulting implied volatility curves are arbitrage-free following the semi-positive state price density condition in (Benko et al. 2007); the risk-neutral density was always positive except at the extrapolation borders where the option price derivative is undefined. The digital call prices were calculated via a Black-Scholes type formula.
} 


$$
E\left(R_{t, T}^{P}\right)=\frac{e^{r \tau} P^{P}(t, \tau, K)}{P(t, \tau, K)}-1
$$

In this study, the CRRA utility function is selected for the representative investor, and this specification referred to as the Implied-CRRA model:

$$
U^{C R R A}(x)=\left\{\begin{array}{cl}
\frac{x^{1-\gamma}-1}{1-\gamma}, & \gamma \in \mathbb{R}_{\geq 0} /\{1\}, x>0 \\
\ln (x), & \gamma=1
\end{array}\right.
$$

Constant Relative Risk Aversion utility (CRRA) represents a standard utility function which has the property of $A(x)=-x \frac{U^{\prime \prime}(x)}{U^{\prime}(x)}$ being a constant, such that decision-making is unaffected by scale as the fraction of wealth optimally invested into the risky asset is independent of the level of initial wealth (Menezes and Hanson 1970; Pratt 1964). One can also show that the Black-Scholes model implies a CRRA risk aversion (Rubinstein 1976) such that we can benchmark the Implied-CRRA model well against it in the following test. Figure 2.1 visualizes the Implied-CRRA option prices and expected option returns by equations (2.3) - (2.7) for the S\&P500 using the sample data discussed in section 2.3. Figure 2.1 Panel (a) shows a monotone decreasing (increasing) relationship for the expected call (put) option payoff and the option strike. This behaviour is expected as the option strike directly affects the intrinsic value of the option. Due to the assumed positive market risk premium, the expected physical call payoffs are higher than the risk-neutral call prices and expected call returns are positive. Conversely, the implied short-position of a put option leads to lower expected physical put payoffs than under the risk-neutral measure and negative expected put returns.

Figure 2.1 Panel (b) shows that expected Implied-CRRA call and put returns are both mainly increasing with the option strike. For calls, a higher option strike implies a higher leverage on the positive market risk premium, such that expected call returns increase with a higher strike and are always positive. For put options, a higher option strike implies a lower leverage on a short position against a positive market risk premium, such that expected put returns also increase though being always negative. Both call and put expected return curves exhibit a kink in the area where the implied volatility was fitted using a quadratic polynomial. 
The observed option return behaviour is consistent with Coval and Shumway (2001), who show under mild assumptions that expected call and put returns are increasing with the option strike, whereas expected call returns lie above the expected return of the underlying and expected put returns lie below the risk-free rate. Christoffersen et al. (2013) and Ni (2009) discuss that deviations of expected option returns from the properties stated in Coval and Shumway (2001) are possible for non-monotonic pricing kernels or risk-seeking investors.

Figure 2.2 presents the at-the-money Implied-CRRA option prices and expected option returns for varying risk aversion using equations (2.3) - (2.7). From panels (a) and (b) one can observe a monotone increasing (decreasing) relationship between investor's risk aversion and expected call (put) option returns and -prices, as a more risk-averse investor discounts the risky underlying before maturity, hence increasing (decreasing) expected physical call (put) option payoffs and returns. 
Figure 2.1: Impact of the option strike on expected option payoffs and returns in the Implied-CRRA model.

(a) Implied-CRRA discounted risk-neutral and physical expected call and put payoffs for different option strikes.

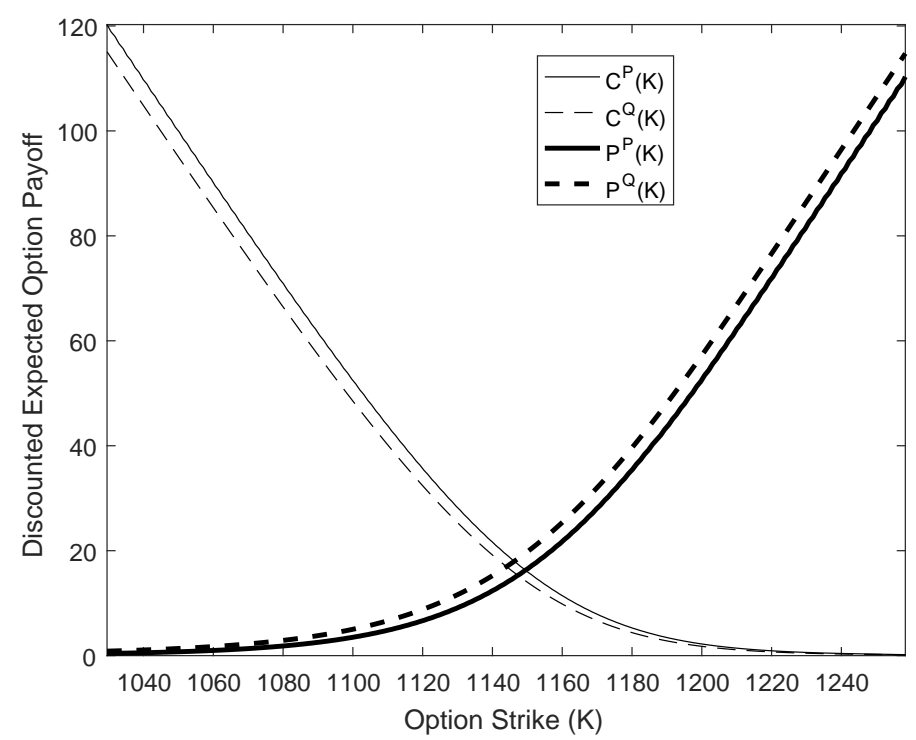

(b) Implied-CRRA hold-to-expiration expected call and put returns for different option strikes.

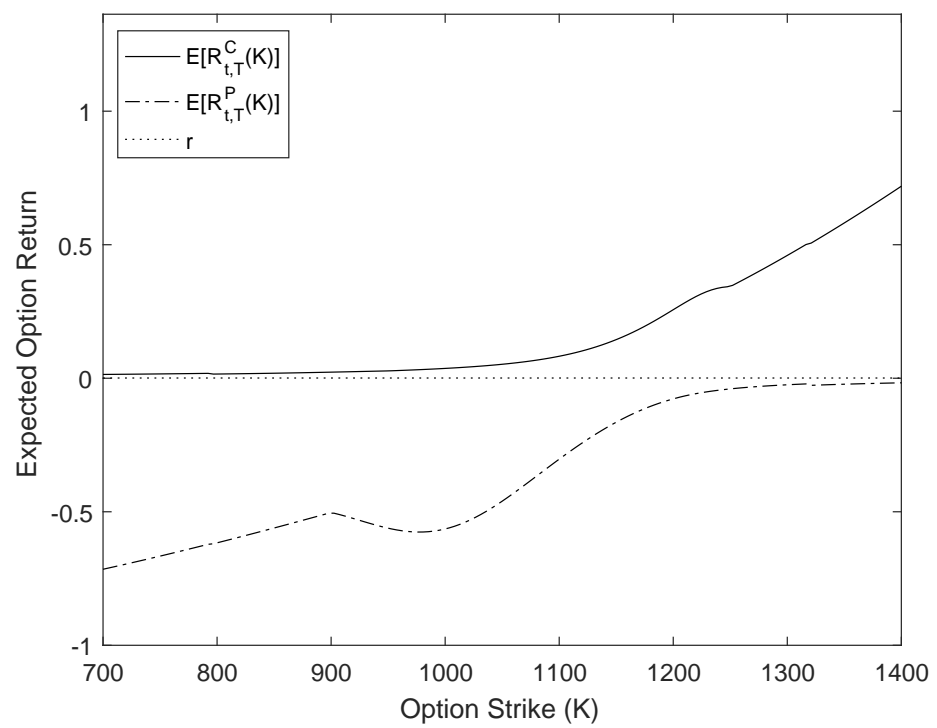

The graphs show the Implied-CRRA discounted risk-neutral and physical expected option payoffs for varying option strikes $(K)$ in panel (a) and expected option returns in panel (b) for the S\&P500 sample on 01/22/2004. Other parameters were fixed at $S_{t}=1143.94, \gamma=$ 2.45, $\tau=28 / 365, r=0.011$. Risk-neutral $(Q)$ and physical $(P)$ discounted expected option payoffs are denoted $C^{Q}(\gamma), C^{P}(\gamma), P^{Q}(\gamma), P^{P}(\gamma)$ for calls $(C)$ and puts $(P)$ respectively. Expected hold-to-expiration option returns over the period $\tau=T-t$ are denoted $E\left[R_{t, T}^{C}(\gamma)\right]$, $E\left[R_{t, T}^{P}(\gamma)\right]$ for calls and puts. 
Figure 2.2: Impact of risk-aversion in the Implied-CRRA model.

(a) Implied-CRRA discounted risk-neutral and physical expected call and put option payoffs for varying risk-aversion.

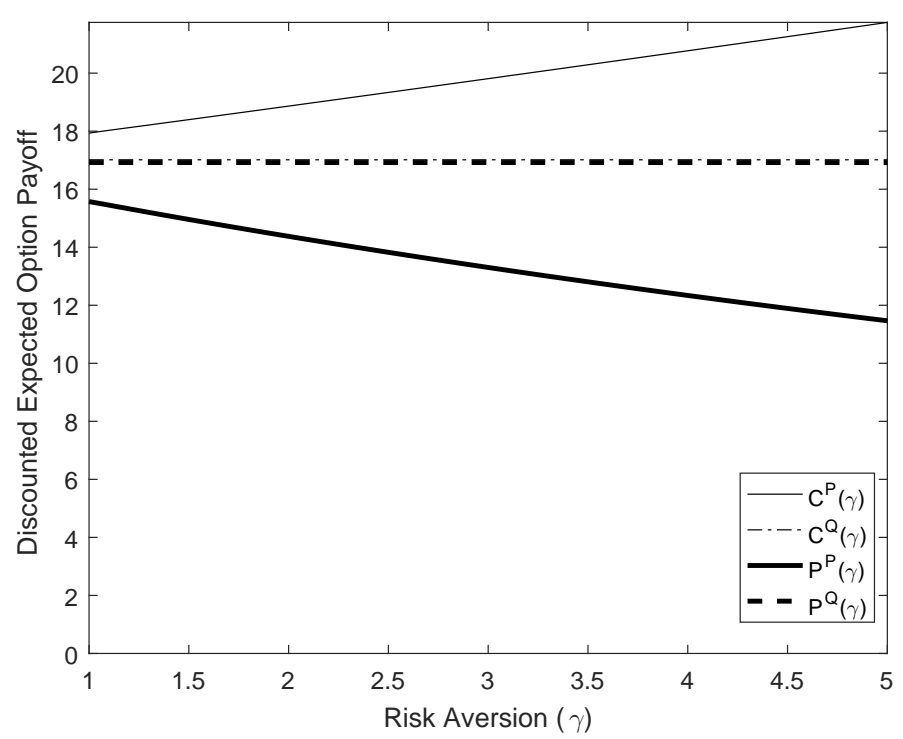

(b) Implied-CRRA expected call and put returns for varying riskaversion.

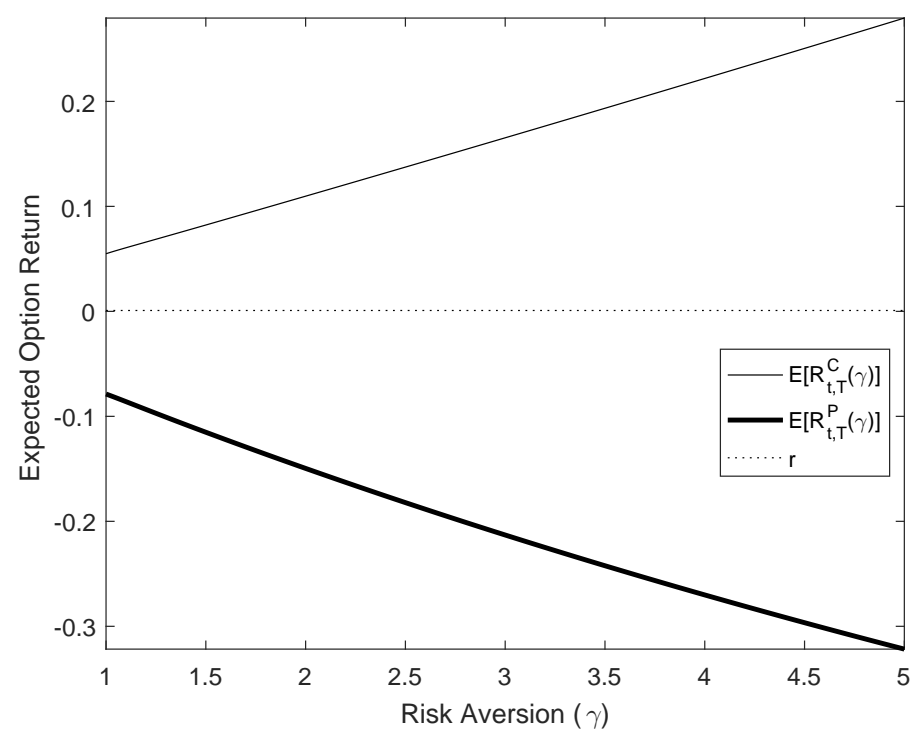

The graphs show the Implied-CRRA discounted risk-neutral and physical expected option payoffs for varying risk-aversion $(\gamma)$ in panel (a) and expected option returns in panel (b) for the S\&P500 sample on 01/22/2004. Other parameters were fixed at $K=S_{t}=1143.94$, $\tau=28 / 365, r=0.011$. Risk-neutral $(Q)$ and physical $(P)$ discounted expected option payoffs are denoted $C^{Q}(\gamma), C^{P}(\gamma), P^{Q}(\gamma), P^{P}(\gamma)$ for calls $(C)$ and puts $(P)$ respectively. Expected hold-to-expiration option returns over the period $\tau=T-t$ are denoted $E\left[R_{t, T}^{C}(\gamma)\right]$, $E\left[R_{t, T}^{P}(\gamma)\right]$ for calls and puts. 


\section{$2.3 \quad$ Realized option returns}

The study will test the Implied-CRRA model on the prediction of monthly realized S\&P500 European option returns over the period 01/1996 - 08/2015. This section discusses the selection and properties of the S\&P500 option sample used in this study.

All option pricing data was obtained from OptionMetrics IvyDB. The sample was filtered following standard methodology (Goyal and Saretto 2009; Cao and Han 2013): S\&P500 options with 28 to 29 days to expiration (depending on bank holidays) and expiration on the 3rd Friday or Saturday of the month were selected. The option bid-ask spread was filtered to be greater than the minimum spread of $\$ 0.05$ when the option mid price was below $\$ 3$, and $\$ 0.1$ minimum option spread else. The midpoint prices of call $\left(C_{t}\right)$ and put $\left(P_{t}\right)$ options lay within the arbitrage-free boundaries: $\left[S_{t} e^{-d_{t} \tau}-K e^{-r_{t} \tau}\right]^{+}<C_{t}<S_{t} e^{-d_{t} \tau}$ and $\left[K e^{-r_{t} \tau}-S_{t} e^{-d_{t} \tau}\right]^{+}<P_{t}<K e^{-r_{t} \tau}$. Best bid and ask quotes, daily trading volume, open interest, implied volatility were filtered to be non-zero and the last trade date of the option had to be available. Since S\&P500 option payoffs were calculated from the index open price on the settlement day and time to expiration was calculated as number of days between the option price date and its settlement day minus one. The settlement day equals the first trading day at or before the expiration day (some expiration days were on a Saturday or bank holidays). The final sample contains 19.912 one-month options, with 50 puts and 35 calls per month on average.

Realized hold-to-expiration option returns for calls $\left(R_{t, T}^{\hat{C}}(K)\right)$ and puts $\left(R_{t, T}^{\hat{P}}(K)\right)$ with strike $K$ and time to maturity $\tau=T-t$ at time $t$ were calculated by equations (2.8), (2.9) for moneyness categories from 0.94 to 1.06 ; moneyness was defined as $k:=S_{t} / K$ for calls and $k:=K / S_{t}$ for puts. Call and put option market prices $(\hat{C}, \hat{P})$ with exact moneyness were obtained via discussed quadratic fit over each month's sample implied volatilities, following the methodology in Chambers et al. (2014) and Broadie et al. (2009).

$$
R_{t, T}^{\hat{C}}(K)=\frac{\left(S_{T}-K\right)^{+}}{\hat{C}(t, \tau, K)}-1
$$




$$
R_{t, T}^{\hat{P}}(K)=\frac{\left(K-S_{T}\right)^{+}}{\hat{P}(t, \tau, K)}-1
$$

Tables 2.1 and 2.2 show the mean realized returns of the selected puts, calls, and the S\&P500 index. All options yielded negative mean returns over the sample period, except for in-the-money (ITM) calls. ITM calls yielded a positive average return of 4 to $7 \%$ per month compared to $0.6 \%$ by the index (implying a 10-fold leverage), however the Sharpe ratios of these options were still lower than for the underlying S\&P500 index. Since call options are considered leveraged long positions in the underlying, it seems susceptible that some calls provided negative mean returns while the underlying S\&P500 index increased at $0.6 \%$ per month. In perfect markets, there are no frictions such as liquidity and hedging costs, hence negative call returns could only be explained by investors accepting a negative return premium due to their risk preferences. Boyer and Vorkink (2014) finds that investors exhibit risk-seeking preferences and therefore pay a premium on options which provide high skewness of returns.

Mean realized S\&P500 put returns are however expected to be negative, as the S\&P500 index was on average increasing over the sample period, such that puts often expired worthless. For the period 01/1996-09/2000, put returns became particularly negative when the mean S\&P500 return doubled to $1.2 \%$ per month during the dot-com bubble. However, during the following dot-com crash from 10/2000 - 02/2003, put options yielded up to $61 \%$ monthly return while the S\&P500 dropped $-1.8 \%$ per month.

Mean realized S\&P500 call returns were negative and decreasing with the option strike over the sample period. Bakshi et al. (2010) observed that this pattern holds for international option markets as well. According to Coval and Shumway (2001), expected call returns should be positive and increasing with the option strike under positive expected return on the underlying. Ni (2009) shows that negative expected call returns are possible when investors are risk-seeking, and finds evidence for a positive idiosyncratic skewness premium on call prices which reduces their returns (also see Boyer and Vorkink (2014)). She also noted that the frequency of large positive stock returns was higher in 1996 - 2005 than 1963 - 1995, such that the negative realized out-of-the-money (OTM) call returns were likely even higher than expected. For the period before the dot-com bubble from 1996 to 
2000, one can observe highly positive call returns, and highly negative call returns during the subsequent crash.

Table 2.1: Average 1-month S\&P500 put returns and S\&P500 index returns over different time periods.

\begin{tabular}{|r|lllllll|l|}
\hline$k$ & 0.94 & 0.96 & 0.98 & 1.00 & 1.02 & 1.04 & 1.06 & Index \\
\hline $01 / 1996-08 / 2015$ & -0.48 & -0.42 & -0.33 & -0.28 & -0.20 & -0.14 & -0.10 & 0.006 \\
$01 / 1996-09 / 2000$ & -0.96 & -0.91 & -0.79 & -0.58 & -0.38 & -0.25 & -0.17 & 0.012 \\
$10 / 2000-02 / 2003$ & 0.61 & 0.54 & 0.46 & 0.46 & 0.39 & 0.30 & 0.23 & -0.018 \\
\hline
\end{tabular}

The table shows average 1-month S\&P500 hold-to-expiration European put returns with moneyness $k$, and the average underlying S\&P500 index return over different time periods. Moneyness was defined as $k:=S_{t} / K$ for calls and $k:=K / S_{t}$ for puts.

Table 2.2: Average 1-month S\&P500 call returns and S\&P500 index returns over different time periods.

\begin{tabular}{|r|lllllll|l|}
\hline$k$ & 0.94 & 0.96 & 0.98 & 1.00 & 1.02 & 1.04 & 1.06 & Index \\
\hline $01 / 1996-08 / 2015$ & -0.38 & -0.29 & -0.10 & -0.002 & 0.04 & 0.04 & 0.04 & 0.006 \\
$01 / 1996-09 / 2000$ & 0.73 & 0.34 & 0.12 & 0.05 & 0.07 & 0.09 & 0.11 & 0.012 \\
$10 / 2000-02 / 2003$ & -0.71 & -0.61 & -0.47 & -0.40 & -0.35 & -0.27 & -0.22 & -0.018 \\
\hline
\end{tabular}

The table shows average 1-month S\&P500 hold-to-expiration European call returns with moneyness $k$, and the average underlying $\mathrm{S} \& \mathrm{P} 500$ index return over different time periods. Moneyness was defined as $k:=S_{t} / K$ for calls and $k:=K / S_{t}$ for puts.

Figure 2.3 presents the time series of realized S\&P500 option returns with moneyness 0.94 (OTM), 1.00 (ATM) and 1.06 (ITM). OTM option return distributions are highly skewed, as many options expired worthless with $-100 \%$ return. A 0.94 -moneyness option requires an index movement of approximately $6 \%$ over the month to yield a positive payoff, which is highly unlikely given the historical $0.6 \%$ mean monthly S\&P500 return. However, when OTM options expired in the money, returns could be as high as $+4103 \%$. Conversely, options with higher moneyness expired worthless less frequently but yielded lower maximum returns. For calls, high moneyness option returns converge to the distribution of the underlying as the value of a call with a strike of zero implies holding the underlying without dividends. 
Figure 2.3: Monthly realized S\&P500 European option returns from 01/1996 - 08/2015.
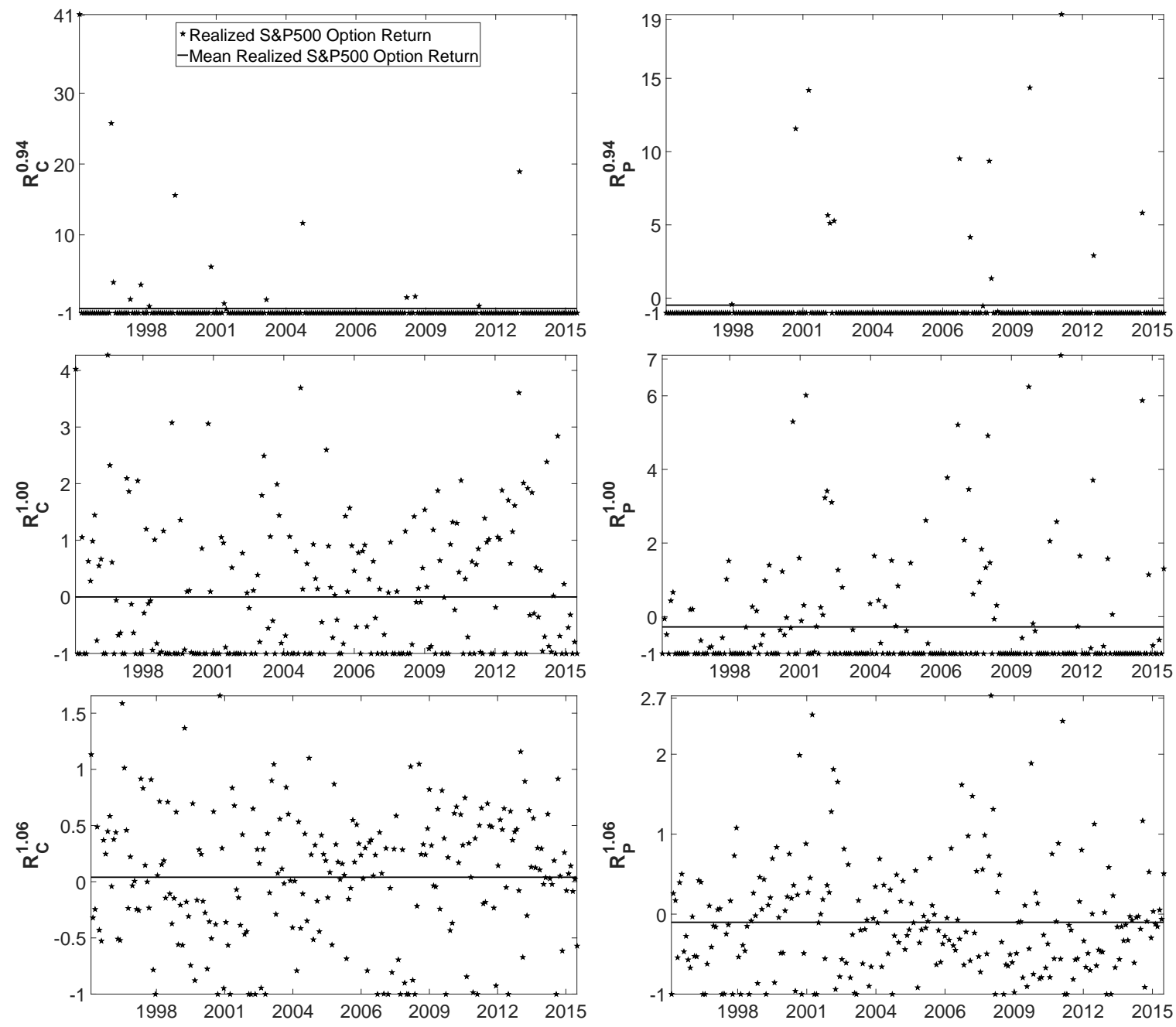

The figure shows the time series of monthly realized S\&P500 European hold-to-expiration call and put returns $\left(R_{C}^{k}, R_{P}^{k}\right)$ with moneyness $k=0.94,1.00,1.06$ and the respective mean option returns over the period 01/1996 - 08/2015. Moneyness was defined as $k:=S_{t} / K$ for calls and $k:=K / S_{t}$ for puts.

\subsection{Option Return Prediction Test}

This section presents an option return prediction test of the Implied-CRRA model and two standard option pricing models as benchmarks.

The Implied-CRRA model requires only an estimate of the monthly risk-aversion parameter $\gamma$ to forecast expected option returns. Following the approach in Broadie et al. (2009) and Chambers et al. (2014), the estimation was performed by equating the expected market 
risk premium to the historical market risk premium of $\mu-r_{f}=0.39 \%$, calculated as the average difference between monthly discrete index returns $(\mu)$ and discrete risk-free rate $\left(r_{f}\right)$ over the sample period. The expected market return each month equals the sum of the prevailing 1-month discrete risk-free rate $r_{t}^{d}$ and the historical market risk premium $\mu-r_{f}$ :

$$
E^{P}\left(\frac{S_{t+\tau}-S_{t}}{S_{t}}\right)=r_{t}^{d}+\left(\mu-r_{f}\right)
$$

As shown in Brinkmann and Korn (2018), expected market return can be expressed via at-the-money physical expected option payoffs:

$$
E^{P}\left(\frac{S_{t+\tau}-S_{t}}{S_{t}}\right)=\frac{e^{r_{t} \tau}}{S_{t}}\left(C^{P}\left(t, \tau, S_{t} \mid \gamma_{t}\right)-P^{P}\left(t, \tau, S_{t} \mid \gamma_{t}\right)\right), \quad \gamma_{t} \geq 0
$$

The CRRA parameter $\gamma_{t}$ is estimated each month by numerically minimizing the absolute difference between the expected market returns in equations (2.10) and (2.11). The range for the estimation of $\gamma$ was set to $\gamma \in\{0 \cup[1,20]\}^{5}$. The calibration was achieved with a mean absolute error of $2 \cdot 10^{-11}$.

Figure 2.4 presents the time series of estimated $\gamma_{t}$ risk aversion and historical S\&P500 index prices over the sample period. One can observe that implied risk aversion after 2001 correlated with the underlying price: when the index reached record highs, investors became more risk-averse and vice versa. The co-movement of risk-aversion and the index price can be interpreted as follows: a higher risk aversion implies a lower marginal utility from holding the underlying, therefore during times when the S\&P500 index strongly increased, investors gained less and less marginal utility from holding their investments and started to sell at the peaks. In market downturns, investor's risk aversion reached 0 implying risk-neutrality. At the lowest possible risk-aversion, marginal utility from any increase of holding the underlying was the highest possible and the index recovered as investors started to buy.

\footnotetext{
${ }^{5}$ The term $\frac{U^{\prime \prime}(x)}{U^{\prime}(x)^{2}}$ in the physical expected option payoffs was numerically unstable for $\gamma \in(0,1)$, hence this interval was excluded for the estimation.
} 
Figure 2.4: Estimated CRRA risk aversion.

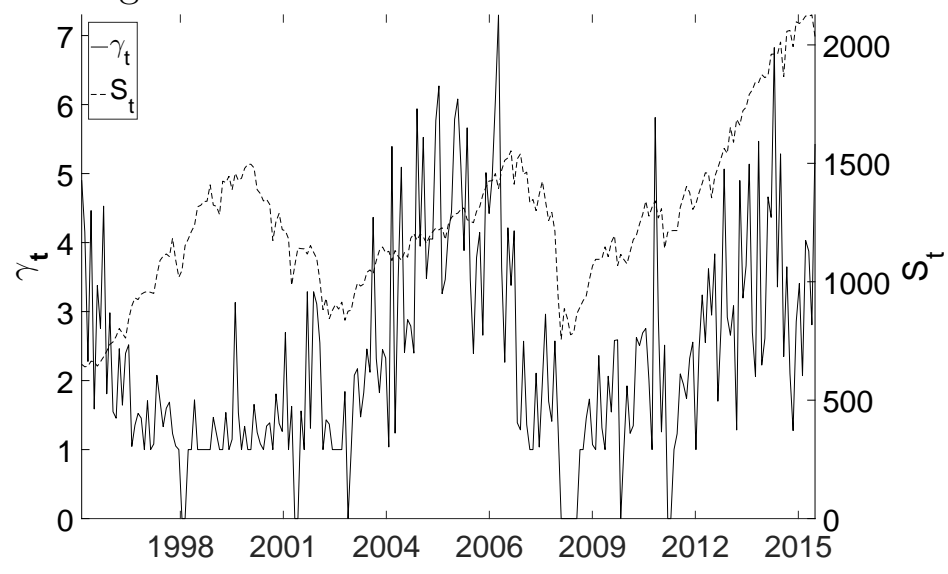

The figure shows the time series of monthly estimated CRRA risk aversion $\left(\gamma_{t}\right)$ and S\&P500 index prices $\left(S_{t}\right)$ over the period 01/1996 - 08/2015.

The Implied-CRRA model captures the believe of the representative investor via the optionimplied risk-neutral distribution, and incorporates his risk preferences via the CRRA utility function. Two benchmark models were selected to assess the importance of each of these components.

The Lognormal-CRRA model assumes a parametric Lognormal risk-neutral price density and CRRA preferences under the physical measure. It enables to compare the accuracy of the option-implied distribution in the Implied-CRRA model versus a standard parametric normal density assumption. As shown in Rubinstein (1976), the Lognormal-CRRA model is equivalent to the Black-Scholes model (Black and Scholes 1973). It can be further shown that a Lognormal risk-neutral price density with parameters $(\mu, \sigma)$ and CRRA risk preferences implies a Lognormal physical density with parameters $\left(\mu+\gamma \sigma^{2}, \sigma\right)$. Hence the Lognormal-CRRA model measures only a single market risk premium $\gamma \sigma^{2}$, whereas all other moment risk premiums such as variance and skewness premiums equal zero. The Implied-CRRA model in contrast utilizes the option-implied distribution without restrictions on the moment risk premiums.

It is a stylized fact that equity returns show certain deviations from Normality, such as peakedness, skewness, and fat tails. This is also true for my data set, as shown via a Kolmogorov-Smirnov test of normality. Using the monthly S\&P500 realized logreturns, the null hypothesis of Normality was rejected at the $1 \%$ level. The Lognormal-CRRA 
model, however, still constitutes a reasonable benchmark model to specifically compare the implied-CRRA approach over a standard parametric density with same type of risk preferences. As the Lognormal-CRRA model derives from the Black-Scholes model, it represents a standard benchmark for option pricing models (also see Broadie et al. (2009); Chambers et al. (2014)). Further the Lognormal-CRRA model uses an implied volatility from option prices and therefore is not just based on the historical volatility of the index, but market expectations thereof, which can be seen as the market correction for the simplifying assumption of normally distributed returns.

Under the Lognormal-CRRA model, the risk-neutral and physical expected option payoffs are calculated by the Black-Scholes formula with respective drift-rates $r_{t}$ and $r_{t}+\gamma_{t} \sigma_{t}^{2}$ under the risk-neutral and the physical measure. As shown in $\mathrm{Hu}$ and Jacobs (2016), expected call $(C)$ and put $(P)$ option returns (including a continuous dividend yield $d_{t}$ ) then follow as

$$
\begin{aligned}
& E\left(R_{t, T}^{C}\right)_{\text {Log. }}=\frac{e^{\left(\mu_{t}^{*}-d_{t}\right) \tau} S_{t} N\left(d_{1}^{*}\right)-K N\left(d_{2}^{*}\right)}{C(t, \tau, K)}-1, \\
& E\left(R_{t, T}^{P}\right)_{\text {Log. }}=\frac{K N\left(-d_{2}^{*}\right)-e^{\left(\mu_{t}^{*}-d_{t}\right) \tau} S_{t} N\left(-d_{1}^{*}\right)}{P(t, \tau, K)}-1
\end{aligned}
$$

with $d_{1}^{*}=\frac{\ln \frac{S_{t}}{K}+\left(\mu_{t}^{*}-d_{t}+\sigma_{t}^{2} / 2\right) \tau}{\sigma_{t} \sqrt{\tau}}, d_{2}^{*}=\frac{\ln \frac{S_{t}}{K}+\left(\mu_{t}^{*}-d_{t}-\sigma_{t}^{2} / 2\right) \tau}{\sigma_{t} \sqrt{\tau}}, \mu_{t}^{*}=r_{t}+\gamma_{t} \sigma_{t}^{2}$.

The volatility parameter was hereby estimated as the average implied volatility of S\&P500 puts and calls each month: $\hat{\sigma}_{t}^{\text {Log. }}=\bar{\sigma}_{t}^{I V}$. We did not estimate historical volatility as to condition both models on option market prices.

Given the functional form of the physical density under the Lognormal-CRRA model, the risk aversion estimator can be inferred from equation (2.10) as:

$$
\hat{\gamma}_{t}^{\text {Log. }}=\frac{\ln \left(e^{\tau r_{t}}+\mu-r_{f}\right)-\tau\left(r_{t}-d_{t}\right)}{\tau \sigma_{t}^{2}}
$$

$\hat{\gamma}_{t}^{\text {Log. }}$ is proportional to the market price of risk in the Black-Scholes model and the Sharpe Ratio. 
Figure 2.5 presents the time series of estimated $\hat{\gamma}_{t}^{\text {Log. }}, \hat{\sigma}_{t}^{\text {Log. }}$, and $S_{t}$ over the sample period. One can observe that $\hat{\sigma}_{t}^{\text {Log. }}$ tends to be anti-correlated with the underlying S\&P500 index: options were cheap when the index grew, and expensive in times of crises. The difference between implied volatility and realized volatility $\left(\hat{\sigma}_{R V}=0.177\right.$, annualized volatility estimated from monthly continuous S\&P500 returns) is commonly used as an indicator for option mispricing (Goyal and Saretto 2009); since $\hat{\sigma}_{t}^{\text {Log. }}$ was mostly higher than $\hat{\sigma}_{R V}$, options are often perceived as overpriced relative to the Black-Scholes model. The large spike in implied volatility around 2008 can be attributed to the Lehman Brothers collapse and following financial crisis in 2008/2009; other spikes in implied volatility can be attributed to the 09/11 attack (2001), dot-com bubble (2002), Flash-Crash (2010), and Greece debt crisis (2011). The estimates of $\hat{\gamma}_{t}^{\text {Log. }}$ under the Lognormal-CRRA model remained close to the estimates under the Implied-CRRA model, but with lower variation due to the constant volatility estimator and equal parametric density type each month. 
Figure 2.5: Estimated Implied-CRRA risk aversion, Lognormal-CRRA risk aversion, Lognormal-CRRA volatility.

(a) Monthly estimated risk aversion and S\&P500 index prices.

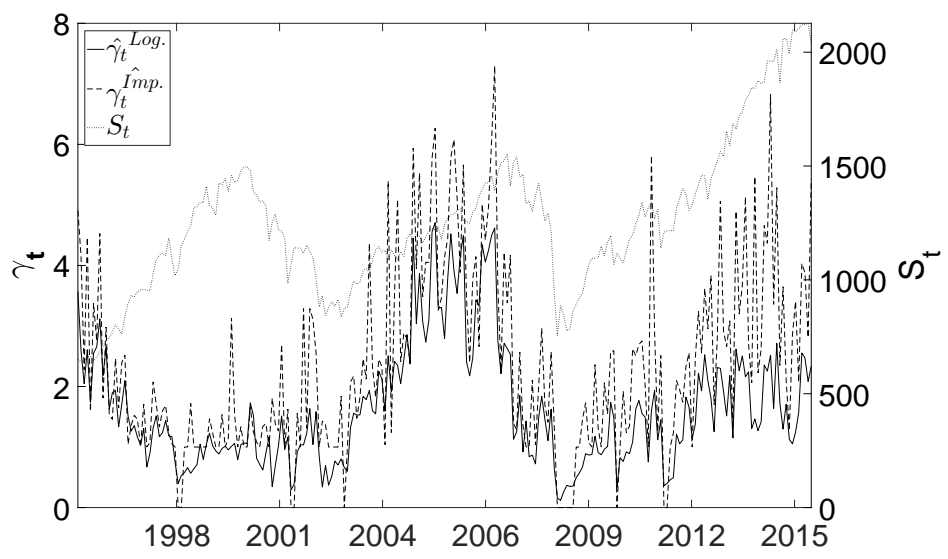

(b) Monthly estimated Lognormal-CRRA volatility, realized volatility, and S\&P500 index prices.

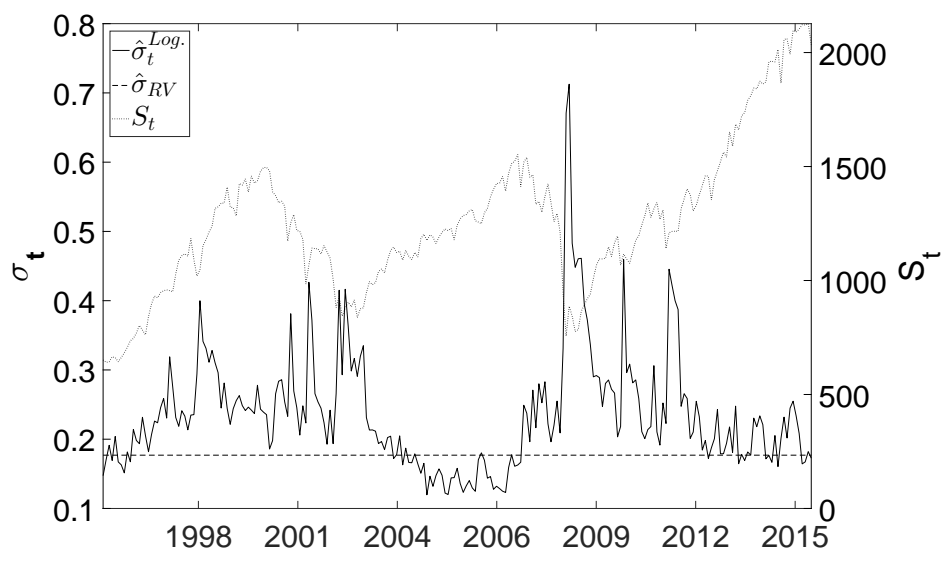

The figure shows the time series of monthly estimated Implied-CRRA risk aversion $\left(\hat{\gamma}_{t}^{\text {Imp. }}\right)$ and Lognormal-CRRA risk aversion $\left(\hat{\gamma}_{t}^{\text {Log. }}\right)$ in panel (a). Panel (b) shows the time series of monthly estimated Lognormal-CRRA volatility $\left(\hat{\sigma}_{t}^{\text {Log. }}\right)$ and the level of realized volatility $\left(\hat{\sigma}_{R V}\right)$ over the sample period 01/1996 - 08/2015. S\&P500 index prices $\left(S_{t}\right)$ are denoted on the second y-axis.

The second benchmark model is represented by the naive risk-neutral approach, which assumes a risk-neutral representative investor to assess the potential benefit of the assumed CRRA risk preferences in the Implied-CRRA approach. In this setting, the risk-neutral and the physical measure are equal $(P=Q)$, such that it follows from equation $(2.1)$ that the expected return on any European option equals the risk-free rate:

$$
E\left(R_{t, T}^{C}\right)=E\left(R_{t, T}^{P}\right)=e^{r_{t} \tau}-1
$$


Hence while the risk-neutral measure determines the option prices, it becomes irrelevant for option returns when investors are risk-neutral. Figure 2.6 shows the time series of annualized continuous risk-free rates, which fell from $7 \%$ to around $0 \%$ after the financial crisis. The mean monthly discrete risk-free rate was $0.22 \%$, which clearly deviates from the mean realized option returns in table 2.1, such that investors are unlikely to have been risk-neutral in S\&P500 options, and the modeling of risk preferences is required.

Figure 2.6: Monthly annualized risk-free rate.

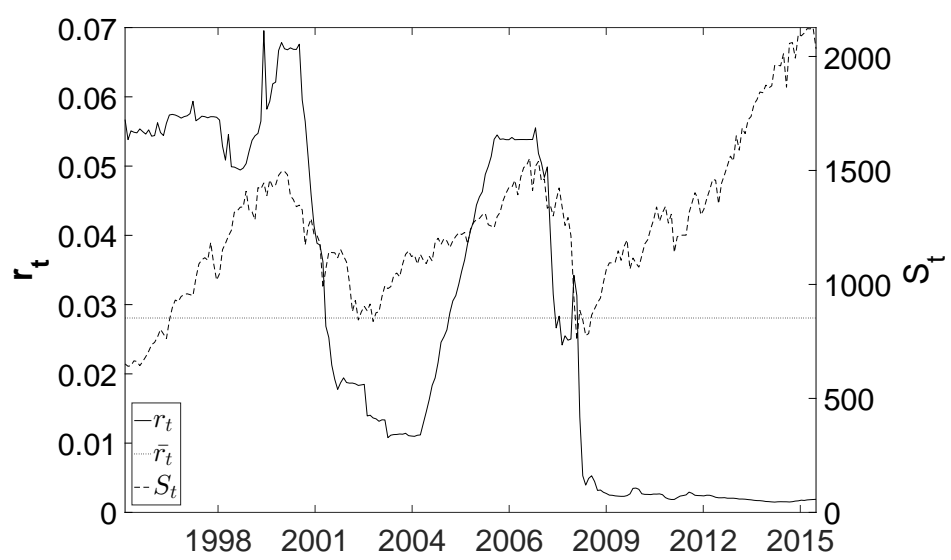

The figure shows the time series of monthly annualized continuously compounded risk-free rates $\left(r_{t}\right)$, mean risk-free rate $\left(\bar{r}_{t}\right)$ and S\&P500 index prices $\left(S_{t}\right)$ over the sample period $01 / 1996-08 / 2015$.

Figure 2.7 presents the time series of predicted and realized option returns with moneyness 0.94, 1.00 and 1.06. Lognormal-CRRA expected option returns behaved relatively stable, while the Implied-CRRA model adjusts stronger to changing market information through the implied volatility curve. One can observe a number of downward spikes in ImpliedCRRA expected option returns, which coincide with the upward spikes of implied volatility in figure 2.5. The Implied-CRRA model therefore translates option overpricing into lower expected option returns. The quality of the predictions can be measured by their average distance to the mean realized option returns. The forecasted positive expected call returns of all three approaches deviate strongly from the low to negative mean realized call returns. For S\&P500 put options, the Implied-CRRA model is clearly closest to the realized mean and, as discussed in more detail later, provided the best predictions of realized S\&P500 put returns. 

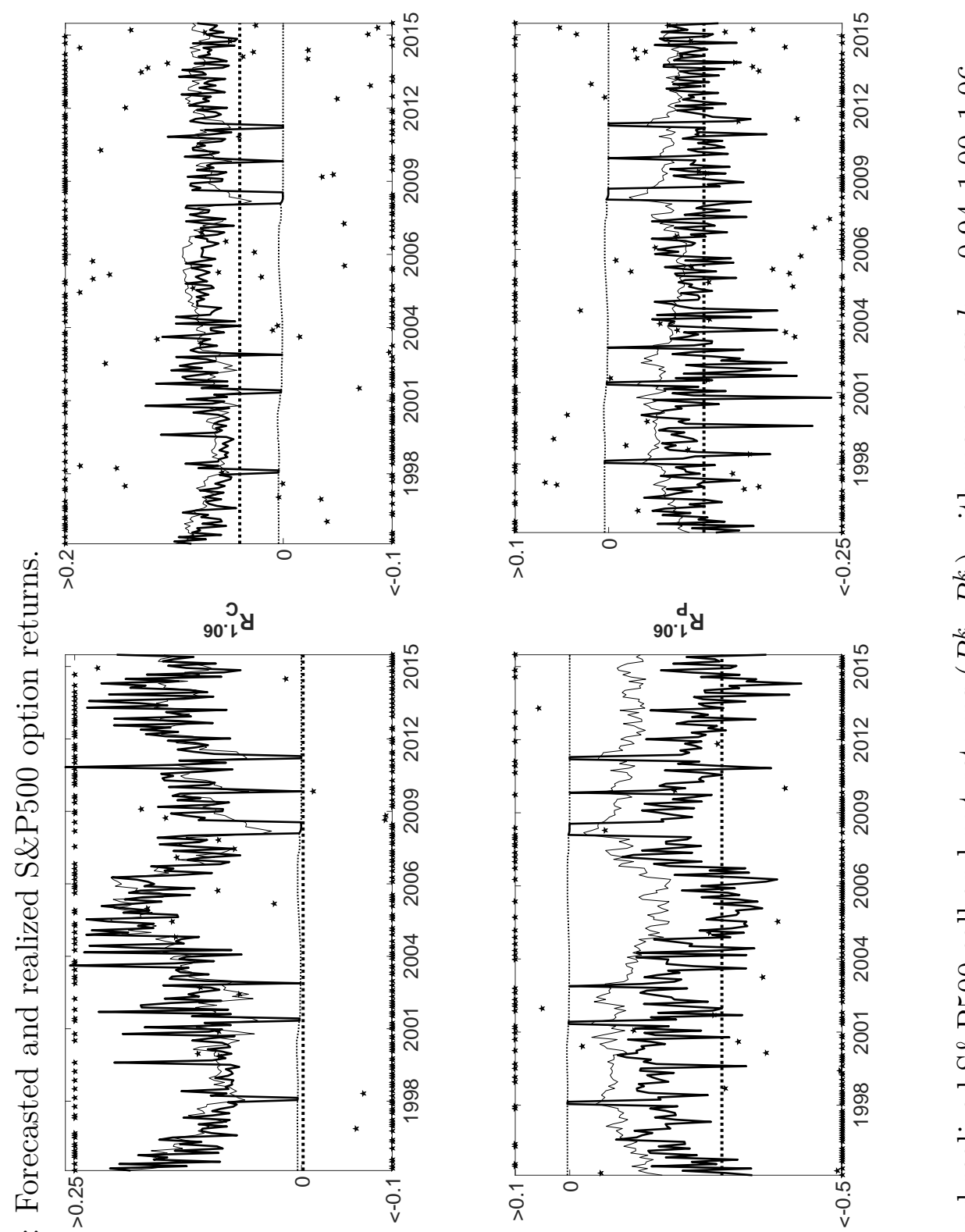

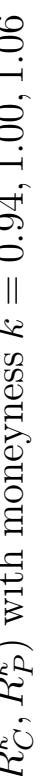
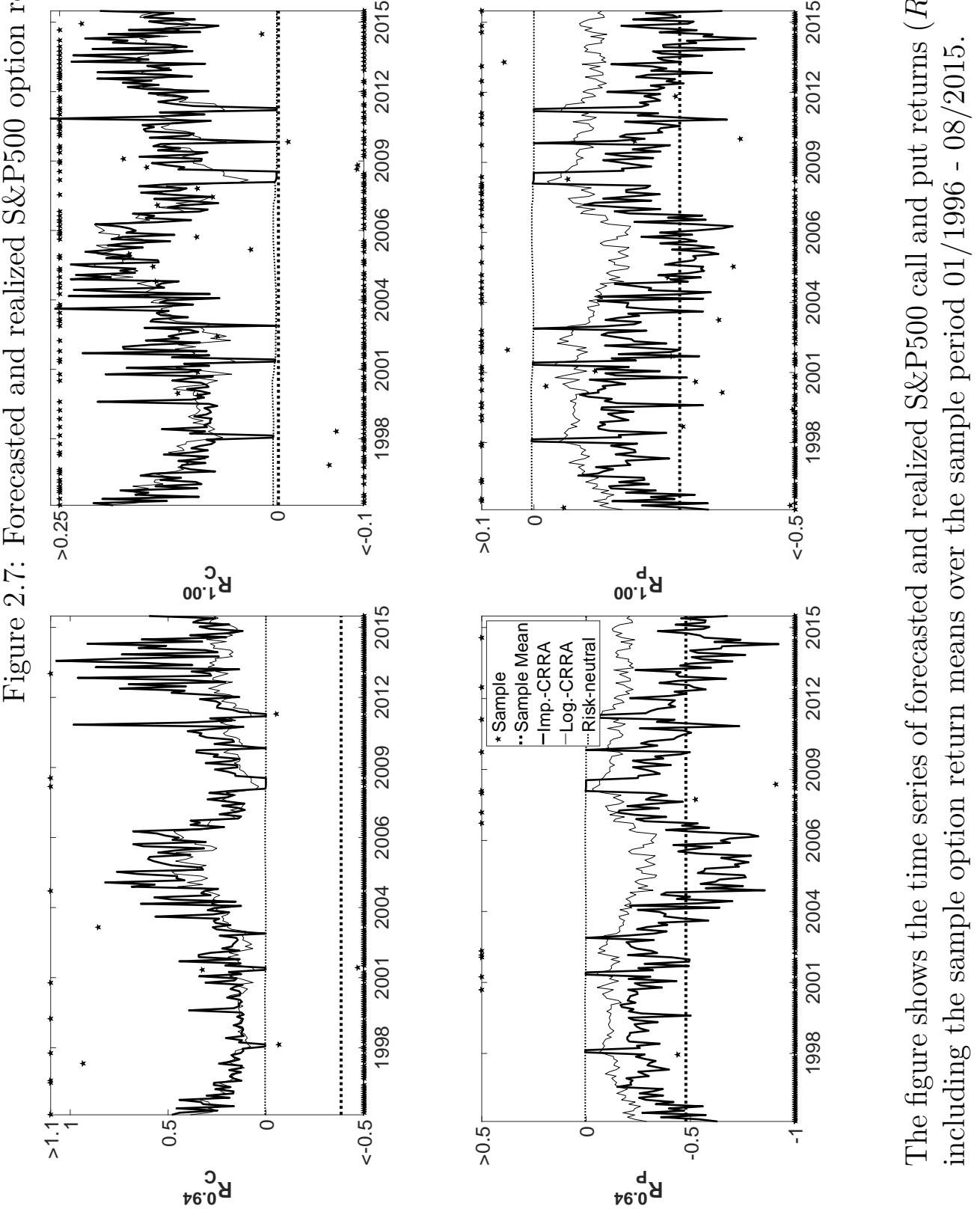
To statistically assess the prediction power of each model, the call $(C)$ and put $(P)$ option return prediction errors $\operatorname{Err}_{t}^{C, P}$ for each month $t$ were calculated as:

$$
\operatorname{Err}_{t}^{C, P}=E\left(R_{t, T}^{C, P}\right)-R_{t, T}^{C, P}
$$

where $R_{t, T}^{C, P}$ indicates the realized call or put return and $E\left(R_{t, T}^{C, P}\right)$ the corresponding predicted option return.

Table 2.3 presents the results of the option return prediction test on the option return prediction errors of each model. The Implied-CRRA model delivered the most accurate expected option return predictions by its mean prediction errors and mean absolute errors for put- and ITM call returns. The high $p$-values of the mean prediction errors indicate that these errors were not significantly different from zero at the $5 \%$ level and the Implied-CRRA approach is not rejected. The leveraged short position of a put option holder always yields highly negative mean returns under a positive expected market return. However, the Implied-CRRA model, as well as the Lognormal-CRRA model, can not explain the highly negative realized OTM call returns due to high and significant prediction errors.

While the Implied-CRRA model forecasted expected 1.04-moneyness put returns with a near zero mean prediction error, its mean absolute prediction error was $66 \%$; this absolute error is still in line with the $88 \%$ standard deviation of realized 1.04-moneyness put returns. The prediction test does not aim to predict individual realized option returns, but only expected option returns. The mean absolute prediction error hereby increased with lower moneyness, as such options contain a higher leverage.

The Lognormal-CRRA forecasts were also not rejected at the $5 \%$ level for put options and ITM calls, such that there was no statistical evidence on mispricing for these S\&P500 option returns even under the standard Black-Scholes model. However, the mean prediction errors and mean absolute errors were higher than for the Implied-CRRA model.

The risk-neutral approach can be clearly rejected at the 5\% level for all S\&P500 puts, whose realized returns deviated significantly from the monthly risk-free rate. For calls, the risk-neutral model delivers significant predictions with lower errors than the other option return models. However, this result may rather be attributed to the inherent problem 
of the Implied-CRRA and Lognormal-CRRA models being unable to predict negative expected call returns under a risk-averse investor. 


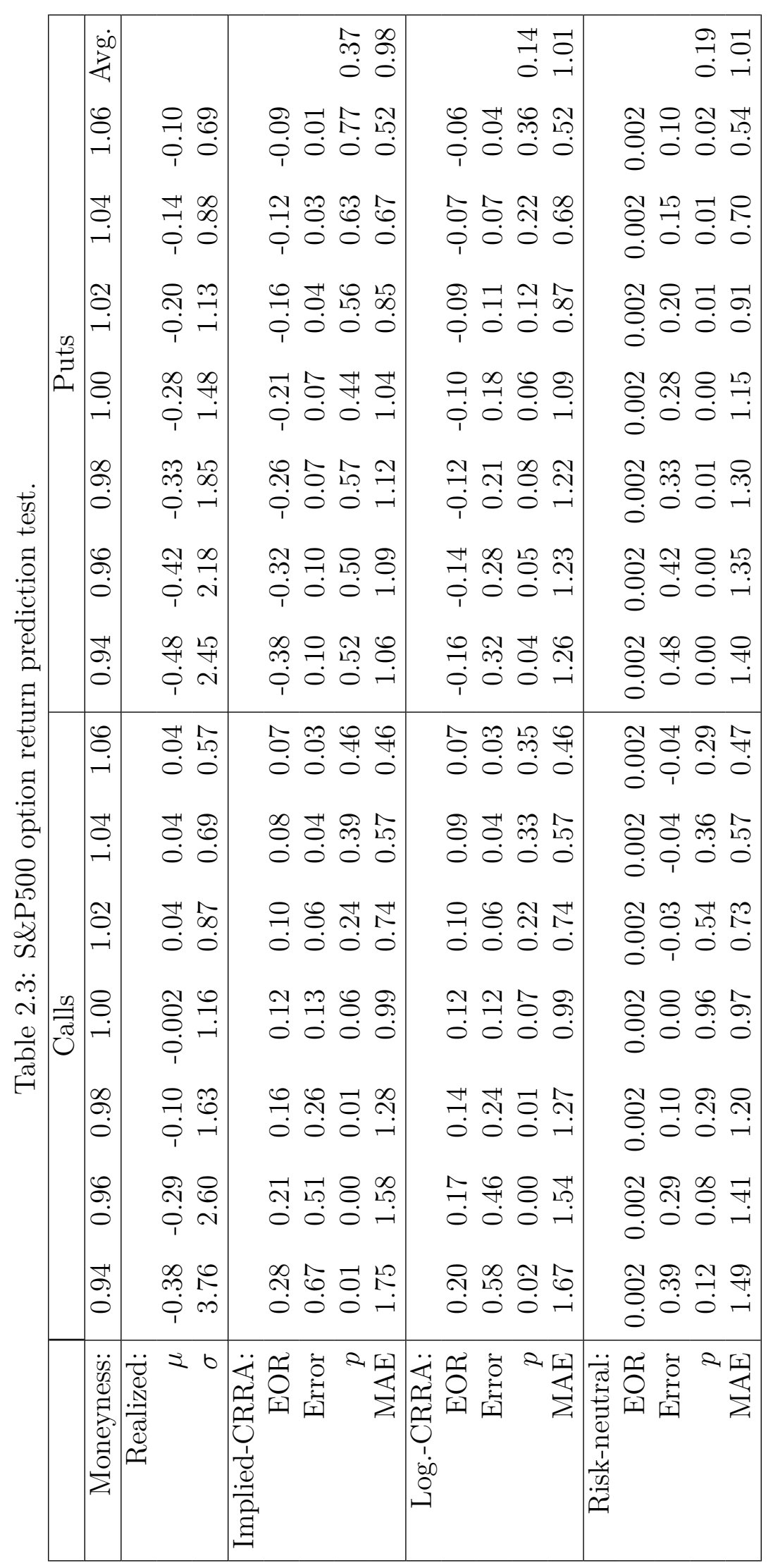

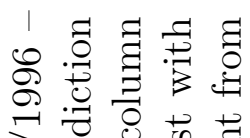

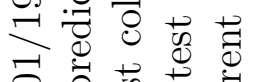

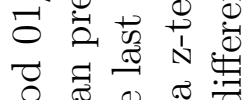

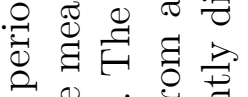
0

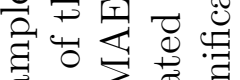

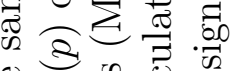

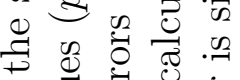
式芯 a 2.0

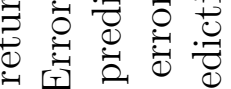

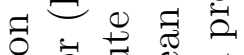
范 : 员. 茎: 결

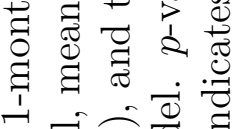

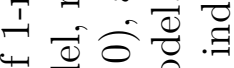
○ 6) छे 車过 000

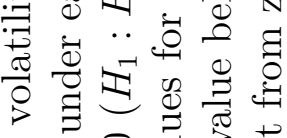

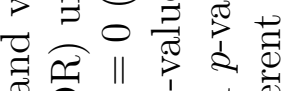
ऽิ च 这范

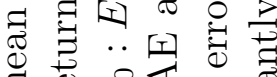

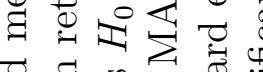
D. बै

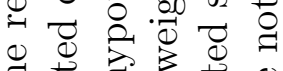

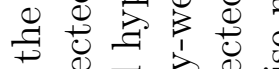

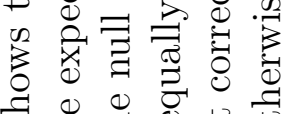

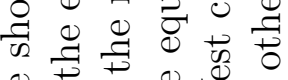

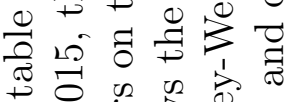

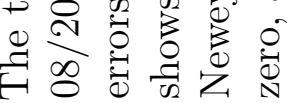


We further investigate whether the Implied-CRRA model provides not only lower, but significantly lower prediction errors compared to the benchmark models. Table 2.4 shows the mean absolute prediction error differences and $p$-values of the Implied-CRRA model compared to the benchmark models Lognormal-CRRA and risk-neutral. A negative mean absolute error difference indicates that the Implied-CRRA model achieved a lower mean prediction error.

Panel (a) shows that the Implied-CRRA model was slightly inferior, but not significantly, to the Lognormal-CRRA model in forecasting ITM call returns based on the mean absolute prediction error differences. The error differences were near zero and not significant for ITM calls with moneyness 1 to 1.06. For OTM calls with moneyness below 1, both models were rejected at the $5 \%$ level in the prediction test, such that the lower Lognormal-CRRA prediction error is not relevant in this case.

The risk-neutral approach, which forecasts all option returns by the risk-free rate, was significantly superior to the Implied-CRRA model for OTM call returns and insignificantly superior for ITM calls. For put options, the Implied-CRRA model was always significantly superior to the risk-neutral benchmark. The fact that the risk-neutral benchmark achieved a lower prediction error for call options may be statistically significant, but economically it rather reflects the anomaly of negative mean realized call returns, which are not possible to predict under the Implied-CRRA and Lognormal-CRRA models due to the assumed risk-averse utility.

Panel (b) presents remarkable results of the Implied-CRRA model, which significantly outpaced both benchmark models in the prediction of put returns. The Implied-CRRA model is particularly strong in predicting OTM put returns, which were often quoted as an option mispricing anomaly due to their extreme negativity (Bondarenko 2014).

In conclusion, the Implied-CRRA model achieves significant prediction results for mean realized S\&P500 put returns, where it also outperformed both benchmark models. The negative mean realized S\&P500 call returns however can not be explained by both ImpliedCRRA and Lognormal-CRRA models. The naive risk-neutral approach is statistically not rejected for the prediction of call returns, but rejected for the prediction of put returns. 
Table 2.4: Mean absolute prediction error differences of the Implied-CRRA model against the benchmark models.

(a) Calls:

\begin{tabular}{rrrrrrrr}
\hline Moneyness $(k)$ & 0.94 & 0.96 & 0.98 & 1.00 & 1.02 & 1.04 & 1.06 \\
\hline$\Delta \operatorname{Err}_{\text {Log.-CRRA }}$ & 0.08 & 0.04 & 0.01 & 0.00 & 0.00 & 0.00 & 0.00 \\
$p$ & $(0.00)$ & $(0.00)$ & $(0.00)$ & $(0.08)$ & $(0.28)$ & $(0.49)$ & $(0.21)$ \\
$\Delta \operatorname{Err}_{\text {risk-neutral }}$ & 0.26 & 0.17 & 0.08 & 0.02 & 0.01 & 0.00 & 0.00 \\
$p$ & $(0.00)$ & $(0.00)$ & $(0.00)$ & $(0.00)$ & $(0.39)$ & $(0.84)$ & $(0.49)$ \\
\hline
\end{tabular}

(b) Puts:

\begin{tabular}{rrrrrrrr}
\hline Moneyness $(k)$ & 0.94 & 0.96 & 0.98 & 1.00 & 1.02 & 1.04 & 1.06 \\
\hline$\Delta \operatorname{Err}_{\text {Log.-CRRA }}$ & -0.20 & -0.14 & -0.09 & -0.05 & -0.02 & -0.01 & 0.00 \\
$p$ & $(0.00)$ & $(0.00)$ & $(0.00)$ & $(0.00)$ & $(0.00)$ & $(0.10)$ & $(0.58)$ \\
$\Delta \operatorname{Err}_{\text {risk-neutral }}$ & -0.35 & -0.25 & -0.18 & -0.11 & -0.06 & -0.03 & -0.02 \\
$p$ & $(0.00)$ & $(0.00)$ & $(0.00)$ & $(0.00)$ & $(0.00)$ & $(0.00)$ & $(0.01)$ \\
\hline
\end{tabular}

The table shows the mean absolute prediction error differences $\Delta E r r_{i}=$ Mean $\left(\left|\operatorname{Err}_{\text {Implied-CRRA }}\right|_{t}-\left|E r r_{i}\right|_{t}\right)$ of the Implied-CRRA model against the benchmark models $(i=$ Log.-CRRA, risk-neutral) for predicted monthly S\&P500 call and put returns over the period $(t)$ from 01/1996 - 08/2015. $p$-values of the mean absolute prediction error differences were calculated from a z-test with Newey-West corrected standard errors on the null hypothesis $H_{0}: \Delta E r r_{i}=0\left(H_{1}: \Delta E r r_{i} \neq 0\right)$. A $p$-value below 0.05 indicates that the error difference is significantly different from zero, and otherwise not significantly different from zero.

Under a positive mean realized return on the underlying, how can the realized mean call returns be negative? An explanation can be found through analysis of the pricing kernel $m\left(S_{t+\tau}\right):=\frac{q\left(S_{t+\tau}\right)}{p\left(S_{t+\tau}\right)}$, which represents a measure for the relative difference between the risk-neutral and the physical measure. From equation (2.2) it follows

$$
m\left(S_{t+\tau}\right)=c \cdot U^{\prime}\left(S_{t+\tau}\right)
$$

The utility function satisfies $U^{\prime}(x)>0$ and $U^{\prime \prime}(x)<0$ for risk-averse investors, $U^{\prime \prime}(x)>0$ for risk-seeking investors, and $U^{\prime \prime}(x)=0$ for risk-neutral investors. As the risk-neutral measure $(q)$ is given from current option market prices and $c$ being a constant, the utility derivative $U^{\prime}$ fully determines the pricing kernel.

Under the Implied-CRRA and Lognormal-CRRA models, the representative investor is by assumption risk-averse, such that the pricing kernel is monotonically decreasing. Empirical 
studies however discovered a historically U-shaped, non-monotone kernel for the S\&P500 index (Bakshi et al. 2010; Brown and Jackwerth 2012). A U-shaped pricing kernel around $S_{t}$ implies risk preferences where investors are risk-averse on losses, and risk-seeking on profits. Figure 2.8 shows the estimated 1-month pricing kernels for each option pricing model, showing that the historical pricing kernel is indeed non-monotone. When computing the expected physical option payoffs, one essentially utilizes the left part of the physical density for puts (which pay only when the asset price falls below the option strike), and the right part of the physical density for calls (above the strike). While the left part of a U-shaped pricing kernel is accurately modeled as monotone decreasing under risk-averse preferences, the right part of a U-shaped kernel is increasing. Therefore realized mean S\&P500 put returns were well predicted by the Implied-CRRA model, while negative mean realized call returns were unexplainable. In the risk-adjusted option-implied approach, a U-shaped pricing kernel would require a non-monotone utility derivative; however, the approach was derived under the explicit assumption of a risk-averse investor with convex utility, such that negative expected call returns cannot be generated under the approach.

Figure 2.8: S\&P500 pricing kernel.

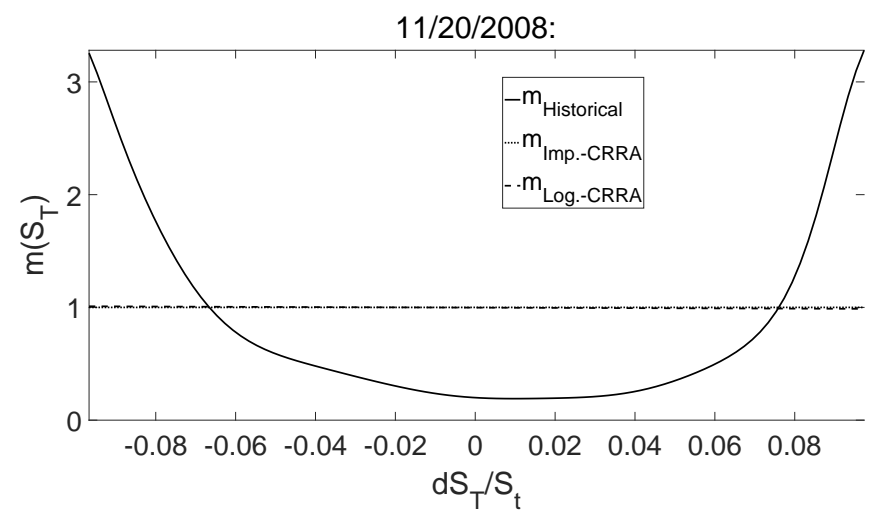

The figure shows the S\&P500 pricing kernels $(m)$ on 11/20/2008. The Implied-CRRA Kernel $\left(m_{\text {Imp.-CRRA }}\right)$ uses the Implied-CRRA physical and risk-neutral densities, the LognormalCRRA kernel $\left(m_{\text {Log.-CRRA }}\right)$ uses the Lognormal-CRRA physical and risk-neutral densities, and the Historical kernel $\left(m_{\text {Historical }}\right)$ uses the empirical physical and risk-neutral densities. The option-implied risk-neutral and physical densities were constructed from the respective put prices as in (Figlewski 2010). The historical physical density was estimated via a Gaussian kernel smoother on the monthly discrete distribution of index levels $\left(S_{T}\right)$. The discrete distribution of $S_{T}$ was estimated by applying the historical 1-month S\&P500 index returns to the prevailing index level adjusted by the implied S\&P500 dividend yield. 


\subsection{Conclusion}

This paper studied the option-implied risk-adjusted approach by Brinkmann and Korn (2018) in predicting mean realized S\&P500 index option returns in perfect markets. The approach extracts the option-implied expectations of a representative investor with riskaverse utility to capture the wedge between the risk-neutral and physical measure. The approach was able to explain the option mispricing puzzle with respect to S\&P500 put returns. The approach is highly flexible and dynamic as it instantly adjusts to changes in current option market prices and can be equipped with arbitrary risk-averse preferences to determine the expected option return for different classes of representative investors.

A prediction error test showed that the option-implied approach with CRRA utility can well explain the magnitude of mean put and ITM call returns, where it was also superior to the standard Black Scholes model as well as the risk-neutral approach. However, none of the tested option pricing models could reproduce the highly negative mean realized OTM call returns. Negative expected call returns require a U-shaped pricing kernel, which is however not compatible with risk-averse preferences as assumed by the implied risk-adjusted approach. We conclude that S\&P500 puts and ITM calls were fairly priced under the Implied-CRRA model over the sample period, while OTM call returns were unexplainable. 


\title{
3 Option Return Volatility
}

\begin{abstract}
Option return volatility can far exceed the underlying volatility due to the high implied leverage and represents an important measure for option risk. The paper studies the theoretical and empirical properties of S\&P500 call and put return volatilities over finite and instantaneous holding periods in a Black-Scholes setting. I derive and illustrate properties and sensitivities of option volatility with respect to maturity, physical drift rate, dividend yield, moneyness, underlying volatility, and the risk-free rate over different holding horizons. While theoretical option volatility is found to behave similarly when comparing hold to maturity or selling prior to maturity horizons, significant differences exist for instantaneous holding periods with respect to the physical drift rate and maturity. In an empirical test, I find that realized S\&P500 put volatilities can be explained by the Black-Scholes model, while S\&P500 call volatilities were unexplainable reconfirming parts of the option mispricing puzzle.
\end{abstract}

Acknowledgment: We would like to thank Olaf Korn for helpful comments and suggestions. This work was supported by the Deutsche Forschungsgemeinschaft [UH 107/4-1, KO 2285/3-1]. 


\subsection{Introduction}

Equity options provide the opportunity for high implied leverage on both long and short positions in the underlying. They can be combined to replicate a desired payoff structure or manage the risk of investor portfolios. The volatility of option returns hereby represents an important measure for option risk.

The known option mispricing puzzle states that mean realized option returns could not be fully explained by standard option pricing models in perfect markets due to extreme negative S\&P500 put returns, overshooting and skewed option-implied volatilities, and negative delta-hedged option returns ${ }^{1}$. As found in this paper, one can observe a similar puzzle with respect to the volatility of call returns.

While no previous paper yet studied option volatility, some studies investigate the relation between expected option returns and underlying volatility. Hu and Jacobs (2016) present analytical expressions for expected option returns under the Black-Scholes model and find that expected call (put) option returns increase (decrease) with underlying volatility. Cao and Han (2013) state that delta-hedged option returns decrease with an increase of the idiosyncratic volatility of the underlying confirming the low-volatility anomaly for option markets. Goyal and Saretto (2009) find that long-short option portfolios sorted on the volatility risk premium generated abnormal returns. They surmise investor's overreaction to extreme stock returns due to temporarily overstated option implied volatility.

This paper presents a first study on the volatility of option returns in perfect markets. Section 3.2 provides analytical expressions for option volatility under the Black-Scholes model for instantaneous, before-expiration and hold-to-expiration holding periods. Section 3.3 illustrates the cross-sectional option volatility sensitivities under each holding period for the different option pricing parameters such as strike, maturity, risk-free rate, underlying volatility, moneyness, physical drift rate. Section 3.4 provides an empirical study on S\&P500 option volatilities to compare the realized and predicted values over different holding periods, moneyness and maturities. Section 3.5 concludes.

\footnotetext{
${ }^{1}$ Bondarenko (2014); Chambers et al. (2014); Goyal and Saretto (2009); Bates (2000); Bakshi et al. (2003)
} 


\subsection{Option Volatility}

The realized return of a European call $\left(R_{t, T}^{C}\right)$ or put $\left(R_{t, T}^{P}\right)$ option with strike $K$ held from time $t \geq 0$ to maturity $T>t$ is given by the ratio of the option payoff at time $T$ over the option price $\left(C_{t}, P_{t}\right)$ at time $t$ :

$$
\begin{aligned}
& R_{t, T}^{C}=\frac{\left(S_{T}-K\right)^{+}}{C_{t}}-1 \\
& R_{t, T}^{P}=\frac{\left(K-S_{T}\right)^{+}}{P_{t}}-1
\end{aligned}
$$

The expected option return follows as the ratio of the expected option payoffs under the physical $(\mathcal{P})$ over the risk-neutral $(\mathcal{Q})$ measure:

$$
\begin{aligned}
E\left[R_{t, T}^{C}\right] & =\frac{E^{\mathcal{P}}\left[\left(S_{T}-K\right)^{+}\right]}{e^{-r(T-t)} E^{\mathcal{Q}}\left[\left(S_{T}-K\right)^{+}\right]}-1 \\
E\left[R_{t, T}^{P}\right] & =\frac{E^{\mathcal{P}}\left[\left(K-S_{T}\right)^{+}\right]}{e^{-r(T-t)} E^{\mathcal{Q}}\left[\left(K-S_{T}\right)^{+}\right]}-1
\end{aligned}
$$

The call return variance $V\left(R_{t, T}^{C}\right)$ and volatility $v\left(R_{t, T}^{C}\right)$ follow as

$$
\begin{aligned}
V\left(R_{t, T}^{C}\right) & =E^{\mathcal{P}}\left[\left(R_{t, T}^{C}-E\left[R_{t, T}^{C}\right]\right)^{2}\right] \\
& =\frac{E^{\mathcal{P}}\left[\left(S_{t+\tau}-K\right)^{+2}\right]-E^{\mathcal{P}}\left[\left(S_{t+\tau}-K\right)^{+}\right]^{2}}{C_{t}^{2}} \\
v\left(R_{t, T}^{C}\right) & =\sqrt{V\left(R_{t, T}^{C}\right)}
\end{aligned}
$$

where $\tau=T-t$ denoting the remaining time to maturity of the option.

Under the Black-Scholes-Merton model (Black and Scholes 1973; Merton 1973), the underlying price at maturity $S_{t+\tau}$ is Lognormally distributed and the call variance follows as

$$
V\left(R_{t, T}^{C}\right)=\frac{S_{t}^{2} e^{\tau\left(2 \mu+\sigma^{2}\right)} N\left(d_{3}^{*}\right)-2 K S_{t} e^{\mu \tau} N\left(d_{1}^{*}\right)+K^{2} N\left(d_{2}^{*}\right)-\left(e^{\mu \tau} S_{t} N\left(d_{1}^{*}\right)-K N\left(d_{2}^{*}\right)\right)^{2}}{C\left(\tau, S_{t}, \sigma, K, r\right)^{2}}
$$


with $z^{*}=\frac{\ln \frac{K}{S_{t}}-\left(\mu-\sigma^{2} / 2\right) \tau}{\sigma \sqrt{\tau}}, d_{1}^{*}=\frac{\ln \frac{S_{t}}{K}+\left(\mu+\sigma^{2} / 2\right) \tau}{\sigma \sqrt{\tau}}, d_{2}^{*}=\frac{\ln \frac{S_{t}}{K}+\left(\mu-\sigma^{2} / 2\right) \tau}{\sigma \sqrt{\tau}}, d_{3}^{*}=\frac{\ln \frac{S_{t}}{K}+\left(\mu+1.5 \sigma^{2}\right) \tau}{\sigma \sqrt{\tau}}$, and $C\left(\tau, S_{t}, \sigma, K, r\right)=S_{t} N\left(d_{1}\right)-e^{-r \tau} K N\left(d_{2}\right)$ representing the Black-Scholes call price with $d_{1}=\frac{\ln \frac{S_{t}}{K}+\left(r+\sigma^{2} / 2\right) \tau}{\sigma \sqrt{\tau}}, d_{2}=\frac{\ln \frac{S_{t}}{K}+\left(r-\sigma^{2} / 2\right) \tau}{\sigma \sqrt{\tau}}$, volatility $\sigma$, risk-free rate $r$ and physical drift rate $\mu$. A detailed derivation of the option return variances can be found in the appendix 3.6.1. Analogously the put variance can be derived as

$$
V\left(R_{t, T}^{P}\right)=\frac{S_{t}^{2} e^{\tau\left(2 \mu+\sigma^{2}\right)} N\left(-d_{3}^{*}\right)-2 K S_{t} e^{\mu \tau} N\left(-d_{1}^{*}\right)+K^{2} N\left(-d_{2}^{*}\right)-\left(e^{\mu \tau} S_{t} N\left(-d_{1}^{*}\right)-K N\left(-d_{2}^{*}\right)\right)^{2}}{P\left(\tau, S_{t}, \sigma, K, r\right)^{2}}
$$

where $P\left(\tau, S_{t}, \sigma, K, r\right)=e^{-r \tau} K N\left(-d_{2}\right)-S_{t} N\left(-d_{1}\right)$ denotes the Black-Scholes put price. A continuous dividend yield $d$ can further be introduced via substituting $S_{t}:=S_{t} e^{-d \tau}$ into equations (3.8), (3.9).

When the option is not held to maturity but priorly sold at market price at time $t+h$, the realized return of a call or put over a holding period $h<\tau=T-t$ is given by the ratio of the option price at time $t+h$ and the current option price at time $t$ :

$$
\begin{aligned}
R_{t, h, T}^{C} & =\frac{C_{T-h}}{C_{t}}-1, \\
R_{t, h, T}^{P} & =\frac{P_{T-h}}{C_{t}}-1
\end{aligned}
$$

The expected option returns follow as

$$
\begin{aligned}
& E\left[R_{t, h, T}^{C}\right]=\frac{E^{\mathcal{P}}\left(C\left(\tau-h, S_{t+h}, \sigma, K, r\right)\right)}{C\left(\tau, S_{t}, \sigma, K, r\right)}-1 \\
& E\left[R_{t, h, T}^{P}\right]=\frac{E^{\mathcal{P}}\left(P\left(\tau-h, S_{t+h}, \sigma, K, r\right)\right)}{P\left(\tau, S_{t}, \sigma, K, r\right)}-1
\end{aligned}
$$

The expected option price at time $t+h$ is evaluated under the physical measure $(\mathcal{P})$ to capture the filtration of realized underlying prices up to time $t+h$.

The variance of call returns for a holding period $h<\tau$ follows as

$$
\begin{aligned}
V\left(R_{t, h, T}^{C}\right) & =E^{\mathcal{P}}\left[\left(R_{t, h, T}^{C}-E^{\mathcal{P}}\left(R_{t, h, T}^{C}\right)\right)^{2}\right] \\
& =E^{\mathcal{P}}\left(R_{t, h, T}^{C}{ }^{2}\right)-E^{\mathcal{P}}\left(R_{t, h, T}^{C}\right)^{2} \\
& =\frac{E^{\mathcal{P}}\left(C\left(\tau-h, S_{t+h}, \sigma, K, r\right)^{2}\right)-E^{\mathcal{P}}\left(C\left(\tau-h, S_{t+h}, \sigma, K, r\right)\right)^{2}}{C\left(\tau, S_{t}, \sigma, K, r\right)^{2}}
\end{aligned}
$$


Under the Black-Scholes model with Lognormally-distributed underlying prices, the call variance and volatility over a period $h<\tau$ follow as:

$$
\begin{gathered}
V\left(R_{t, h, T}^{C}\right)=\frac{\int_{\mathbb{R}} C\left(\tau-h, S_{t} e^{\mu h-\frac{1}{2} \sigma^{2} h+\sigma \sqrt{h} z}, \sigma, K, r\right)^{2} \frac{1}{\sqrt{2 \pi}} e^{-\frac{z^{2}}{2}} d z-\left(\int_{\mathbb{R}} C\left(\tau-h, S_{t} e^{\mu h-\frac{1}{2} \sigma^{2} h+\sigma \sqrt{h} z}, \sigma, K, r\right) \frac{1}{\sqrt{2 \pi}} e^{-\frac{z^{2}}{2}} d z\right)^{2}}{C\left(\tau, S_{t}, \sigma, K, r\right)^{2}} \\
v\left(R_{t, h, T}^{C}\right)=\sqrt{V\left(R_{t, h, T}^{C}\right)}
\end{gathered}
$$

Analogously, the put return variance and volatility over period $h$ equals:

$$
\begin{gathered}
V\left(R_{t, h, T}^{P}\right)=\frac{\int_{\mathbb{R}} P\left(\tau-h, S_{t} e^{\mu h-\frac{1}{2} \sigma^{2} h+\sigma \sqrt{h} z}, \sigma, K, r\right)^{2} \frac{1}{\sqrt{2 \pi}} e^{-\frac{z^{2}}{2}} d z-\left(\int_{\mathbb{R}} P\left(\tau-h, S_{t} e^{\mu h-\frac{1}{2} \sigma^{2} h+\sigma \sqrt{h} z}, \sigma, K, r\right) \frac{1}{\sqrt{2 \pi}} e^{-\frac{z^{2}}{2}} d z\right)^{2}}{P\left(\tau, S_{t}, \sigma, K, r\right)^{2}} \\
v\left(R_{t, h, T}^{P}\right)=\sqrt{V\left(R_{t, h, T}^{P}\right)}
\end{gathered}
$$

A detailed derivation can be found in the appendix 3.6.2.

Finally, consider the realized call return for an infinitesimal holding period $h \rightarrow 0$ :

$$
R_{t, 0, T}^{C}=\frac{d C_{t}}{C_{t}}
$$

Recall that in the Black-Scholes model, the dynamics of the underlying under the physical measure are given by

$$
d S_{t}=\sigma S_{t} d W_{t}+\mu S_{t} d t
$$

where $d W_{t}$ represents standard Brownian Motion increments.

Applying Itó's Lemma to a twice-differentiable claim $C\left(S_{t}, t\right): \mathbb{R}_{+}^{2} \mapsto \mathbb{R}$ yields

$$
d C_{t}=\frac{\delta C_{t}}{\delta S_{t}} \sigma S_{t} d W_{t}+\left(\mu S_{t} \frac{\delta C_{t}}{\delta S_{t}}+\frac{1}{2} \sigma^{2} S_{t}^{2} \frac{\delta^{2} C_{t}}{\delta S_{t}^{2}}\right) d t
$$


The infinitesimal return variance follows as:

$$
\begin{aligned}
V\left(R_{t, 0, T}^{C}\right) & =\frac{V\left(d C_{t}\right)}{C_{t}^{2}} \\
& =\frac{\left(\frac{\delta C_{t}}{\delta S_{t}} \sigma S_{t}\right)^{2} d t}{C_{t}^{2}}
\end{aligned}
$$

The infinitesimal call and put return volatilities follow as

$$
\begin{gathered}
v\left(R_{t, 0, T}^{C}\right)=\frac{\Delta_{t} \sqrt{d t} \sigma S_{t}}{C\left(\tau, S_{t}, \sigma, K, r, d\right)} \\
v\left(R_{t, 0, T}^{P}\right)=\frac{\left|\Delta_{t}-e^{-d \tau}\right| \sqrt{d t} \sigma S_{t}}{P\left(\tau, S_{t}, \sigma, K, r, d\right)}
\end{gathered}
$$

with $\Delta_{t}=\frac{e^{-d \tau} N\left(\left(\ln \left(S_{t} / K\right)+\left(r-d+0.5 \sigma^{2}\right) \tau\right)\right.}{\sigma \sqrt{\tau}}$. A detailed derivation can be found in the appendix 3.6.3.

Formulas (3.26) - (3.27) intuitively define the instantaneous return volatility of the option by the volatility of the instantaneous underlying price change $v\left(d S_{t}\right)=\sigma S_{t} \sqrt{d} t$ times the sensitivity of the option price to a change in the underlying price $\Delta_{t}$ scaled by the option price.

\subsection{Cross-Section of Option Volatilities}

This section illustrates the cross-sectional relation between the Black-Scholes option volatilities and the option pricing parameters based on a standard parameter set estimated from monthly S\&P500 index prices provided by Optionmetrics IvyDB over the period 01/1996-07/2015: $r=0.0280, \mu=0.0965, \sigma=0.1773, d=0.0176, K=S_{t}=100$, $t=0, T=\tau=d t=1$. The following illustrations therefore refer to the volatilities of at-the-money S\&P500 European options under the Black-Scholes model.

Figure 3.1 presents the cross-section of call and put volatilities for variying time to maturity $(\tau)$ and moneyness $(K / S)$. One can observe that call (put) option volatility increases (decreases) with time to maturity for finite holding periods in panels (a) and (b). The assumed positive physical drift rate $(\mu>0)$ leads to an expected increase of the stock price 
over time such that call options will more likely expire in the money allowing for higher payoff variability, while puts more likely expire worthless in which case any underlying volatility is absorbed. For infinitesimal holding periods in panel (c), the call and put volatilities are nearly identical (call and put deltas are around 0.5 and the option prices are approximately equal) and monotone decreasing with time to maturity. It seems surprising that option volatilities hereby behave differently for infinitesimal and finite holding periods. In the infinitesimal case, the delta of both call and put converges to zero for increasing time-to-maturity, while the call and put prices increase, such that call and put volatilities both decrease strongly with time to maturity. Furthermore unlike under finite holding periods, infinitesimal option volatilities are independent of the phyisical drift rate of the underlying.

Figure 3.1 shows that at-the-money call volatility is always higher than put option volatility for varying time to maturity, which can be explained by the fact that the put payoff is bounded between 0 and $K$, while the call payoff is unbounded above zero.

Panels (d)-(f) show that call and put volatilities increase with lower moneyness (higher $K / S$ ratio for calls and lower $K / S$ ratio for puts) since out-of-the-money options are more risky with higher implied leverage. A call with a strike of zero $(K / S=0)$ equals a long position in the underlying and risk-free asset, such that the underlying volatility $\sigma$ poses a lower bound to the call volatility. Put volatility is only bounded by 0 as a strike going to infinity implies an almost certain (risk-free) put payoff equal to the strike. 

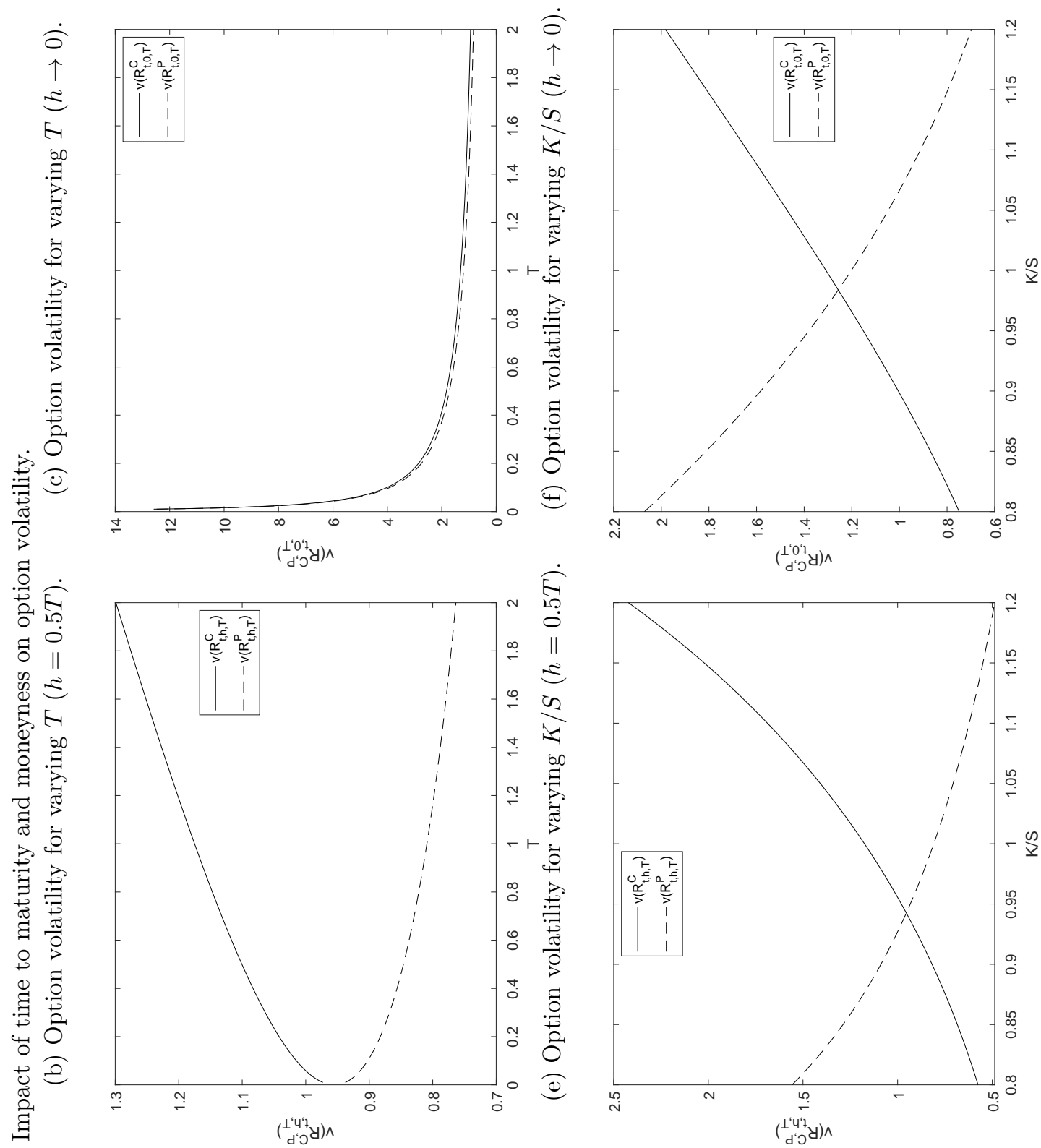

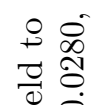

जी 11

웅

包 11

क क

$\Xi \omega$

.0

胥

on 4

赵赵

范

ซี

下

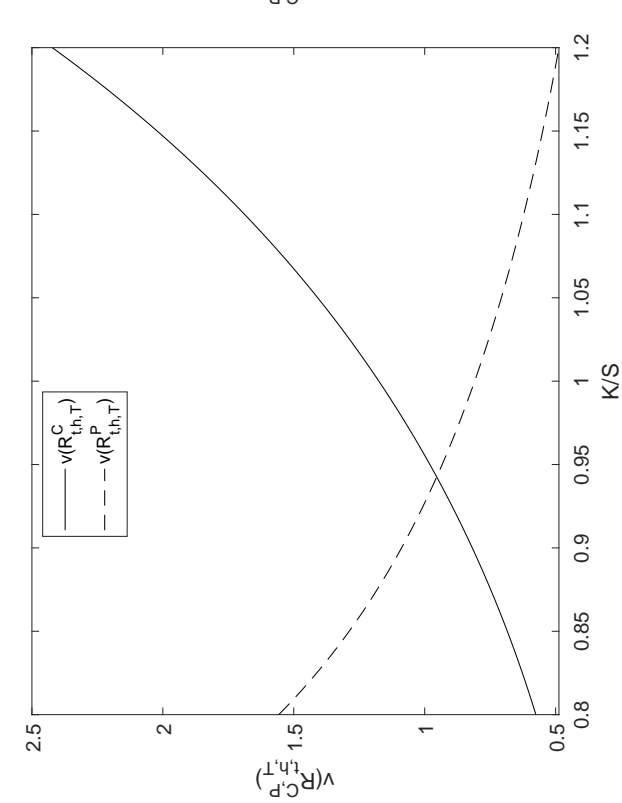

$\| \dot{\Xi}$

E

:

苛

$\stackrel{\square}{2}$

$\circ:$

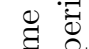

$\exists$

so

荬

苞

들

氧

氜

ค न

灵茖
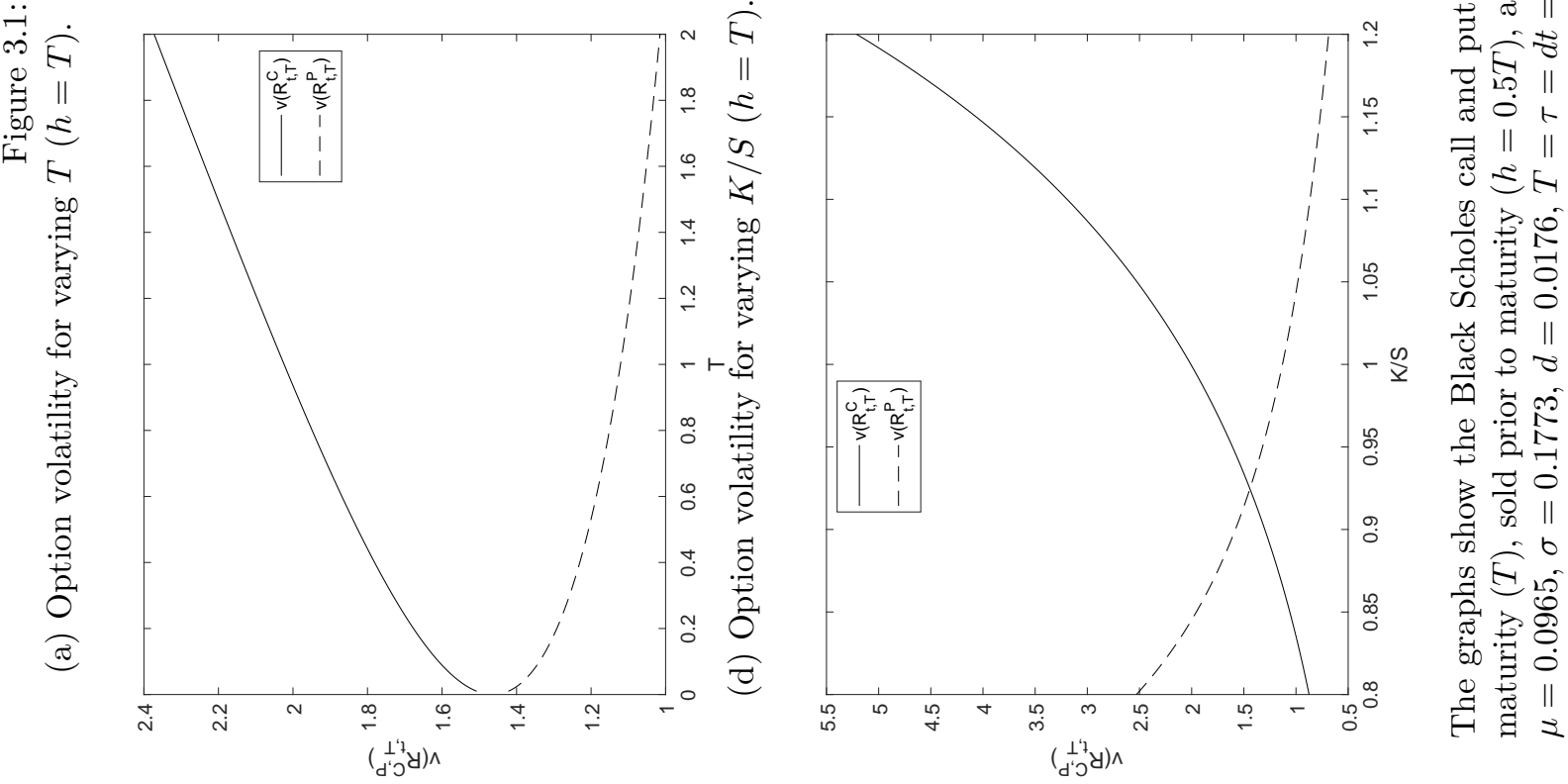
Figure 3.2 presents the cross-sections of call and put volatilities for different underlying volatilities $(\sigma)$ and physical drift rates $(\mu)$. Call volatility overall increases with underlying volatility for all three holding periods in panels (a) to (c), which does not seem surprising as the call payoff is sublinear in $S_{t}$. The initial non-monotone region of call volatility against underlying volatility can be explained by the fact that both option payoff volatility and option price increase with underlying volatility, where one can observe a small region where the call payoff volatility increases less strongly than the option price.

One can further confirm that call volatility is always higher than put volatility in panels (a) and (b) as the call payoff is unbounded while the put payoff is bounded. For the instantaneous holding period in panel (c), the put volatility can be higher than the call volatility. From an instantaneous view, at-the-money call and put options are equally affected going out-of-money and in-the-money for an instantaneous change in the underlying price, such that volatilities may be determined by the difference in option prices rather than payoff sensitivity.

Put volatility exhibits a non-monotone concave curve for varying underlying volatility and finite holding periods in panels (a) and (b) of figure 3.2. The put payoff is bounded from both below and above, unlike the call. When the underlying volatility equals 0 , a put option cannot have any volatility. When underlying volatility increases, it adds chances for positive payoffs, such that put return volatility increases. However, when underlying volatility goes to infinity, put return volatility cannot go to infinity as its payoffs are bounded between 0 and $K$. The price of the put option in the Black-Scholes model is known to monotonically increase with underlying volatility up to an upper bound $K e^{-r \tau}$. The observed put return curves over the finite holding periods imply that the volatility of the put payoff first increases stronger than the put price, then increases less than the put price. For infinitesimal holding periods, panel (c) shows that put volatility decreases with underlying volatility, which implies that the put price increases stronger than the put payoff volatility for an increase in the underlying volatility.

For varying underlying physical drift rates $(\mu)$, call volatility increases monotonically with the underlying drift rate for finite holding periods in figure 3.2 panels (d) and (e). A higher drift rate increases call volatility by enabling additional positive payoffs which 
otherwise would have been absorbed at the option strike. Furthermore, the option price under the risk-neutral measure is independent of the physical drift rate, such that the only dependency is in the option payoff. The infinitesimal volatilities of call and put payoffs are independent of the physical drift rate and therefore constant in panel (f).

Put volatility decreases with the underlying physical drift rate for finite holding periods in panels (d) and (e) of figure 3.2 as a higher expected return on the underlying increases the probability to hit the upper strike barrier where the put payoff is constant zero. The put price is also independent of the physical drift rate under the risk-neutral measure. 

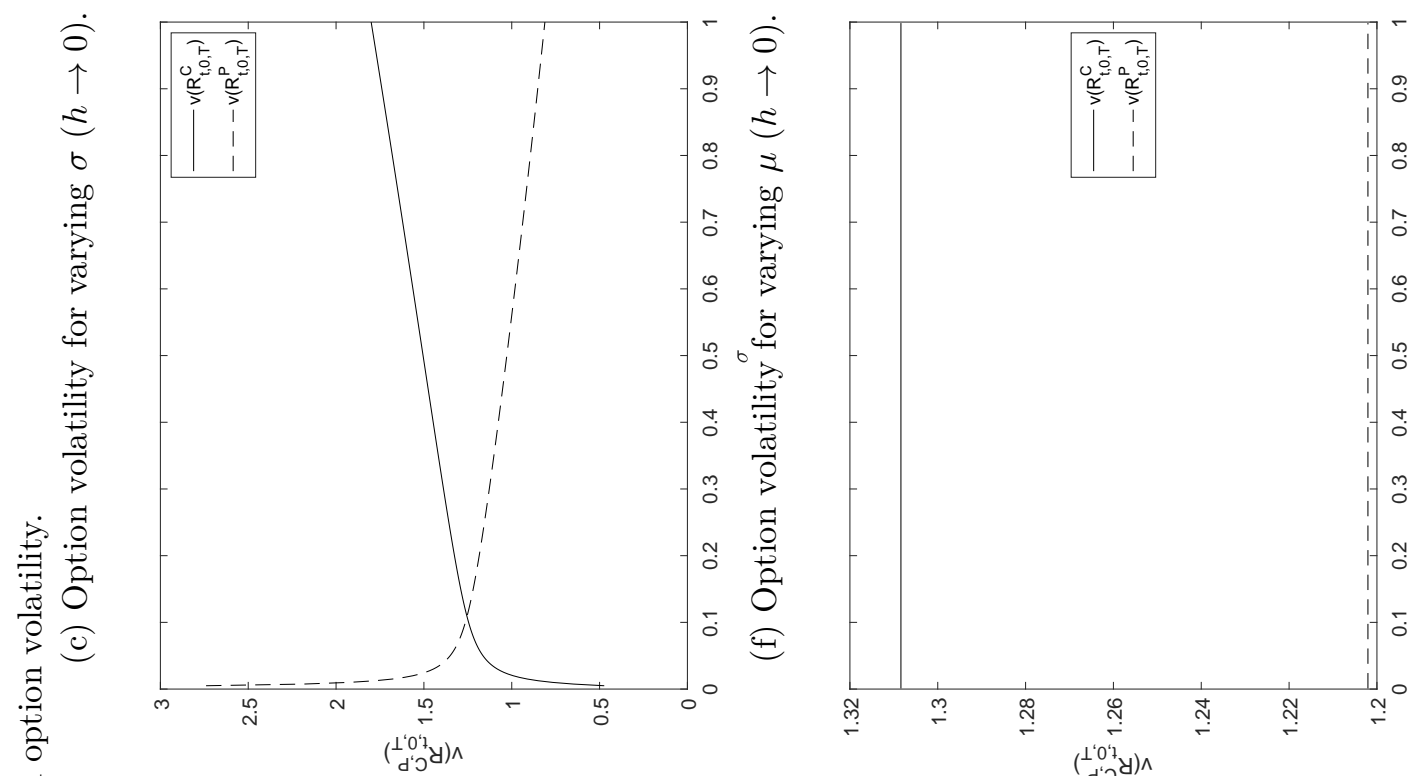

:

ఊ్ర $\stackrel{1}{\circ}$

엉

공

के

害山

క

荧

苛

శ్ర

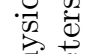
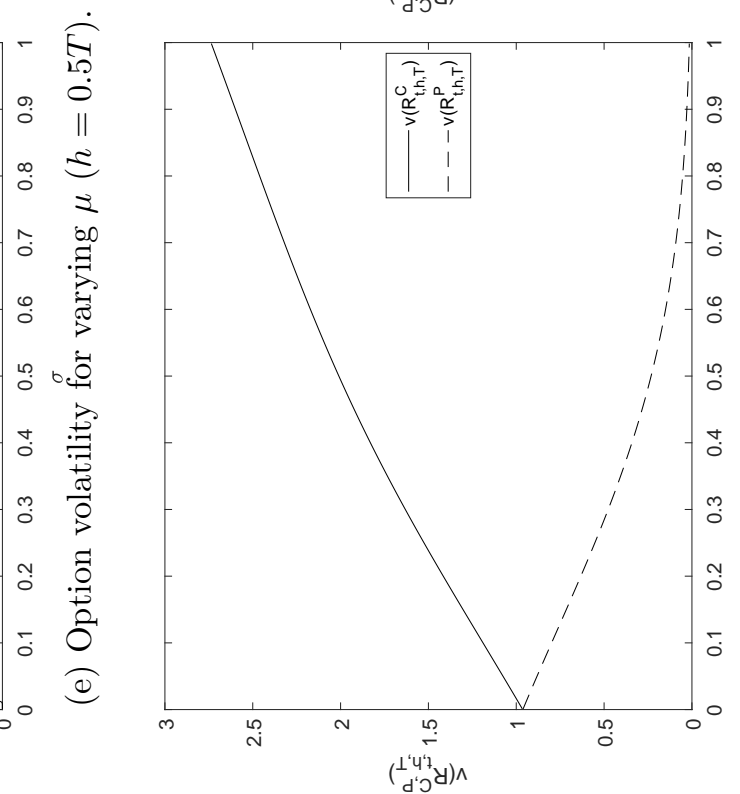

范

동
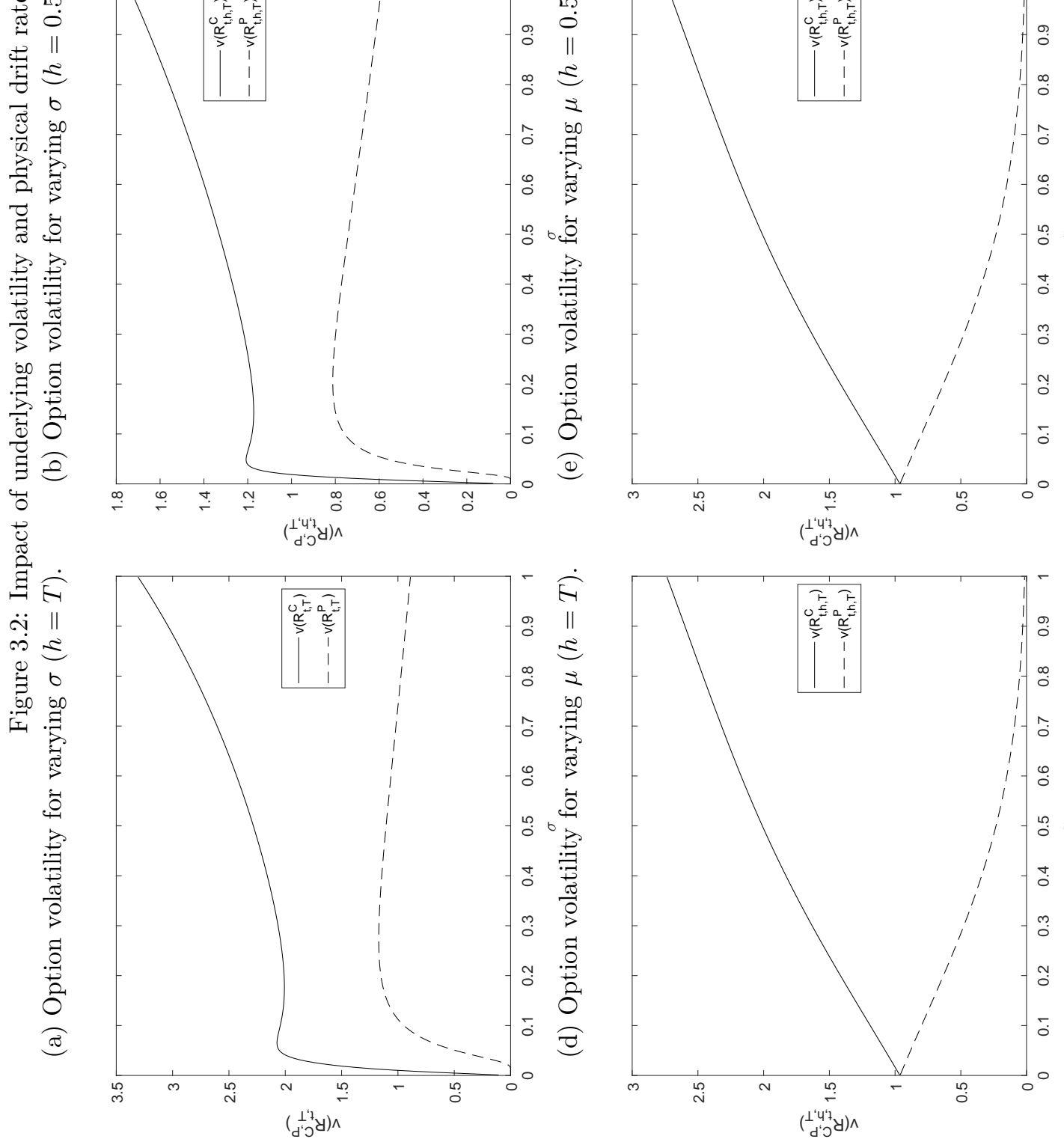

票

$\rightarrow \uparrow$

.

$\rightarrow=$

过

.0

西

5.

ล.

.

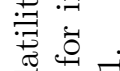

$\overrightarrow{8}$,

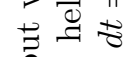

?.

西

辰 11

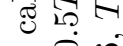

운 0

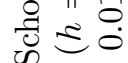

$4 \geqslant 11$

范

ח

의

s.

जी

马

권 긍 \& 
Figure 3.3 presents the option volatility curves for varying risk-free rate $r$ and dividend yield $d$. Panels (a) to (c) show that a higher risk-free rate always increases the call price as it increases the opportunity cost from holding the underlying, while the expected physical option payoff is unaffected, such that call return volatility decreases. Conversely, the put price decreases with an increase of the risk-free rate while its payoff remains unaffected, such that put return volatility increases.

The dividend yield in panels (d) to (f) unlike the risk-free rate affects both the expected option payoff and the current option price. As the dividend yield is introduced to the Black-Scholes model via substitution $S_{t}:=S_{t} e^{-d \tau}$, it is essentially equivalent to a change in option moneyness and the observed sensitivities are therefore similar to a change in the $K / S$ ratio. A higher dividend yield decreases put volatility as the put price decreases in anticipation of the underlying price drop. The put payoff volatility in the nominator increases as the final underlying price is less likely to be absorbed by the strike $K$, however the net effect is dominated by the put price increase. The call volatility shows an opposite behaviour as it increases with the dividend yield due to a decrease in the call price, which dominates the decreasing volatility of the call payoff. 

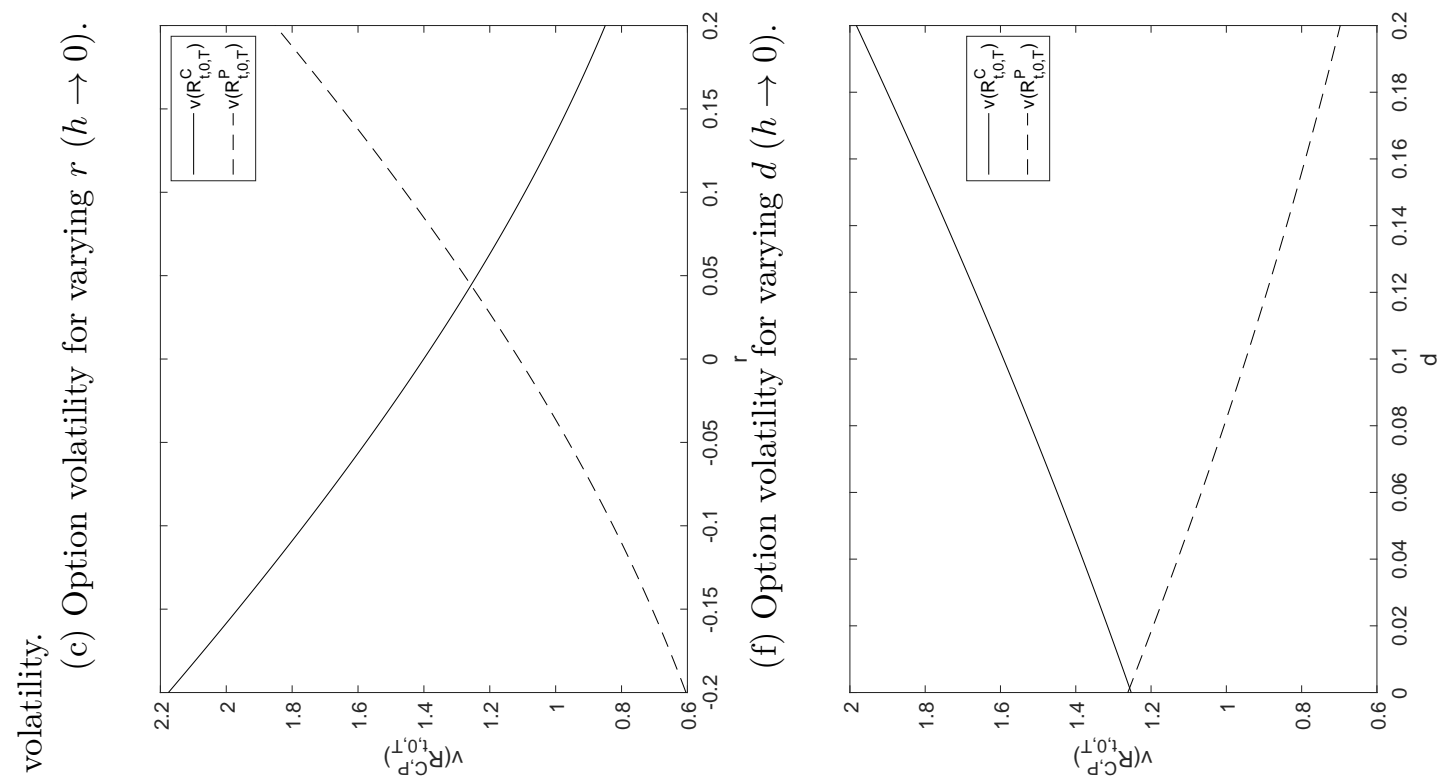

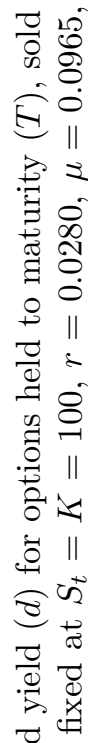
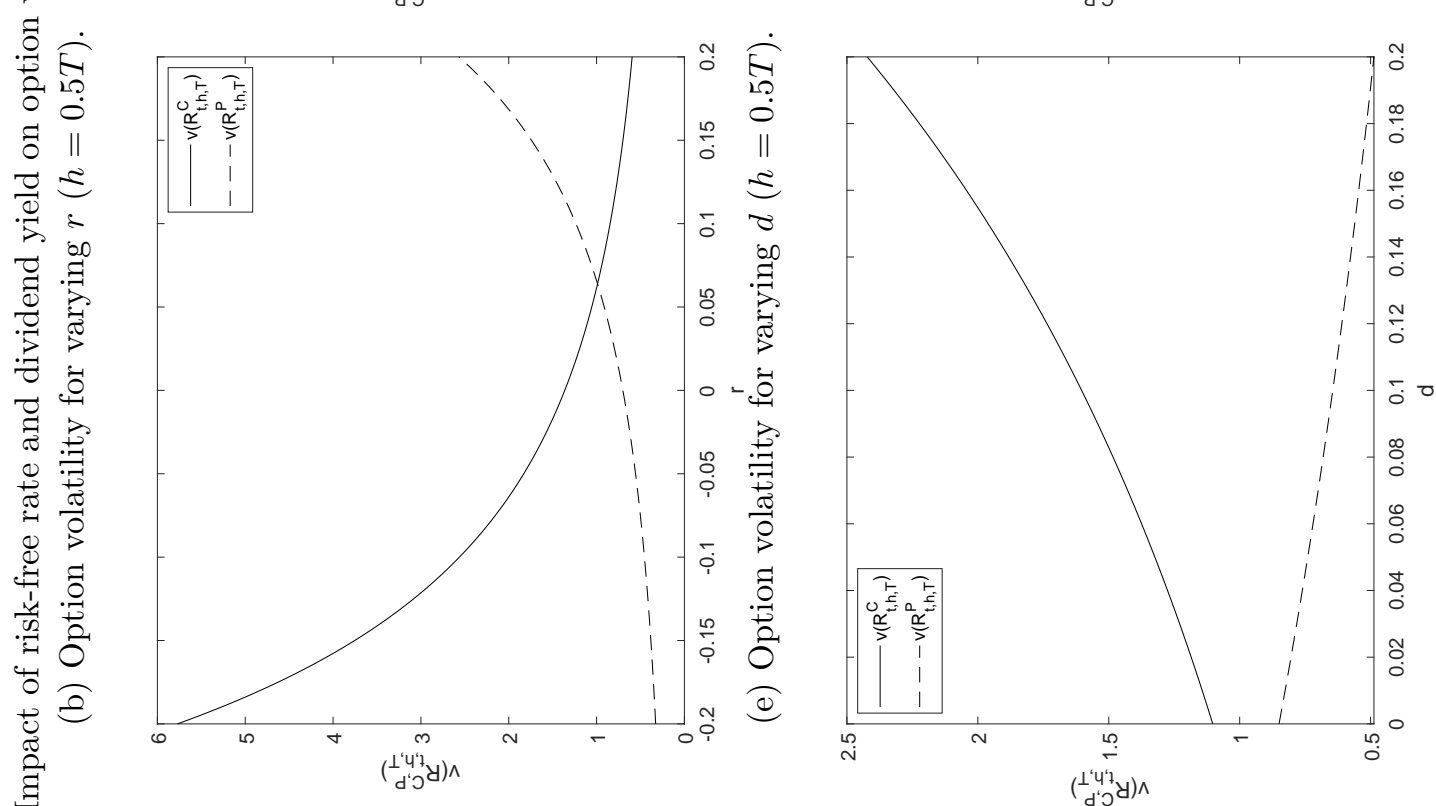

:

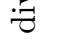

$\bar{z}$

E

$\underset{0}{2}$

苋苞

$\bigotimes_{i=1}$

.

$\overbrace{0}^{\infty} \uparrow$

.8

节。

苛

(2)

蚂茟

द्g

$\ddot{\leftrightarrow}$

党
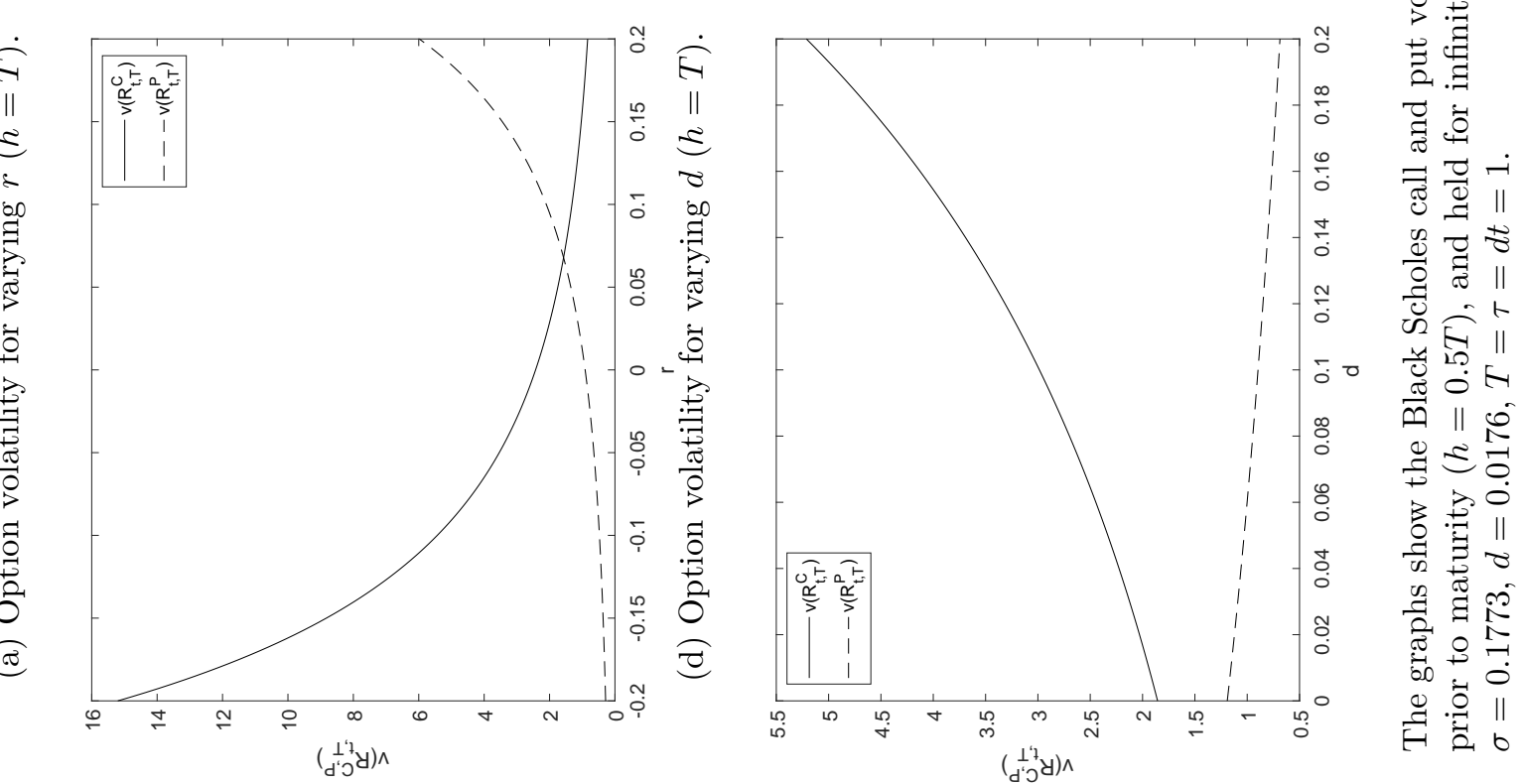
The hereby presented option volatility sensitivities illustrate the properties of European S\&P500 call and put options, whereby an analytical discussion thereof could still lead to more detailed results in the limits. The option volatility formulas represent ratios of two highly non-linear terms with semi-closed expressions, such that a graphical analysis can give more intuitive insights into the properties of the Black-Scholes option volatilities. The sensitivities may further change when bumping more than one parameter, e.g. comparing out-of-the money options with long-term maturities and in-the-money options with shortterm maturities. There exists an infinite space for the 6 option pricing parameters in the Black-Scholes model. This study focuses on an illustrative comparative-static analysis of at-the-money option volatility.

\subsection{Empirical study on S\&P500 Option Volatilities}

The following empirical study estimates the Black-Scholes option volatilities for the S\&P500 index over the period 01/1996 - 07/2015 and tests whether they coincide with the realized volatilities. The setting of the test follows the approach in Broadie et al. (2009).

The option pricing data was obtained from the OptionMetrics IvyDB US database and filtered following standard methodology (Goyal and Saretto 2009; Cao and Han 2013): S\&P500 1-month options with 28 to 29 days to maturity (depending on bank holidays) and expiration on the 3rd Friday or Saturday of the month were selected. The option bid-ask spread was filtered to be greater than the minimum spread of $\$ 0.05$ when the option mid price was below $\$ 3$, and greater than $\$ 0.1$ minimum option spread else. The midpoint prices of call $\left(C_{t}\right)$ and put $\left(P_{t}\right)$ options were filtered by the arbitrage-free boundaries: $\left[S_{t} e^{-d_{t} \tau}-K e^{-r_{t} \tau}\right]^{+}<C_{t}<S_{t} e^{-d_{t} \tau}$ and $\left[K e^{-r_{t} \tau}-S_{t} e^{-d_{t} \tau}\right]^{+}<P_{t}<K e^{-r_{t} \tau}$. Best bid and ask quotes, daily trading volume, open interest, implied volatility were filtered to be non-zero and the last trade date of the option had to be available. S\&P500 option payoffs were calculated from the index open price on the settlement day. The final sample contains 19.912 one-month options over 235 months, with 50 puts and 35 calls per month on average. Call and put options with specific moneyness were obtained via a quadratic fit over each month's sample implied volatilities, following the methodology in Chambers et al. (2014) 
and Broadie et al. (2009). When considering option returns with holding periods below 1 month, the same methodology as above was applied.

The study assumes the following parameters estimated from the time series of monthly realized S\&P500 logreturns as well as the corresponding average risk-free rates and implied dividend yields provided by Optionmetrics IvyDB over the sample period 01/1996 - 07/2015: $r=0.0280, \mu=0.0965, \sigma=0.1773, d=0.0176$. The option strikes vary from $94 \%$ to $106 \%$ of the underlying price. The underlying price is set to $S_{t}=100$ (noting that option volatility does not depend on the level but the ratio of $S_{t}$ and $K$ ). The time to maturity equals $\tau=28 / 365$ with holding periods $h=\tau, h=0.5 \tau$ and $h \rightarrow 0$. The infinitesimal case where $h \rightarrow 0$ is approximated by the smallest available holding period of one business day as $d t=1 / 252$.

Following the approach in Broadie et al. (2009) where a test of realized mean option returns is presented, the study compares realized and predicted option return volatilities under the Black Scholes model based on the mean prediction error. The significance of the mean prediction errors as differences between the mean predicted and realized monthly option volatilities was inferred from the distributions of 25.000 simulated Black-Scholes option volatilities with sample paths of 235 months (the sample period 01/1996 - 07/2015) for moneyness categories from 0.94 to 1.06. Figure 3.4 illustrates the distributions of the simulated hold-to-maturity Black-Scholes option volatilities together with the corresponding predicted and realized S\&P500 volatilities. One can observe that consistent with the previous findings, out-of-money option volatilities were considerably larger than in-themoney volatilities. Realized call volatilities were consistently lower than simulated call volatilities under the Black-Scholes model, while realized put volatilities were close to the model, which is surprising as the option mispricing puzzle is often described as put puzzle. Table 3.1 presents the option return prediction test comparing the mean 1-month realized S\&P500 option volatilities with the predicted Black-Scholes option volatilities for different moneyeness and holding periods $(h=\tau, h=0.5 \tau, h \rightarrow 0)$. The realized option volatilities represent the standard deviations of realized S\&P500 option returns, the predicted option volatilities were calculated from the derived equations under the Black-Scholes model using the discussed set of estimated parameters. For $h=\tau$, realized option returns were 

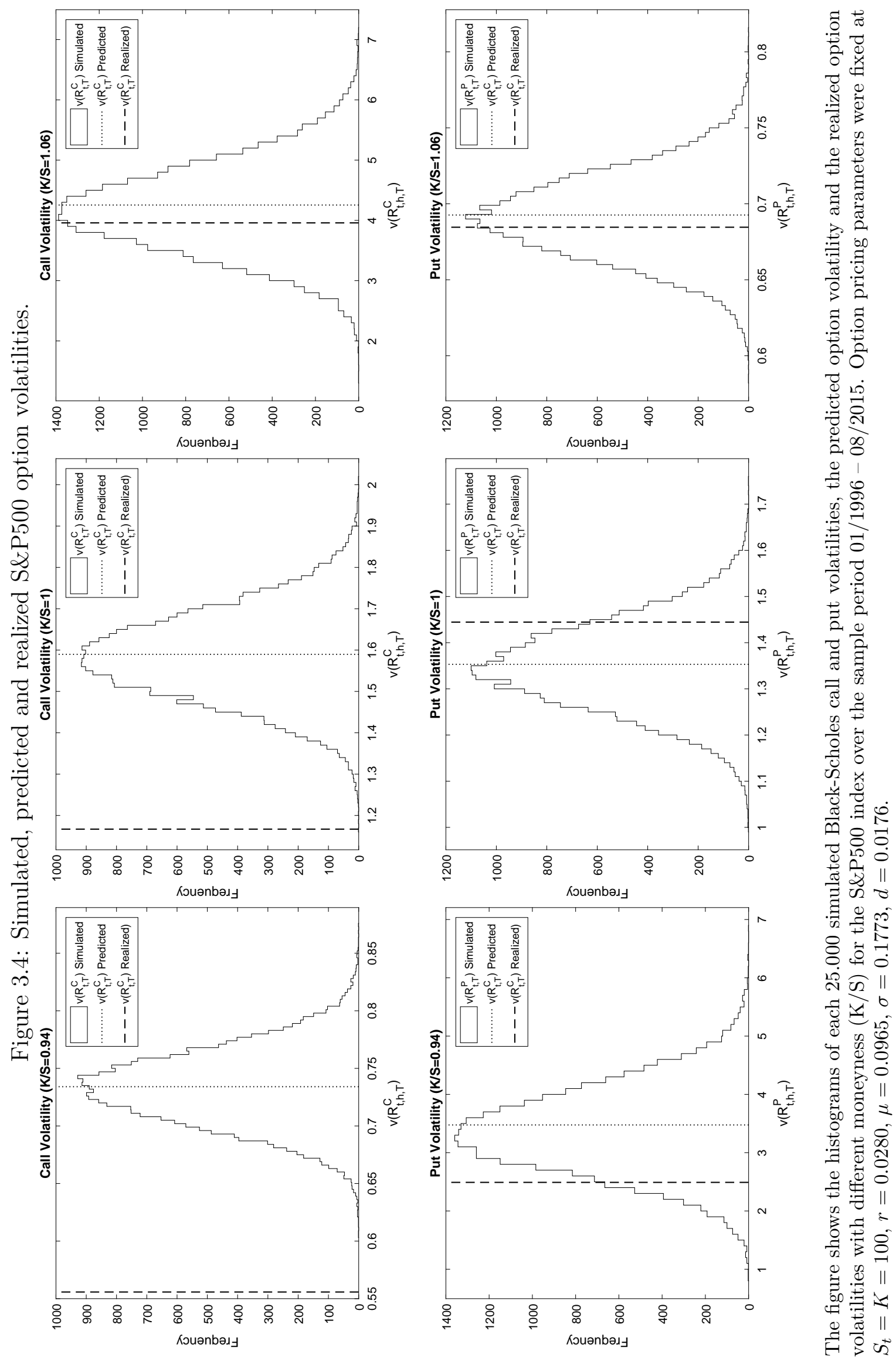
calculated as the ratio of the option payoff at maturity and the initial option market prices minus one. For $h=0.5 \tau$ and $h \rightarrow 0$, realized option returns were calculated by the ratio of the option market price at the end of the holding period and the option market price at initiation minus one. To obtain option prices with exact moneyness each month, a quadratic fit with flat extrapolation over the monthly implied volatility curve was applied (see Brinkmann and Korn (2018)).

For calls, the Black-Scholes model was rejected at the $5 \%$ level for almost all moneyness ratios and holding periods due to high significant prediction errors. All of the call volatility prediction errors are negative as realized call volatility was lower than under the BlackScholes model. As the physical payoff distribution was directly fitted from the realized S\&P500 returns, the observed significant prediction errors were caused by the call prices. The significantly lower realized S\&P500 call volatilities point to the well-known option overpricing stylized fact. One can observe that consistent with the Black-Scholes model, realized call volatilities increase with the $\mathrm{K} / \mathrm{S}$ ratio as presented in figure 3.1.

For put options, the Black-Scholes model was not rejected at the 5\% level for all moneyness ratios when held to maturity. For $h=0.5 \tau$, the Black-Scholes model was rejected at the extreme moneyess where $K / S=0.94$ and $K / S=1.06$. The fitted implied volatility curves to obtain option prices with exact moneyness were extrapolated flat, which may induce a bias on the extreme ends of the $\mathrm{K} / \mathrm{S}$ ratio. Note that the prediction error of the out-of-money put $(K / S=0.94)$ is quite high at over $99 \%$, however the variation of the simulated out-of-money put volatilities was so high that this error did not lead to a rejection.

The option volatility prediction test in table 3.1 followed the approach in Broadie et al. (2009) by fitting the Black-Scholes model parameters to the distribution of realized underlying returns to infer both model option prices and expected option payoffs. However, this approach ignores the information contained in the option market prices as well as time varying parameters. Therefore the following second option volatility prediction test allows for time-varying monthly underlying parameters and option-implied volatilities instead of realized underlying volatility in table 3.2. The monthly implied volatility was estimated via a quadratic fit over the monthly option-implied volatility samples. The monthly underlying 


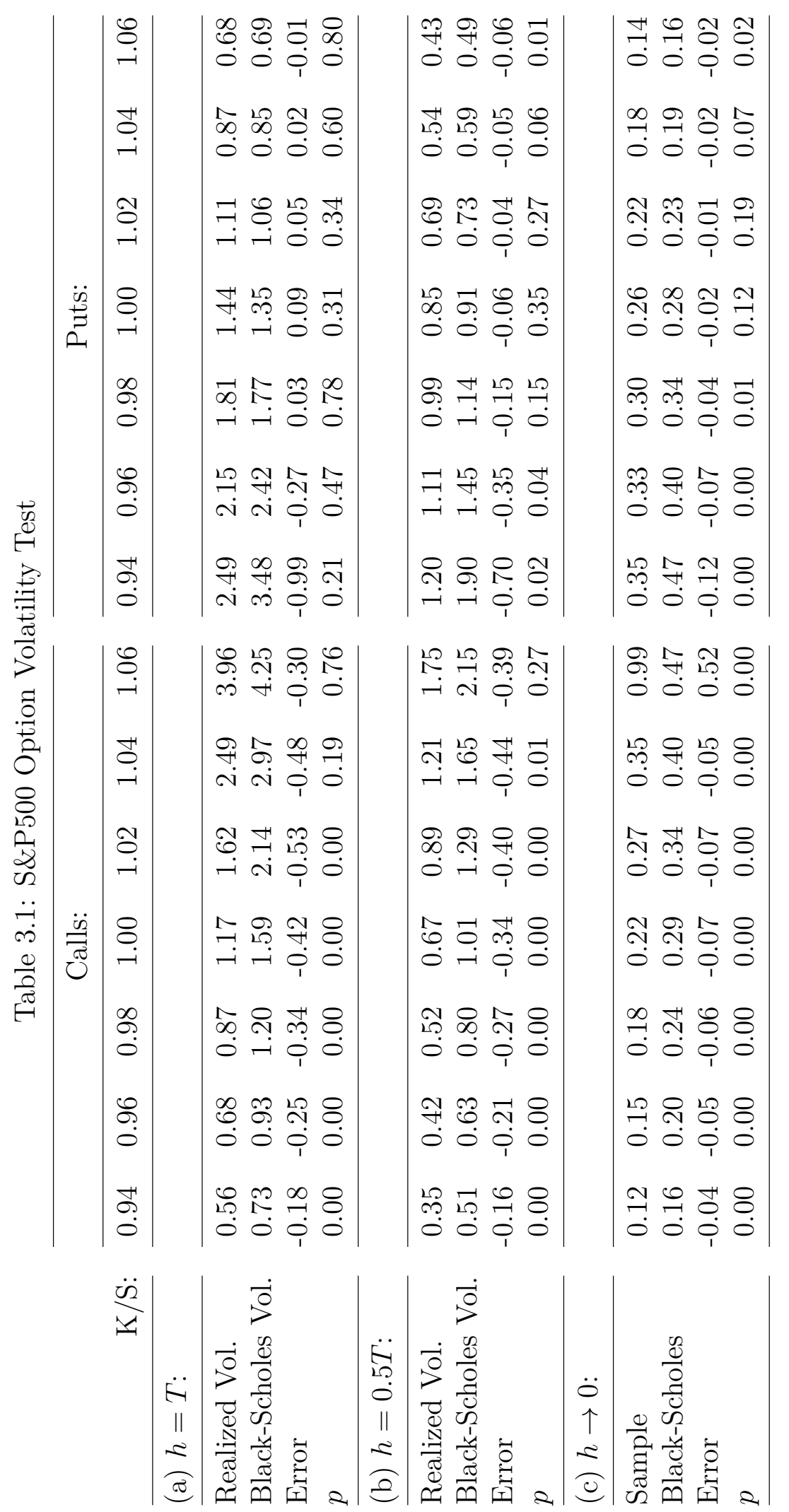

.0.

范

过的范

获

品药的

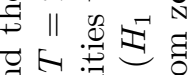

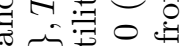

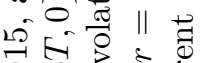

ำ

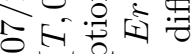

$\begin{array}{lll}1 & u \\ 0 & 0 & 0 \\ 0 & 0\end{array}$

웡

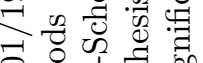

-

임 200

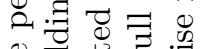

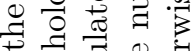

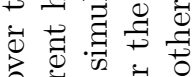

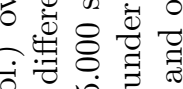

3 究

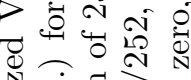

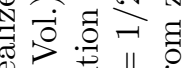

Q

?

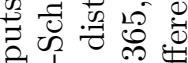

च

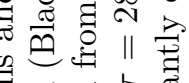

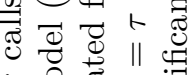

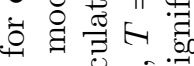

q 0

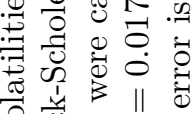

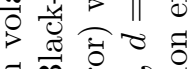

$\approx \vec{m}$

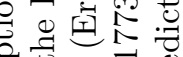

品

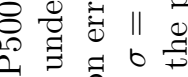

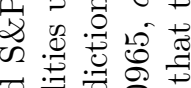

굴

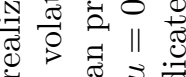

范

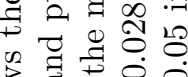

$O=$

क ङ

焉要 8 
physical drift rate was estimated as the sum of the current risk-free rate and the mean realized market risk premium over the sample period (the difference between the mean risk-free rate and the mean realized drift rate). The monthly implied dividend yield estimates on the S\&P500 were provided by Optionmetrics IvyDB.

To test whether the realized option volatilities are consistent with the Black-Scholes model in the dynamic setting, the following $z$-score time series were generated for calls $\left(z_{t}^{C}\right)$ and puts $\left(z_{t}^{P}\right)$ :

$$
\begin{aligned}
z_{t}^{C} & =\frac{R_{t, h, T}^{C}-E\left(R_{t, h, T}^{C}\right)}{v\left(R_{t, h, T}^{C}\right)}, \\
z_{t}^{P} & =\frac{R_{t, h, T}^{P}-E\left(R_{t, h, T}^{P}\right)}{v\left(R_{t, h, T}^{P}\right)}
\end{aligned}
$$

The expected option returns $\left(E\left(R_{t, h, T}^{C}\right)\right)$ were calculated based on the holding period $h$. The hold-to-maturity expected option return $(h=\tau)$ under the Black-Scholes model was derived in $\mathrm{Hu}$ and Jacobs (2016):

$$
\begin{aligned}
E\left(R_{t, T}^{C}\right) & =\frac{e^{(\mu-d) \tau} S_{t} N\left(d_{1}^{*}\right)-K N\left(d_{2}^{*}\right)}{C\left(\tau, S_{t}, \sigma, K, r, d\right)}-1, \\
E\left(R_{t, T}^{P}\right) & =\frac{K N\left(-d_{2}^{*}\right)-e^{(\mu-d) \tau} S_{t} N\left(-d_{1}^{*}\right)}{P\left(\tau, S_{t}, \sigma, K, r, d\right)}-1
\end{aligned}
$$

with $d_{1}^{*}=\frac{\ln \frac{S_{t}}{K}+\left(\mu-d+\sigma^{2} / 2\right) \tau}{\sigma \sqrt{\tau}}, d_{2}^{*}=\frac{\ln \frac{S_{t}}{K}+\left(\mu-d-\sigma^{2} / 2\right) \tau}{\sigma \sqrt{\tau}}$, using a dividend yield $d$ via substitution $S_{t}:=S_{t} e^{-d \tau}$.

For a finite holding period $h<\tau$, the expected option return under the Black-Scholes model is defined as

$$
\begin{aligned}
E\left(R_{t, h, T}^{C}\right) & =\frac{E^{\mathcal{P}}\left(C\left(\tau, S_{t+h}, \sigma, K, r, d\right)\right)}{C\left(\tau, S_{t}, \sigma, K, r, d\right)} \\
& =\frac{\int_{\mathbb{R}} C\left(\tau-h, S_{t} e^{(\mu-d) h-\frac{1}{2} \sigma^{2} h+\sigma \sqrt{h} z}, \sigma, K, r, d\right) \frac{1}{\sqrt{2 \pi}} e^{-\frac{z^{2}}{2}} d z}{C\left(\tau, S_{t}, \sigma, K, r, d\right)}-1, \\
E\left(R_{t, h, T}^{P}\right) & =\frac{E^{\mathcal{P}}\left(P\left(\tau, S_{t+h}, \sigma, K, r, d\right)\right)}{P\left(\tau, S_{t}, \sigma, K, r, d\right)} \\
& =\frac{\int_{\mathbb{R}} P\left(\tau-h, S_{t} e^{(\mu-d) h-\frac{1}{2} \sigma^{2} h+\sigma \sqrt{h} z}, \sigma, K, r, d\right) \frac{1}{\sqrt{2 \pi}} e^{-\frac{z^{2}}{2}} d z}{P\left(\tau, S_{t}, \sigma, K, r, d\right)}-1
\end{aligned}
$$


The above integrals were approximated using trapezoidal integration.

The infinitesimal expected option returns where $h \rightarrow 0$ follow from Itó's lemma in equation (3.83):

$$
E\left(R_{t, 0, T}^{C}\right)=\frac{E^{\mathcal{P}}\left(d C_{t}\right)}{C_{t}}=\frac{\left((\mu-d) S_{t} \frac{\delta C_{t}}{\delta S_{t}}+\frac{1}{2} \sigma^{2} S_{t}^{2} \frac{\delta^{2} C_{t}}{\delta S_{t}^{2}}\right) d t}{C_{t}}
$$

Therefore:

$$
\begin{aligned}
E\left(R_{t, 0, T}^{C}\right) & =\frac{\left((\mu-d) S_{t} \Delta_{t}+\frac{1}{2} \sigma^{2} S_{t}^{2} \Gamma_{t}\right) d t}{C\left(\tau, S_{t}, \sigma, K, r, d\right)} \\
E\left(R_{t, 0, T}^{P}\right) & =\frac{\left((\mu-d) S_{t}\left|\Delta_{t}-e^{-d \tau}\right|+\frac{1}{2} \sigma^{2} S_{t}^{2} \Gamma_{t}\right) d t}{P\left(\tau, S_{t}, \sigma, K, r, d\right)}
\end{aligned}
$$

with $\Delta_{t}=\frac{e^{-d \tau} N\left(\left(\ln \left(S_{t} / K\right)+\left(r+0.5 \sigma^{2}\right) \tau\right)\right.}{\sigma \sqrt{\tau}}, \Gamma_{t}=\frac{e^{-d \tau} N^{\prime}\left(d_{1}\right)}{S_{t} \sigma \sqrt{\tau}}$.

Under the Black-Scholes model, the volatilities of the above $z$-scores $\left(v\left(z_{t}^{C, P}\right)\right)$ equal one such that I test the hypothesis $H_{0}: v\left(z_{t}^{C, P}\right)=1\left(H_{1}: v\left(z_{t}\right)^{C, P} \neq 1\right)$, whereas the distribution of $v\left(z_{t}^{C, P}\right)$ was generated by drawing 25.000 times with replacement from the time series of $z_{t}^{C, P}$.

Figure 3.5 illustrates the distributions of the simulated hold-to-maturity $z$-score volatilities, the corresponding predicted volatility of 1 and the realized $z$-score volatilities. One can observe that the realized call $z$-score volatilities were significantly lower than one, while the realized put $z$-score volatilities were close to one, again indicating that the call prices are too high.

Table 3.2 presents the results of the dynamic option volatility test. Surprisingly, the BlackScholes model is now rejected even stronger for the realized call returns in all moneyness and holding period categories except $h=0$ with $K / S=1.06$ based on the mean absolute prediction error. One would expect that using the implied volatilities which perfectly match the option prices, as well as monthly parameters for $r, d$ and $\mu$, would result in superior prediction results. The volatility of the $z$-score test statistic depends on the accuracy of the predicted option volatility but also the expected option return, which cannot be separated in this setting. For the put options, the Black-Scholes model is not rejected as before in 

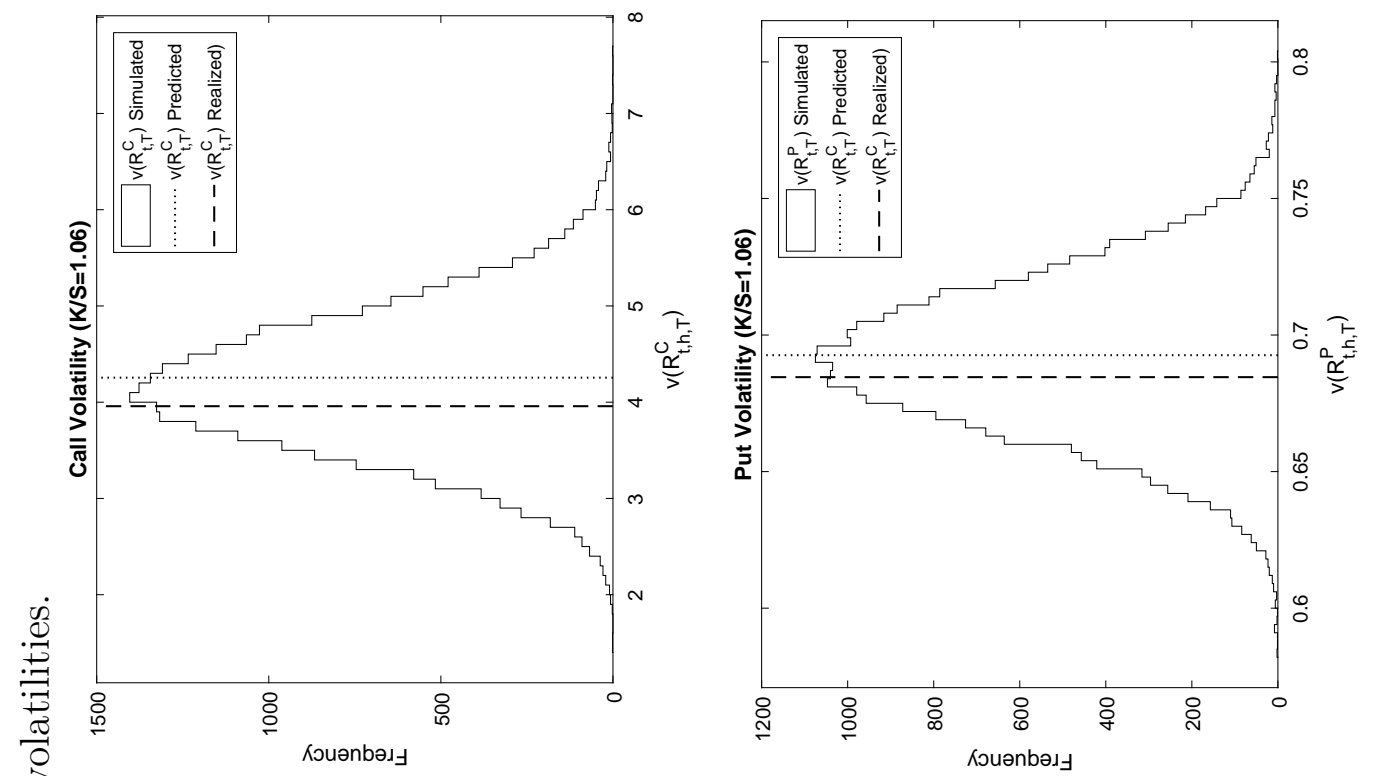

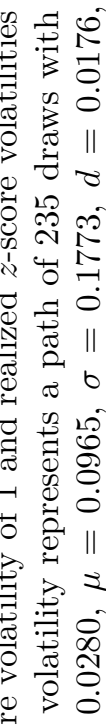

:
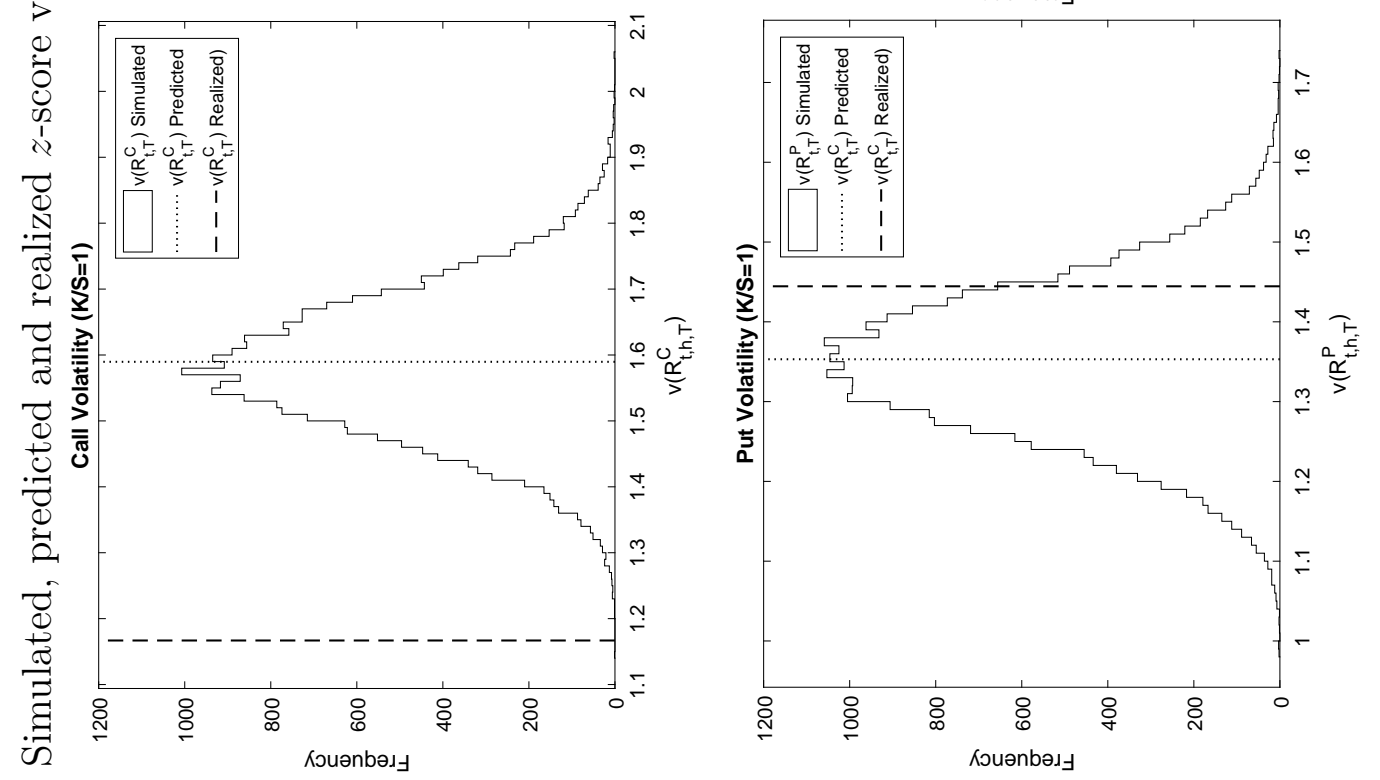

Ne

둥

要

$\vec{a}: \pm$

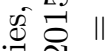

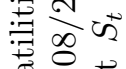

热

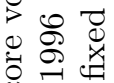

㻤

ฮี

范

芝, 范

उ。

范
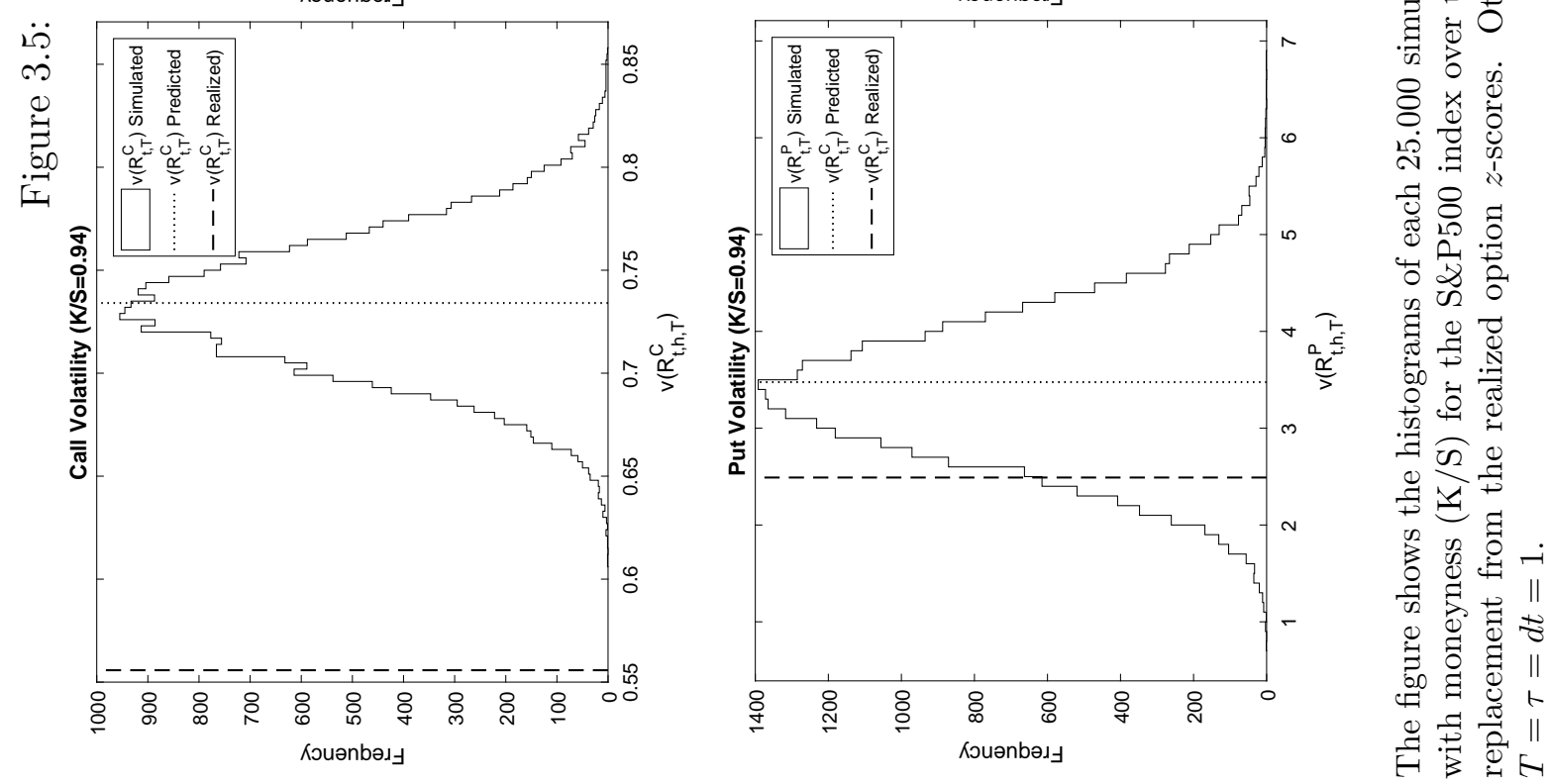
almost all cases except out-of-money instantaneous volatilities; the absolute prediction errors here are mostly lower than under the static prediction test.

In conclusion, both prediction tests reject the Black-Scholes model with respect to realized call volatilities over finite and instantaneous holding periods, while realized put volatilities were not rejected for all holding periods except instantaneous out-of-money put volatilities. The instantaneous option volatilities had the highest rejection rates in both tests, however the realized instantaneous option volatilities were only approximated by 1-day option returns, such that the rejection of the instantaneous option volatilities may partly express discretization errors. 


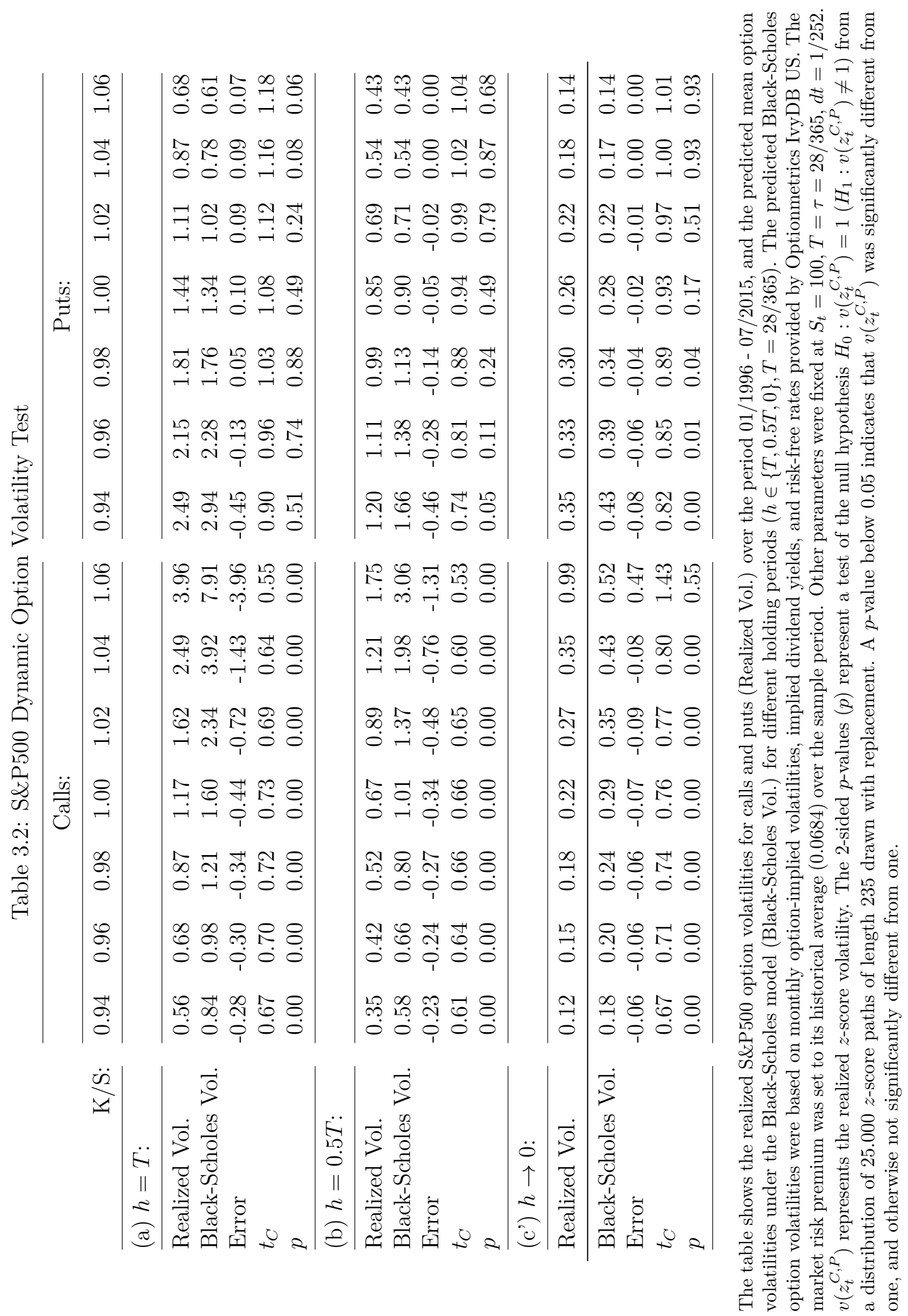




\subsection{Conclusion}

The paper studied option return volatility in a perfect markets setting. I provide analytical expressions for option return volatility under the Black-Scholes model for instantaneous, before-expiration and hold-to-expiration time periods. The theoretical cross-sectional option volatility sensitivities for the option pricing parameters are further illustrated and an empirical test on realized S\&P500 option volatilities against the Black-Scholes model is conducted.

I find that at-the-money Black-Scholes call volatility over finite holding periods increases with time to maturity, underlying volatility, underlying physical drift and dividend yield, and decreases with the risk-free rate and moneyness. At-the-money Black-Scholes put volatility over finite holding periods decreases with time to maturity, underlying physical drift, dividend yield and moneyness, can increase and decrease with underlying volatility, and increases with the risk-free rate. Option volatilities under the Black-Scholes model behave similarly when held to maturity or sold prior to maturity, but differences exist for the instantaneous holding period where at-the-money call volatility decreases with time-to-maturity, and both call and put volatility are independent of the physical drift rate.

Empirical tests on S\&P500 1-month option volatilities show that Black-Scholes option volatilities were rejected with respect to realized call volatilities over finite and instantaneous holding periods, while put volatilities were not rejected for these holding periods except instantaneous out-of-money put volatilities. 


\subsection{Appendix}

\subsubsection{Option volatility held to maturity}

The realized option return of a call $\left(R_{t, T}^{C}\right)$ or put $\left(R_{t, T}^{P}\right)$ option with strike $K$ which is held from time $t \geq 0$ to maturity $T>t$ is given by the ratio of the option payoff at time $T$ over the option price $\left(C_{t}, P_{t}\right)$ at time $t$ :

$$
\begin{aligned}
R_{t, T}^{C} & =\frac{\left(S_{T}-K\right)^{+}}{C_{t}}-1, \\
R_{t, T}^{P} & =\frac{\left(K-S_{T}\right)^{+}}{P_{t}}-1
\end{aligned}
$$

The expected return of a call or put option follows as the ratio of the expected option payoffs under the physical $(\mathcal{P})$ over the risk-neutral $(\mathcal{Q})$ measure:

$$
\begin{aligned}
E\left[R_{t, T}^{C}\right] & =\frac{E^{\mathcal{P}}\left[\left(S_{T}-K\right)^{+}\right]}{e^{-r(T-t)} E^{\mathcal{Q}}\left[\left(S_{T}-K\right)^{+}\right]}-1 \\
E\left[R_{t, T}^{P}\right] & =\frac{E^{\mathcal{P}}\left[\left(K-S_{T}\right)^{+}\right]}{e^{-r(T-t)} E^{\mathcal{Q}}\left[\left(K-S_{T}\right)^{+}\right]}-1
\end{aligned}
$$

$\mathrm{Hu}$ and Jacobs (2016) derive the expected physical call payoff in the context of the Black-Scholes model as

$$
\begin{aligned}
E^{\mathcal{P}}\left[\left(S_{t+\tau}-K\right)^{+}\right] & =\int_{z^{*}}^{\infty}\left(S_{t} e^{\mu \tau-\frac{1}{2} \sigma^{2} \tau+\sigma \sqrt{\tau} z}-K\right) \frac{1}{\sqrt{2 \pi}} e^{-\frac{z^{2}}{2}} d z \\
& =e^{\mu \tau} S_{t} N\left(d_{1}^{*}\right)-K N\left(d_{2}^{*}\right)
\end{aligned}
$$

with $z^{*}=\frac{\ln \frac{K}{S_{t}}-\left(\mu-\sigma^{2} / 2\right) \tau}{\sigma \sqrt{\tau}}, d_{1}^{*}=\frac{\ln \frac{S_{t}}{K}+\left(\mu+\sigma^{2} / 2\right) \tau}{\sigma \sqrt{\tau}}, d_{2}^{*}=\frac{\ln \frac{S_{t}}{K}+\left(\mu-\sigma^{2} / 2\right) \tau}{\sigma \sqrt{\tau}} . K$ denotes the option strike, $S_{t}$ the underlying price at time $t, \sigma$ volatility of the underlying, drift-rate $\mu$ under the physical measure, time to maturity $\tau$ and expiration date $T . N(\cdot)$ represents the cumulative standard Normal distribution. 
The expected call return follows from equations (3.41) and (3.44) as:

$$
E\left[R_{t, T}^{C}\right]=\frac{e^{\mu \tau} S_{t} N\left(d_{1}^{*}\right)-K N\left(d_{2}^{*}\right)}{C\left(\tau, S_{t}, \sigma, K, r\right)}-1
$$

where $C\left(\tau, S_{t}, \sigma, K, r\right)=S_{t} N\left(d_{1}\right)-e^{-r \tau} K N\left(d_{2}\right)$ denotes the Black-Scholes call price under the risk-neutral measure with $d_{1}=\frac{\ln \frac{S_{t}}{K}+\left(r+\sigma^{2} / 2\right) \tau}{\sigma \sqrt{\tau}}, d_{2}=\frac{\ln \frac{S_{t}}{K}+\left(r-\sigma^{2} / 2\right) \tau}{\sigma \sqrt{\tau}}$.

The expected put return follows analogously as

$$
E\left[R_{t, T}^{P}\right]=\frac{K N\left(-d_{2}^{*}\right)-e^{\mu \tau} S_{t} N\left(-d_{1}^{*}\right)}{P\left(\tau, S_{t}, \sigma, K, r\right)}-1
$$

with $P\left(\tau, S_{t}, \sigma, K, r\right)=e^{-r \tau} K N\left(-d_{2}\right)-S_{t} N\left(-d_{1}\right)$.

The variance of call returns is defined as

$$
\begin{aligned}
V\left(R_{t, T}^{C}\right) & =E^{\mathcal{P}}\left[\left(R_{t, T}^{C}-E\left(R_{t, T}^{C}\right)\right)^{2}\right] \\
& =E^{\mathcal{P}}\left(R_{t, T}^{C}{ }^{2}\right)-E^{\mathcal{P}}\left(R_{t, T}^{C}\right)^{2} \\
& =\frac{E^{\mathcal{P}}\left(\left(S_{t+\tau}-K\right)^{+2}\right)-E^{\mathcal{P}}\left(\left(S_{t+\tau}-K\right)^{+}\right)^{2}}{C\left(\tau, S_{t}, \sigma, K, r\right)^{2}}
\end{aligned}
$$

Hereby note that it holds $V\left(R_{t, T}^{C}\right)=V\left(R_{t, T}^{C}+1\right)$.

The squared first physical moment $E^{\mathcal{P}}\left(\left(S_{t+\tau}-K\right)^{+}\right)^{2}$ follows directly from equation (3.44). The second physical moment can be derived as follows:

$$
\begin{aligned}
E^{\mathcal{P}}\left(\left(S_{t+\tau}-K\right)^{+2}\right) & =\int_{z^{*}}^{\infty}\left(S_{t} e^{\mu \tau-\frac{1}{2} \sigma^{2} \tau+\sigma \sqrt{\tau} z}-K\right)^{2} \frac{1}{\sqrt{2 \pi}} e^{-\frac{z^{2}}{2}} d z \\
& =\int_{z^{*}}^{\infty}\left(S_{t}^{2} \cdot e^{2 \mu \tau-\sigma^{2} \tau+2 \sigma \sqrt{\tau} z}-2 K S_{t} e^{\mu \tau-\frac{1}{2} \sigma^{2} \tau+\sigma \sqrt{\tau} z}+K^{2}\right) \frac{1}{\sqrt{2 \pi}} e^{-\frac{z^{2}}{2}} d z
\end{aligned}
$$

The latter two integration terms hereby follow from equation (3.44) as they constitute the same integrals just over different constants (let $S_{t}^{\prime}=-2 K S_{t}$ and $K^{\prime}=K^{2}$ ):

$$
\begin{aligned}
\int_{z^{*}}^{\infty}-2 K S_{t} e^{\mu \tau-\frac{1}{2} \sigma^{2} \tau+\sigma \sqrt{\tau} z} \frac{1}{\sqrt{2 \pi}} e^{-\frac{z^{2}}{2}} d z & =-2 K S_{t} e^{\mu \tau} N\left(d_{1}^{*}\right), \\
\int_{z^{*}}^{\infty} K^{2} \frac{1}{\sqrt{2 \pi}} e^{-\frac{z^{2}}{2}} d z & =K^{2} N\left(d_{2}^{*}\right)
\end{aligned}
$$


with $z^{*}=\frac{\ln \frac{K}{S_{t}}-\left(\mu-\sigma^{2} / 2\right) \tau}{\sigma \sqrt{\tau}}, d_{1}^{*}=\frac{\ln \frac{S_{t}}{K}+\left(\mu+\sigma^{2} / 2\right) \tau}{\sigma \sqrt{\tau}}, d_{2}^{*}=\frac{\ln \frac{S_{t}}{K}+\left(\mu-\sigma^{2} / 2\right) \tau}{\sigma \sqrt{\tau}}$.

The first part of the integral in equation (3.50) can be arranged as

$$
\begin{aligned}
\int_{z^{*}}^{\infty} S_{t}^{2} \cdot e^{2 \mu \tau-\sigma^{2} \tau+2 \sigma \sqrt{\tau} z} \frac{1}{\sqrt{2 \pi}} e^{-\frac{z^{2}}{2}} d z & =S_{t}^{2} e^{2 \mu \tau} \int_{z^{*}}^{\infty} \frac{1}{\sqrt{2 \pi}} e^{-\frac{1}{2} \cdot 2 \sigma^{2} \tau+\frac{1}{2} \cdot 4 \sigma \sqrt{\tau} z-\frac{z^{2}}{2}} d z \\
& =S_{t}^{2} e^{2 \mu \tau} \int_{z^{*}}^{\infty} \frac{1}{\sqrt{2 \pi}} e^{-\frac{1}{2}\left(z^{2}-4 \sigma \sqrt{\tau} z+2 \sigma^{2} \tau\right)} d z \\
& =S_{t}^{2} e^{2 \mu \tau} \int_{z^{*}}^{\infty} \frac{1}{\sqrt{2 \pi}} e^{-\frac{1}{2}\left(z^{2}-4 \sigma \sqrt{\tau} z+4 \sigma^{2} \tau-2 \sigma^{2} \tau\right)} d z \\
& =S_{t}^{2} e^{2 \mu \tau+\sigma^{2} \tau} \int_{z^{*}}^{\infty} \frac{1}{\sqrt{2 \pi}} e^{-\frac{1}{2}\left(z^{2}-4 \sigma \sqrt{\tau} z+4 \sigma^{2} \tau\right)} d z \\
& =S_{t}^{2} e^{2 \mu \tau+\sigma^{2} \tau} \int_{z^{*}}^{\infty} \frac{1}{\sqrt{2 \pi}} e^{-\frac{1}{2}(z-2 \sigma \sqrt{\tau})^{2}} d z \\
& =S_{t}^{2} e^{2 \mu \tau+\sigma^{2} \tau} \int_{z^{*}-2 \sigma \sqrt{\tau}}^{\infty} \frac{1}{\sqrt{2 \pi}} e^{-\frac{1}{2} z^{2}} d z \\
& =S_{t}^{2} e^{2 \mu \tau+\sigma^{2} \tau} \int_{-\infty}^{-z^{*}+2 \sigma \sqrt{\tau}} \frac{1}{\sqrt{2 \pi}} e^{-\frac{1}{2} z^{2}} d z \\
& =S_{t}^{2} e^{\tau\left(2 \mu+\sigma^{2}\right)} N\left(d_{3}^{*}\right)
\end{aligned}
$$

with $d_{3}^{*}=-\frac{\ln \frac{K}{S_{t}}-\left(\mu-\sigma^{2} / 2\right) \tau}{\sigma \sqrt{\tau}}+2 \sigma \sqrt{\tau}=\frac{\ln \frac{S_{t}}{K}+\left(\mu-\sigma^{2} / 2\right) \tau+2 \sigma^{2} \tau}{\sigma \sqrt{\tau}}=\frac{\ln \frac{S_{t}}{K}+\left(\mu+1.5 \sigma^{2}\right) \tau}{\sigma \sqrt{\tau}}$.

Finally we can plug the results into the call variance from equation (3.47):

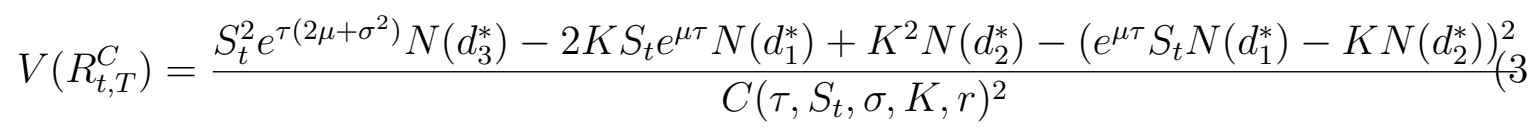

And call volatility follows as

$$
v\left(R_{t, T}^{C}\right)=\sqrt{V\left(R_{t, T}^{C}\right)}
$$

The derivation of put variance follows analogously:

$$
\begin{aligned}
V\left(R_{t, T}^{P}\right) & =E^{\mathcal{P}}\left[\left(R_{t, T}^{P}-E^{\mathcal{P}}\left(R_{t, T}^{P}\right)\right)^{2}\right] \\
& =E^{\mathcal{P}}\left(R_{t, T}^{P}{ }^{2}\right)-E^{\mathcal{P}}\left(R_{t, T}^{P}\right)^{2} \\
& =\frac{E^{\mathcal{P}}\left(\left(K-S_{t+\tau}\right)^{+2}\right)-E^{\mathcal{P}}\left(\left(K-S_{t+\tau}\right)^{+}\right)^{2}}{P\left(\tau, S_{t}, \sigma, K, r\right)^{2}}
\end{aligned}
$$


Solving the first expectation term:

$$
\begin{aligned}
E^{\mathcal{P}}\left(\left(K-S_{t+\tau}\right)^{+2}\right) & =\int_{-\infty}^{z^{*}}\left(K-S_{t} e^{\mu \tau-\frac{1}{2} \sigma^{2} \tau+\sigma \sqrt{\tau} z}\right)^{2} \frac{1}{\sqrt{2 \pi}} e^{-\frac{z^{2}}{2}} d z \\
& =\int_{-\infty}^{z^{*}}\left(S_{t}^{2} \cdot e^{2 \mu \tau-\sigma^{2} \tau+2 \sigma \sqrt{\tau} z}-2 K S_{t} e^{\mu \tau-\frac{1}{2} \sigma^{2} \tau+\sigma \sqrt{\tau} z}+K^{2}\right) \frac{1}{\sqrt{2 \pi}} e^{-\frac{z^{2}}{2}} d z
\end{aligned}
$$

The above integration terms are identical to equation (3.51), except for the integration limits. Using the symmetry property of the standard Normal distribution, we can flip the limits and set opposite signs:

$$
\begin{aligned}
\int_{-\infty}^{z^{*}}-2 K S_{t} e^{\mu \tau-\frac{1}{2} \sigma^{2} \tau+\sigma \sqrt{\tau} z} \frac{1}{\sqrt{2 \pi}} e^{-\frac{z^{2}}{2}} d z & =-2 K S_{t} e^{\mu \tau} N\left(-d_{1}^{*}\right) \\
\int_{-\infty}^{z^{*}} K^{2} \frac{1}{\sqrt{2 \pi}} e^{-\frac{z^{2}}{2}} d z & =K^{2} N\left(-d_{2}^{*}\right) \\
\int_{-\infty}^{z^{*}} S_{t}^{2} \cdot e^{2 \mu \tau-\sigma^{2} \tau+2 \sigma \sqrt{\tau} z} \frac{1}{\sqrt{2 \pi}} e^{-\frac{z^{2}}{2}} d z & =S_{t}^{2} e^{\tau\left(2 \mu+\sigma^{2}\right)} N\left(-d_{3}^{*}\right)
\end{aligned}
$$

The put return variance follows as

$V\left(R_{t, T}^{P}\right)=\frac{S_{t}^{2} e^{\tau\left(2 \mu+\sigma^{2}\right)} N\left(-d_{3}^{*}\right)-2 K S_{t} e^{\mu \tau} N\left(-d_{1}^{*}\right)+K^{2} N\left(-d_{2}^{*}\right)-\left(e^{\mu \tau} S_{t} N\left(-d_{1}^{*}\right)-K N\left(-d_{2}^{*}\right)\right)^{2}}{P\left(\tau, S_{t}, \sigma, K, r\right)^{2}}$

and put return volatility

$$
v\left(R_{t, T}^{P}\right)=\sqrt{V\left(R_{t, T}^{P}\right)}
$$

An extension for a continuous dividend yield $d$ can be achieved by substituting the underlying price with the dividend-discounted price as $S_{t}:=S_{t} e^{-d \tau}$ :

$$
V\left(R_{t, T}^{C}\right)=\frac{S_{t}^{2} e^{\tau\left(2(\mu-d)+\sigma^{2}\right)} N\left(d_{3}^{*}\right)-2 K S_{t} e^{(\mu-d) \tau} N\left(d_{1}^{*}\right)+K^{2} N\left(d_{2}^{*}\right)-\left(e^{(\mu-d) \tau} S_{t} N\left(d_{1}^{*}\right)-K N\left(d_{2}^{*}\right)\right)^{2}}{C\left(\tau, S_{t} e^{-d \tau}, \sigma, K, r\right)^{2}}
$$


and

$V\left(R_{t, T}^{P}\right)=\frac{S_{t}^{2} e^{\tau\left(2(\mu-d)+\sigma^{2}\right)} N\left(-d_{3}^{*}\right)-2 K S_{t} e^{(\mu-d) \tau} N\left(-d_{1}^{*}\right)+K^{2} N\left(-d_{2}^{*}\right)-\left(e^{(\mu-d) \tau} S_{t} N\left(-d_{1}^{*}\right)-K N\left(-d_{2}^{*}\right)\right)^{2}}{P\left(\tau, S_{t} e^{-d \tau}, \sigma, K, r\right)^{2}}$

with $z^{*}=\frac{\ln \frac{K}{S_{t}}-\left(\mu-d-\sigma^{2} / 2\right) \tau}{\sigma \sqrt{\tau}}, d_{1}^{*}=\frac{\ln \frac{S_{t}}{K}+\left(\mu-d+\sigma^{2} / 2\right) \tau}{\sigma \sqrt{\tau}}, d_{2}^{*}=\frac{\ln \frac{S_{t}}{K}+\left(\mu-d-\sigma^{2} / 2\right) \tau}{\sigma \sqrt{\tau}}, d_{3}^{*}=\frac{\ln \frac{S_{t}}{K}+\left(\mu-d+1.5 \sigma^{2}\right) \tau}{\sigma \sqrt{\tau}}$.

\subsubsection{Option volatility over finite holding periods}

When the option is not held to maturity but priorly sold in the market at time $t+h$, the realized return of a call or put option over a holding period $h<\tau=T-t$ is given by the ratio of the option price at time $t+h$ and the current option price at time $t$ :

$$
\begin{aligned}
R_{t, h, T}^{C} & =\frac{C_{T-h}}{C_{t}}-1, \\
R_{t, h, T}^{P} & =\frac{P_{T-h}}{C_{t}}-1
\end{aligned}
$$

The expected option returns follow as

$$
\begin{aligned}
& E\left[R_{t, h, T}^{C}\right]=\frac{E^{\mathcal{P}}\left(C\left(\tau-h, S_{t+h}, \sigma, K, r\right)\right)}{C\left(\tau, S_{t}, \sigma, K, r\right)}-1 \\
& E\left[R_{t, h, T}^{P}\right]=\frac{E^{\mathcal{P}}\left(P\left(\tau-h, S_{t+h}, \sigma, K, r\right)\right)}{P\left(\tau, S_{t}, \sigma, K, r\right)}-1
\end{aligned}
$$

The expected option price at time $t+h$ is evaluated under the physical measure $(\mathcal{P})$ to capture the filtration of realized underlying prices up to time $t+h$.

The variance of call returns for a holding period $h<\tau$ follows as

$$
\begin{aligned}
V\left(R_{t, h, T}^{C}\right) & =E^{\mathcal{P}}\left[\left(R_{t, h, T}^{C}-E^{\mathcal{P}}\left(R_{t, h, T}^{C}\right)\right)^{2}\right] \\
& =E^{\mathcal{P}}\left(R_{t, h, T}^{C}{ }^{2}\right)-E^{\mathcal{P}}\left(R_{t, h, T}^{C}\right)^{2} \\
& =\frac{E^{\mathcal{P}}\left(C\left(\tau-h, S_{t+h}, \sigma, K, r\right)^{2}\right)-E^{\mathcal{P}}\left(C\left(\tau-h, S_{t+h}, \sigma, K, r\right)\right)^{2}}{C\left(\tau, S_{t}, \sigma, K, r\right)^{2}}
\end{aligned}
$$

The call variance in equation (3.74) hence requires the derivation of three expected values: 
The denominator equals the squared call price, which can be directly calculated under the Black-Scholes model as $C\left(\tau, S_{t}, \sigma, K, r\right)^{2}=\left(S_{t} N\left(d_{1}\right)-e^{-r \tau} K N\left(d_{2}\right)\right)^{2}$.

The first term in the nominator can be written out by plugging the geometric Brownian motion $S_{t+h}=S_{t} e^{\mu h-\frac{1}{2} \sigma^{2} h+\sigma \sqrt{h} z}$ and calculating the expectation for $Z \sim N(0,1)$ :

$$
E^{\mathcal{P}}\left(C\left(\tau-h, S_{t+h}, \sigma, K, r\right)^{2}\right)=\int_{\mathbb{R}} C\left(\tau-h, S_{t} e^{\mu h-\frac{1}{2} \sigma^{2} h+\sigma \sqrt{h} z}, \sigma, K, r\right)^{2} \frac{1}{\sqrt{2 \pi}} e^{-\frac{z^{2}}{2}} d z
$$

The second term in the nominator follows analogously:

$$
E^{\mathcal{P}}\left(C\left(\tau-h, S_{t+h}, \sigma, K, r\right)\right)^{2}=\left(\int_{\mathbb{R}} C\left(\tau-h, S_{t} e^{\mu h-\frac{1}{2} \sigma^{2} h+\sigma \sqrt{h} z}, \sigma, K, r\right) \frac{1}{\sqrt{2 \pi}} e^{-\frac{z^{2}}{2}} d z\right)^{2}
$$

The call option holding period variance follows as:

$V\left(r_{t, h, T}^{C}\right)=\frac{\int_{\mathbb{R}} C\left(\tau-h, S_{t} e^{\mu h-\frac{1}{2} \sigma^{2} h+\sigma \sqrt{h} z}, \sigma, K, r\right)^{2} \frac{1}{\sqrt{2 \pi}} e^{-\frac{z^{2}}{2}} d z-\left(\int_{\mathbb{R}} C\left(\tau-h, S_{t} e^{\mu h-\frac{1}{2} \sigma^{2} h+\sigma \sqrt{h} z}, \sigma, K, r\right) \frac{1}{\sqrt{2 \pi}} e^{-\frac{z^{2}}{2}} d z\right)^{2}}{C\left(\tau, S_{t}, \sigma, K, r\right)^{2}}$

And call option holding period volatility

$$
v\left(R_{t, T}^{C}\right)=\sqrt{V\left(R_{t, T}^{C}\right)}
$$

Analogously, the put option holding period variance can be found by simply replacing the call price with the put price:

$V\left(r_{t, h, T}^{P}\right)=\frac{\int_{\mathbb{R}} P\left(\tau-h, S_{t} e^{\mu h-\frac{1}{2} \sigma^{2} h+\sigma \sqrt{h} z}, \sigma, K, r\right)^{2} \frac{1}{\sqrt{2 \pi}} e^{-\frac{z^{2}}{2}} d z-\left(\int_{\mathbb{R}} P\left(\tau-h, S_{t} e^{\mu h-\frac{1}{2} \sigma^{2} h+\sigma \sqrt{h} z}, \sigma, K, r\right) \frac{1}{\sqrt{2 \pi}} e^{-\frac{z^{2}}{2}} d z\right)^{2}}{P\left(\tau, S_{t}, \sigma, K, r\right)^{2}}$

And put option holding period volatility

$$
v\left(R_{t, T}^{P}\right)=\sqrt{V\left(R_{t, T}^{P}\right)}
$$


with $P\left(\tau, S_{t}, \sigma, K, r\right)=K e^{-r \tau} N\left(-d_{2}\right)-S_{t} N\left(-d_{1}\right)$. One may further introduce a continuous dividend yield $d$ via discussed substitution $S_{t}:=S_{t} e^{-d \tau}$. The above integrals are numerically approximated via trapezoidal integration.

\subsubsection{Option volatility over infinitesimal holding period}

Consider the option return for infinitesimal holding periods $h \rightarrow 0$. Recall that in the Black-Scholes model, the instantaneous dynamics of the underlying under the physical measure are given by

$$
d S_{t}=\sigma S_{t} d W_{t}+\mu S_{t} d t
$$

where $d W_{t}$ represents standard Brownian Motion increments.

Applying Itó's Lemma to a twice-differentiable claim $C\left(S_{t}, t\right): \mathbb{R}_{+}^{2} \mapsto \mathbb{R}$ and noting the quadratic variation of a Brownian motion as $\left\langle d W_{t}\right\rangle=d t$ yields

$$
\begin{aligned}
d C_{t} & =\frac{\delta C_{t}}{\delta S_{t}} d S_{t}+\frac{1}{2} \frac{\delta^{2} C_{t}}{\delta S_{t}^{2}}\left\langle d S_{t}\right\rangle \\
& =\frac{\delta C_{t}}{\delta S_{t}} \sigma S_{t} d W_{t}+\left(\mu S_{t} \frac{\delta C_{t}}{\delta S_{t}}+\frac{1}{2} \sigma^{2} S_{t}^{2} \frac{\delta^{2} C_{t}}{\delta S_{t}^{2}}\right) d t
\end{aligned}
$$

The infinitesimal return of $C\left(S_{t}, t\right)$ is given as

$$
R_{t, 0, T}^{C}=\frac{d C_{t}}{C_{t}}
$$

The infinitesimal variance follows as

$$
\begin{aligned}
V\left(R_{t, 0, T}^{C}\right) & =\frac{V\left(d C_{t}\right)}{C_{t}^{2}} \\
& =\frac{V\left(\frac{\delta C_{t}}{\delta S_{t}} \sigma S_{t} d W_{t}\right)}{C_{t}^{2}} \\
& =\frac{\left(\frac{\delta C_{t}}{\delta S_{t}} \sigma S_{t}\right)^{2} d t}{C_{t}^{2}}
\end{aligned}
$$


The infinitesimal call and put volatilities follow as

$$
\begin{gathered}
v\left(R_{t, 0, T}^{C}\right)=\frac{\Delta_{t} \sqrt{d t} \sigma S_{t}}{C\left(\tau, S_{t}, \sigma, K, r, d\right)} \\
v\left(R_{t, 0, T}^{P}\right)=\frac{\left|\Delta_{t}-e^{-d \tau}\right| \sqrt{d t} \sigma S_{t}}{P\left(\tau, S_{t}, \sigma, K, r, d\right)}
\end{gathered}
$$

with $\Delta_{t}=\frac{e^{-d \tau} N\left(\left(\ln \left(S_{t} / K\right)+\left(r-d+0.5 \sigma^{2}\right) \tau\right)\right.}{\sigma \sqrt{\tau}}$. 


\title{
4 A New Look at the Low-Volatility Effect
}

Joint work with Olaf Korn and Niklas Trappe

\begin{abstract}
A widespread anomaly in financial markets is the inverse relation between volatility and future returns: the low-volatility effect. We take a new look at this phenomenon in the market for equity options. Our empirical results show that the negative association between stock return volatilities and option returns is not a general pattern, but is conditional on market makers being net short in options. If they are net long, the effect can even be reversed. The conditional nature of the low-volatility effect in option markets stresses the importance of market imperfections and the reaction of market makers in explaining the anomaly. Moreover, the conditional low-volatility effect contains important information for option market investors because it is three to four times stronger than the unconditional effect.
\end{abstract}

Acknowledgment: We would like to thank Jelena Eberbach, Michael Hofmann, Philipp Schuster, and Marliese Uhrig-Homburg for their helpful comments and suggestions. Special thanks go to Bing Han for providing detailed information on data filters employed in Cao and Han (2013). This work was supported by the Deutsche Forschungsgemeinschaft [UH 107/4-1, KO 2285/3-1]. 


\subsection{Introduction}

Volatility is negatively related to future returns. This empirical regularity, often called the low-volatility anomaly or the low-volatility effect, is one of the most interesting puzzles in financial economics and has been observed in many markets (Ang et al. 2006, 2009). Cao and Han (2013) have documented a specific variant of this anomaly: delta-hedged option returns decrease with an increasing idiosyncratic volatility (IVOL) of the underlying stock. In this paper, we provide new empirical evidence on the low-volatility effect in stock options that sheds new light on the economic forces behind the anomaly. By doing so, we contribute to a better understanding of the anomaly generally.

We propose and investigate the conditional low-volatility effect, arguing that a negative relation between stock volatility and future option returns is conditional on market makers being net short in options. If market makers are net long in options, there can be a converse relation, leading to a high-volatility effect. A reason for this conditional low-volatility effect is based on the idea that high IVOLs cause problems for market makers in option markets because they are accompanied by high volatility risk that cannot be hedged easily due to a lack of volatility derivatives for individual stocks. If there is end-user buying pressure, market makers need extra compensation in the form of higher prices for writing options on high-volatility stocks, driving option returns down. If there is selling pressure by end users and market makers need to buy options, then option prices need to be lower, leading to higher returns for options on high-volatility stocks. The effect may not be symmetric, however. As short positions in options impose a higher risk on market makers than long positions in terms of maximum losses, the low-volatility effect could be stronger than the high-volatility effect, causing an inverse relation between volatility and option returns on average - that is, an unconditional low-volatility effect.

Our empirical results provide clear evidence for a conditional low-volatility effect. An inverse relation between stock volatility and future option returns holds for a fraction of options only. Using double-sorts based on stock volatility and a proxy for market-maker positions, only those quintiles where market makers are most likely to hold short positions show a low-volatility effect. For the quintiles where market makers are most likely net 
long in options, the effect can be reversed. This conditional high-volatility effect, however, is much weaker than the conditional low-volatility effect and not statistically significant. Due to this asymmetry, the average (unconditional) relation shows increasing mean option returns with decreasing stock volatility, confirming the results by Cao and Han (2013). Separation between systematic volatility (SVOL) and idiosyncratic volatility (IVOL) via a one-factor market model reveals that IVOL is the crucial component. When separation is instead based on the three-factor model by Fama and French (1993), SVOL also leads to significant effects. We interpret these findings as evidence for unhedgeable volatility riskthat is, non-market volatility risk, being an important economic driver of the low-volatility effect.

The results of our paper contribute to a better economic understanding of the low-volatility effect by providing new evidence on the importance of market makers-facing market frictions and market incompleteness - in the relation between stock volatility and option returns. Our analysis also offers new insights for investors. If investors want to integrate the low-volatility effect in stock options into their trading strategy, they could just concentrate on a fraction of options: those that actually show this pattern. Moreover, the conditional effect is about three to four times stronger than the unconditional one. Because the conditioning variable that we use in our empirical study requires knowledge of historical stock and option prices only, the necessary information is relatively easy to obtain. To investigate the potential benefits for investors in more detail, we check whether the conditional low-volatility effect is related to common factor risks in stock and options markets and whether it remains stable over time. Finally, we explore if it is strong enough to be exploited via a simple long-short trading strategy under transaction costs.

Our paper contributes to two strands of literature. First, it belongs to the group of studies that investigate the low-volatility effect. Different explanations for this effect have been put forward in the literature. One line of argument points to the extra demand for high-volatility assets, caused either by leverage constraints that investors have to meet (Frazzini and Pedersen 2014), the irrational behavior of private investors (Mohrschladt and Schneider 2018), or speculative demand due to investor preferences for lottery-like payoffs (Bali et al. 2011, 2017). Such speculative demand is also what Cao and Han (2013) have 
in mind as a reason for the low-volatility effect in option markets. ${ }^{1}$ Our suggestion of a conditional low-volatility effect is fully consistent with these demand-based explanations. However, we broaden the picture by looking at the supply side and ask how costly it is to meet a specific demand. Even if end-user demand for high-volatility stocks and low-volatility stocks were equal, if market makers have to bear higher costs to meet the demand for high-volatility stocks, then there is still a low-volatility effect. This change of perspective from demand towards the balancing of supply and demand may also be fruitful for analyses of the low-volatility effect in other markets.

Second, our paper contributes to the literature on the cross section of expected option returns. Most importantly, it shows that two well-known return patterns - the low-volatility effect, as discovered by Cao and Han (2013), and the "expensiveness effect" by Goyal and Saretto (2009) - are closely related, because expensiveness serves as a conditioning variable to proxy market-maker positions in our study. Our paper also complements other results on specific regularities in option returns by stressing the importance of conditioning on market-maker positions (Kanne et al. 2018), the importance of the different risk profiles of long versus short positions in options that are reflected in margin requirements (Hitzemann et al. 2018), and the general importance of market imperfections for the understanding of the cross section of expected option returns (Christoffersen et al. 2018).

Our paper is structured as follows: In Section 4.2, we introduce the conditional low-volatility effect and develop hypotheses for our empirical investigation. Section 4.3 describes our data set and the data processing. Next, we present our main results on the conditional low-volatility effect in Section 4.4. In Section 4.5, we provide additional results, centering on the extent to which the effect is beneficial for investors. Section 4.6 concludes.

\footnotetext{
${ }^{1}$ Further evidence on the relation between lottery-like preferences and option returns is provided by Byun and Kim (2016).
} 


\subsection{Volatility and Imperfect Markets: The Conditional Low-Volatility Effect}

This paper takes a new look at the economic forces behind the low-volatility effect in options markets. In particular, it investigates a potential link between the low-volatility effect and market imperfections. Market imperfections and volatility are related because stochastic IVOL is an important non-hedgeable risk for market makers, and the magnitude of volatility risk is likely to grow with the volatility level. ${ }^{2}$ Non-hedgeable risks lead to inventory risk, and inventory risk can have significant effects on option prices and returns (Garleanu et al. 2009). Does such a link, however, suffice to constitute a low-volatility effect? Should delta-hedged option returns be lower or higher when market imperfections are more severe? That is, should option returns decrease or increase with growing stock volatility? In our view, the answer depends on whether market makers are net long or net short in options. If there is end-user buying pressure and market makers end up with net short positions in options, market imperfections should lead to higher option prices and lower returns. Therefore, option returns should decrease with stock volatility and there is a low-volatility effect. If market makers are net long, however, higher stock volatilities should be associated with higher option returns and there is a high-volatility effect. This argument leads to our first hypothesis.

Hypothesis 1: Delta-hedged option returns decrease with stock volatility in the cross section for options with net short positions of market makers, leading to a low-volatility effect. For options with net long positions of market makers, option returns increase with stock volatility, leading to a high-volatility effect.

Hypothesis 1 conjectures a low-volatility effect that is conditional on the net position of market makers being negative. Conversely, if market makers are net long, a positive

\footnotetext{
${ }^{2}$ This latter point is in line with standard option pricing models. In the model by Heston (1993), variance risk is proportional to volatility. In the model by Christoffersen et al. (2018), both market variance risk and idiosyncratic variance risk are proportional to market volatility and IVOL, respectively.
} 
relation between volatility and option return should appear: that is, stocks with higher volatility will have options with higher expected returns. However, the two settings of negative versus positive net positions of market makers may not be symmetric. Consider a market maker who has bought a call option. The downside risk of this position is capped at the option premium. In contrast, if the market maker had written the call, the downside risk of the position is unlimited. Such differences between long and short positions in terms of risk are also reflected in margin requirements, leading to different margin costs. It is therefore reasonable to conjecture that stock volatility affects option returns more severely if market makers have to deal with short positions, as stated in our second hypothesis.

Hypothesis 2: The relation between stock volatility and option returns is not symmetric with respect to a net short or net long position of market makers: the conditional lowvolatility effect is stronger than the conditional high-volatility effect.

If Hypothesis 2 were true, it could resolve the empirical puzzle of an unconditional lowvolatility effect that is associated with market makers being net long on average (over all stocks) in stock options (Ni et al. 2008; Muravyev 2016; Christoffersen et al. 2018). ${ }^{3}$ If more stocks show a high-volatility effect (market makers being net long in stock options) than low-volatility effect (market makers being net short in stock options), but the latter effect is much stronger, then the unconditional effect could well be a negative relation between stock volatility and delta-hedged options returns.

When investigating the link between stock volatility and option returns, conditioning on the market-maker position is not the only issue to consider. It is also crucial to be precise about the relevant volatility concept. Because it is non-hedgeable risk that causes problems for market makers' inventories, the hedgeable and non-hedgeable parts of volatility should be distinguished. This distinction is not necessarily the same as that between SVOL and IVOL, however, because the latter depends on the specific factor model employed in an empirical study. If market imperfections are the root cause of the low-volatility effect, then

\footnotetext{
${ }^{3}$ However, these studies also show a very large variation in market-maker positions between option series. That is, although market makers are net long on average, there are many stocks where market makers are net short in the respective options.
} 
what matters should be the availability of liquid hedging instruments for volatility risk, leading to our third hypothesis.

Hypothesis 3: Only volatility risk that cannot be easily hedged via volatility derivatives is relevant for the low-volatility effect.

Hypotheses 1 to 3 take the perspective that market imperfections are at the heart of the lowvolatility effect. Even if these hypotheses are supported empirically, potential alternative explanations for the conditional low-volatility effect are still to be considered. The reason is that these alternative explanations may have important consequences for investors. First, there is the question of whether the observed empirical patterns are at least partly explained by risk premiums for common factor risks. If investors try to incorporate options into factor-investing strategies, this information is key to making judgments about the potential to generate alpha and achieve diversification benefits. Second, is the conditional low-volatility effect big enough to offer significant trading profits even after accounting for common risks and transaction costs? If the answer is yes, then at least part of the effect could be a result of market inefficiencies. The question of whether such market inefficiencies still exist or were reduced over time is another important piece of information for investors. We investigate these issues in the penultimate section of this paper.

\subsection{Data and Data Processing}

\section{Data Sources and Filters}

Our first major data source is the OptionMetrics IvyDB database. This database contains information on all US exchange-listed individual equity and index options. For our analysis, we use the daily closing bid and ask quotes of options written on individual stocks, deltas, implied volatilities (IVs), and the matching stock prices. Deltas and IVs are calculated by OptionMetrics's proprietary algorithms, which account for discrete dividend payments and the early exercise of American options. OptionMetrics also provides 365-day historical 
return volatilities of the options' underlying stocks. The sample period for the options data is from January 1996 to August 2015.

We use similar data filters as in previous studies (e.g., Goyal and Saretto 2009; Cao and Han 2013; Kanne et al. 2018) to reduce the impact of recording errors. We drop all observations where the option bid price is zero, the bid price is higher than the ask price, the bid-ask spread is lower than the minimum tick size, and the mid price is smaller than $\$ 1 / 8$. Options written on stocks with an ex-dividend date during the option's remaining time-to-maturity as well as options that violate obvious no-arbitrage conditions are also excluded. Moreover, we require a non-missing delta, IV, and 365-day historical volatility (HV), to retain an observation in our sample.

Our second major data source is the Center for Research in Security Prices database. Daily stock returns from the database are matched with the options data to calculate historical 30-day stock volatilities. Finally, we use Kenneth French's database to obtain the returns of specific factor portfolios. These factor portfolios are required to distinguish SVOL from IVOL and to control for potential factor risk premiums. Risk-free interest rates are also taken from Kenneth French's database.

\section{Delta-Hedged Option Returns}

Following Cao and Han (2013), we take the end of each month and select for each underlying stock the put and call options that are closest to at-the-money and have the shortest remaining time-to-maturity of all options with a maturity of at least one month. We also require the actual moneyness to fall within the range $[0.8,1.2]$, with moneyness measured as the ratio of spot price to strike. We then calculate delta-hedged option returns for calls and puts according to

$$
\begin{aligned}
& R_{t, t+\tau}^{C}=\frac{\max \left(S_{t+\tau}-K^{C}, 0\right)-\Delta_{t}^{C} S_{t+\tau}-\left(C_{t}-\Delta_{t}^{C} S_{t}\right) e^{r \tau}}{A b s\left(C_{t}-\Delta_{t}^{C} S_{t}\right)}, \\
& R_{t, t+\tau}^{P}=\frac{\max \left(K^{P}-S_{t+\tau}, 0\right)-\Delta_{t}^{P} S_{t+\tau}-\left(P_{t}-\Delta_{t}^{P} S_{t}\right) e^{r \tau}}{A b s\left(P_{t}-\Delta_{t}^{P} S_{t}\right)},
\end{aligned}
$$


where $t$ refers to the day when we set up the delta-hedged option position (end of month) and $t+\tau$ is the last trading day of the option. $S_{t}$ and $S_{t+\tau}$ denote the matched prices of the underlying stock at times $t$ and $t+\tau$, respectively, $K^{C}$ and $K^{P}$ are the options' strike prices, and $\Delta_{t}^{C}$ and $\Delta_{t}^{P}$ denote the deltas. The option prices $C_{t}$ and $P_{t}$ are the closing mid prices at date $t$. According to Equations (4.1) and (4.2), we use the returns of delta-hedged call and put options that buy one option contract and sell delta shares of the underlying stock. The above return definitions also consider that a positive initial value (at date $t$ ) of a delta-hedged option requires some capital which could alternatively be invested at the risk-free rate. If the initial value is negative, the delta-hedged option provides some capital that could alternatively be obtained via risk-free borrowing. Because our delta-hedged option returns take these opportunities for risk-free investing or borrowing into account, they are to be interpreted as excess returns.

\section{[ Insert Table 4.1 about here]}

Given our data period and the data filters, we have 357,551 delta-hedged call returns and 359,136 delta-hedged put returns. As the data period covers 236 months, we have on average 1,515 calls and 1,522 puts in a cross section. However, the number of observations per cross section increases over time. Panels A and B of Table 4.1 provide some descriptive statistics of the delta-hedged call and put returns. Average delta-hedged returns are negative for both calls and puts and show a very large dispersion. The return period (time-to-maturity of options) is, on average, close to 50 days and the moneyness of the options is close to one.

\section{Stock-Return Volatilities}

To investigate the cross-sectional relation between option returns and stock volatilities, we need to calculate volatilities in a next step. Again, we closely follow Cao and Han (2013). For every stock and every date $t$, we calculate the standard deviation of daily stock returns over the previous 30 -day period. ${ }^{4}$ This is our measure of total volatility (VOL). To separate

\footnotetext{
${ }^{4}$ To maintain a sufficient number of observations, we require to have at least 17 daily returns available over this period.
} 
IVOL from SVOL, we use either the market factor or the three-factor model by Fama and French (1993). ${ }^{5}$ Because liquid derivatives contracts are available to hedge changes in market volatility - for example, futures on the Chicago Board Options Exchange Volatility Index $(\mathrm{VIX})^{6}$ — the one-factor model should be more appropriate than the three-factor model in distinguishing between hedgeable and non-hedgeable ${ }^{7}$ volatility risk. This is what we will exploit to test Hypothesis 3. Panel C of Table 4.1 shows some descriptive statistics of the (annualized) volatilities that we use in our study. On average, IVOL is greater than SVOL whether the one- or three-factor model is used. We also see the extent to which the three-factor model changes IVOL versus SVOL values compared to the one-factor model.

\section{Conditioning Variables}

The core idea of this paper is that the low-volatility effect should be investigated conditionally by considering whether market makers are net long or net short in specific options. To proxy market-maker positions, we take a pragmatic view and use a conditioning variable that is based on the market prices of stocks and options. Such a conditioning variable, based on public information only, has the advantage that a corresponding conditional low-volatility effect could be exploited more easily via trading strategies. No proprietary information on the actual holdings of market makers is required. The proxy that we use is option expensiveness, measured as the difference between the option's IV and a benchmark volatility estimate from historical stock-return data (i.e., HV). As shown by Bollen and Whaley (2004) and Garleanu et al. (2009), there is a strong relation between end-user demand pressure and expensiveness, which affects market-maker positions. The higher the expensiveness of an option, the more likely it is that market makers are net short in this option. The implementation of the expensiveness measure uses the date $t$ IVs of the call and put options from OptionMetrics. For the HV benchmark, we use OptionMetrics's 365-day volatility for the period preceding date $t$, as in Goyal and Saretto (2009). Descriptive

\footnotetext{
${ }^{5}$ We use the daily data from Kenneth French's database to obtain factor returns that exactly match the return periods of the options.

${ }^{6}$ More information on VIX futures is provided, for example, by Shu and Zhang (2012) and Simon and Campasano (2014).

${ }^{7}$ Volatility derivatives are not generally available for individual stocks and factor portfolios besides the market factor.
} 
statistics for the expensiveness measure IV-HV are provided in Panel D of Table 4.1. In the latter part of our paper, we provide results that are conditional on different transaction cost scenarios. The core element of these scenarios is the option's quoted spread. Descriptive statistics for quoted spreads are also provided in Panel D of Table 4.1.

\subsection{The Conditional Low-Volatility Effect: Empirical Evidence}

For each month in our data period, we take all delta-hedged call (put) returns and sort them into quintiles according to the corresponding stock volatility. We use either VOL, IVOL, or SVOL in this sort. A single sort by volatility provides evidence on the unconditional low-volatility effect. Next, we sort the returns in each volatility quintile by IV-HV and again build quintiles. The purpose of this second sort is an (approximate) conditioning on net market-maker positions. With higher expensiveness, options in the respective quintiles should have a higher likelihood of market makers holding short positions. In contrast, if expensiveness is lower, market makers should more likely be net long in the corresponding options. For each of the 25 resulting groups, we calculate average returns. Finally, we obtain time-series averages of the average returns in each group.

Table 4.2 provides the results of these calculations, based on a one-factor market model to distinguish between IVOL and SVOL. Panel A presents the results for call options and Panel B the corresponding results for put options. The first five columns (1-low to 5-high) refer to the different expensiveness quintiles, and the last column (all) shows the average returns over all expensiveness categories; that is, it provides the results of the single sort by volatility. Therefore, the last column delivers information on the unconditional low-volatility effect. The first five rows (1-low to 5-high) refer to the respective volatility quintiles. The sixth row (5-1), contains the average returns of a long-short trading strategy that buys the high-volatility portfolio (5-high) and sells the low-volatility portfolio (1-low). If there is a low-volatility effect, the average return of this trading strategy should be 
negative. Positive returns of this trading strategy are indicative for a high-volatility effect. Finally, the seventh row shows the t-values for the average returns of the $5-1$ portfolios.

\section{[ Insert Table 4.2 about here]}

The results in Table 4.2 provide clear support for a conditional low-volatility effect, as stated in Hypothesis 1. Average delta-hedged option returns clearly decrease with total volatility for the two highest expensiveness quintiles. Moreover, the effect is much stronger for the highest expensiveness quintile. In terms of average 50-day returns of the 5-1 strategy, the effect is about three times bigger in the highest expensiveness quintile $(-3.7 \%)$ than in the second highest expensiveness quintile $(-1.2 \%)$ for call options. For put options, it is more than two times bigger $(-2.4 \%$ versus $-1.1 \%)$. However, no low-volatility effect can be found in the other three quintiles, meaning that the effect is only present in a fraction of the whole data set. Average returns of 5-1 strategies are even positive for the two lowest expensiveness quintiles, pointing towards a high-volatility effect. However, the effect is much smaller (in absolute terms) than the effect in the highest expensiveness quintiles and not statistically significant. This finding supports Hypothesis 2: a conditional high-volatility effect, if it exists at all, is much weaker than the corresponding conditional low-volatility effect. Consequently, the unconditional effect shows an inverse relation between stock volatility and future option returns, which was first discovered by Cao and Han (2013) and is confirmed by the results of the 5-1 strategy in the last column (all). It is also important to compare the magnitudes of the conditional and unconditional low-volatility effects. Examining the options with the highest expensiveness, returns of the 5-1 strategy are more than four times larger (in absolute terms) for calls $(-3.7 \%$ versus $-0.8 \%)$ and more than three times larger for puts $(-2.4 \%$ versus $-0.7 \%)$, as compared to a strategy based on all options.

In line with market imperfections being at the heart of the low-volatility effect in options markets, Hypothesis 3 states that only non-hedgeable volatility risk is relevant for the low-volatility effect. To provide evidence on this issue, we replace VOL with either SVOL or IVOL in our sorts. In particular, we use a one-factor market model to distinguish between the systematic and idiosyncratic parts of volatility. In such a setting, SVOL equals market 
volatility, and market volatility risk can be hedged via liquid volatility derivatives like VIX futures.

When using IVOL instead of VOL for sorting, the conditional volatility effect appears even stronger. If we condition on SVOL instead, there is no longer any significant low-volatility effect even in the highest expensiveness quintile. We interpret this finding as evidence for the dominant role of non-market volatility and non-hedgeable volatility risk, supporting Hypothesis 3. To further substantiate Hypothesis 3, we repeat our analysis of SVOL versus IVOL, this time using the three-factor model by Fama and French (1993) for separation. Table 4.3 provides our results. Given that the three-factor model differently defines IVOL and SVOL (compared to the one-factor model), the effects are slightly weaker for IVOL but stronger for SVOL. In the highest expensiveness quintile, we now find a significant low-SVOL effect for both calls and puts. By classifying volatility due to the two additional factors as systematic, SVOL becomes important for the low-volatility effect. This finding is consistent with the view that it is important whether market makers in options markets can easily hedge the corresponding volatility risk or not. Finally, it is worth noting that the effects of moving from a one- to a three-factor model cannot be observed by looking at the unconditional low-volatility effect alone. Therefore, our focus on the conditional low-volatility effect, which is much stronger in the highest expensiveness quintiles, helps us to study more subtle aspects of the whole phenomenon.

[ Insert Table 4.3 about here]

\subsection{Benefits for Investors}

In this section, we further explore the value of the conditional low-volatility effect for investors. Our first question is whether the returns of a conditional low-volatility trading strategy relate to some common factors that are priced either in stock or options markets. If the returns of such a strategy were merely compensation for common factor risks, then the value for investors is limited because more straightforward strategies exist to earn the respective risk premiums. 
For our analysis of this question, we use a trading strategy that holds a long position in options on low-volatility stocks (1-low) and a short positions in options on high-volatility stocks (5-high), using the highest expensiveness quintile (5-high in Table 4.2) and IVOL according to the one-factor market model (IVOL-1F in Table 4.2). We consider both stock market factors and option market factors to explain the returns of this strategy. Although we try to avoid stock price exposure by using delta-hedged option returns, these hedges are unlikely to be perfect, and a remaining stock price exposure may be priced. To capture such effects, we use the three factors - market (MKT), size (SMB), and value (HML) - from the Fama and French (1993) model, the momentum factor (MOM) by Carhart (1997), and a low-volatility stock market factor ( $\mathrm{Low} \mathrm{Vol})$. The latter factor uses the returns of a long-short portfolio that buys low-volatility stocks and sells high-volatility stocks. The term "low-volatility stocks" refers to the 1-low quintile of all stocks according to IVOL (IVOL-1F in Table 4.2), and "high-volatility stocks" refers to the 5-high quintile of all stocks. Inclusion of the LowVol factor ensures that our results on delta-hedged option returns are not simply picking up the low-volatility effect in the stock market, due to our sorting by stock volatility. We also consider option market factors. The market volatility risk premium is approximated by the return of zero-beta straddles written on the Standard \& Poors' (S\&P) 500 Index (ZB-STR Index), as suggested by Coval and Shumway (2001). Changes in the VIX (dVIX) are used as an indicator for the magnitude of market volatility risk. In addition to market volatility risk, correlation risk may be priced in the low-volatility trading strategy. As shown by Driessen et al. (2009), correlation risk premiums can be captured via differences between the market variance risk premium and the average variance risk premium of the component stocks. Therefore, we add the average returns of zero-beta straddles written on all component stocks (ZB-STR Stocks) of the S\&P 500 Index as an additional factor. All factor returns cover the same return periods as our delta-hedged option returns.

\section{[ Insert Table 4.4 about here]}

Table 4.4 presents the results of time-series regressions that regress the delta-hedged option returns of the 1-5 strategy on different combinations of factors. Panel A gives the results 
for call options and Panel B for put options. Model 1 explores the impact of the stock market factors; Model 2, the importance of a market variance risk premium; Model 3, the impact of variance risk; and Model 4, the joint influence of variance and correlation risk premiums. Finally, Model 5 considers all factors simultaneously. The regression analysis shows some explanatory power for certain factors. Model 1 has significant coefficients for the MKT and HML factors, and Model 3 indicates some explanatory power of volatility risk. These results hold for both call and put options. For call options, there seems to be also an effect of the variance risk premium, according to Model 2. Most importantly, for all models in Table 4.4, alphas are highly significant and very close to the average return of a $1-5$ strategy, which is $4.03 \%$ for calls and $2.67 \%$ for puts. Therefore, we can conclude that the cross-sectional phenomenon of a conditional low-volatility effect in option markets is not just a compensation for some common factor risks.

The second question that we ask in this section is whether the conditional low-volatility effect is only present in the early years of our data period and disappearing over time. If this were the case, the conditional low-volatility effect is likely to be a result of market inefficiencies that were reduced over time and should no longer be considered by investors. In particular, the Securities and Exchange Commission's (SEC's) market linkage plan, finally becoming effective in April 2003, may have contributed to the reduction of such inefficiencies. Moreover, we ask whether the positive average returns of our low-volatility trading strategy merely results from a few extreme observations during the financial crisis between June 2007 and December 2009, which would suggest that the conditional low-volatility effect would be irrelevant for investors in normal times.

\section{[ Insert Table 4.5 about here]}

Table 4.5 provides the average returns and alphas (according to Model 5 in Table 4.4) for four different time periods. We consider the full period (January 1996 to August 2015), the full period excluding the time of the financial crisis from June 2007 to December 2009, the period until the SEC's market linkage plan became effective (January 1996 to April 2003), and the period thereafter (May 2003 to August 2015). There is no evidence that the conditional low-volatility effect is only driven by market inefficiencies during the early 
years of our data period. To the contrary, if we use the more recent data period from May 2003 onwards, both mean returns and alphas increase, as compared to the whole data period. This is true for both calls and puts. If anything, the effect becomes stronger over time and there is no indication that it should be disregarded. There is also no indication that the effect is strongly driven by some extreme observations from the financial crisis. Excluding the crisis period, both average returns and alphas change very little.

The third question we deal with in this section is whether the conditional low-volatility effect can be exploited by investors via a simple trading strategy even in the presence of transaction costs. So far, our analysis of the low-volatility trading strategy was based on the assumption that trades can be executed at the mid quotes. Now we take option spreads into account and consider different transaction cost scenarios. We follow Cao and Han (2013) and assume that the effective spread (ESPR) of transactions equals a certain fraction of the quoted spread (QSPR). ${ }^{8}$ Specifically, we assume ESPR/QSPR ratios of $10 \%$, 25\%, and 50\%, respectively, following Cao and Han (2013). As a reference point, we also repeat results under the assumption of no transaction costs (i.e., mid price [MidP]).

\section{[ Insert Table 4.6 about here]}

Table 4.6 reports the average delta-hedged option returns and alphas (according to Model 5 in Table 4.4) of the 1-5 portfolio in the highest expensiveness quintile under the different transaction cost scenarios. Panel A gives results for calls and Panel B gives results for puts. Average returns and alphas stay statistically and economically significant for an ESPR/QSPR ratio of $25 \%$. If we move to $50 \%$, however, we lose significance for both call and put options. In conclusion, only investors with low transactions costs can exploit the conditional low-volatility effect profitably, though the effect is three to four times stronger than that of unconditional low-volatility.

However, this finding does not mean that knowledge of the conditional low-volatility effect is useless for investors with higher transactions costs. To the contrary, our findings show that the effect cannot be easily arbitraged away (due to the transactions costs) and does

\footnotetext{
${ }^{8}$ Compare Cao and Han (2013), page 246, Table 10, for analogous results with respect to the unconditional low-volatility effect.
} 
not tend to shrink over time, making it more likely that the effect will persist in the future and should be considered. For example, if investors with lottery-like preferences want to buy options on high-volatility stocks, they should think about selecting these options from the lowest IV-HV quintile (i.e., 1-low) instead of the highest one (i.e., 5-high). By doing so, they would avoid the strong low-volatility effect in the highest quintile and could even profit from the slight high-volatility effect in the lowest quintile. If we take the results from Table 4.2, the differences in average 50-day delta-hedged returns (using IVOL-1F) when selecting options on high-volatility stocks from the lowest IV-HV quintile instead of the highest quintile would be $6.5 \%$ for calls and $4.5 \%$ for puts. ${ }^{9}$

\subsection{Conclusions}

The low-volatility effect is a well-known phenomenon in many financial markets that challenges the intuitive idea of a risk-return trade-off. Our empirical investigation into the low-volatility effect in stock options contributes to a better understanding of this phenomenon. We show that the low-volatility effect is not a general pattern, but is conditional on option expensiveness being high. Where option expensiveness is low, the effect is even reversed, although the reverse effect is quantitatively much weaker.

Our empirical findings support the view that market imperfections and the reaction of market makers to these imperfections are at the heart of the effect. If high option expensiveness is a good proxy for market makers being net short in options and high IVOL is a good proxy for severe market imperfections, the observed pattern suggests that market makers receive a compensation because they sell at higher option prices if market imperfections become more severe. If market makers are net long, however, they receive a compensation because they buy at lower option prices. Because risk profiles of long and short positions in options are different, the former compensation should be greater, which is exactly what we observe. More generally, our analysis complements demand-based explanations of the low-volatility effect by drawing attention to the potential costs to meet

\footnotetext{
${ }^{9}$ The calculations in Table 4.2 are based on mid quotes. If we take transaction costs into account and repeat the calculations based on ask prices, the differences in 50-day delta-hedged returns are $7 \%$ for calls and $4.9 \%$ for puts.
} 
a certain demand. This is an interesting avenue for further research in other markets as well.

The conditional low-volatility effect that we document in this paper also provides important information for investors in options markets. First, the conditional effect is three to four times stronger than the unconditional one. Second, it cannot be explained by common factor risks in stock and option markets and therefore offers some potential to create alpha. Finally, it is stable over time and cannot easily be arbitraged away in the presence of transaction costs. Therefore, the effect is likely to persist in the future and should be considered in the design of investment strategies in stock options. 
Table 4.1: Summary Statistics of Options and Stock Data

Panel A: Call Options (357,551 observations)

\begin{tabular}{lcccccc}
\hline & $\mu$ & $\sigma$ & $q_{0.1}$ & $q_{0.25}$ & $q_{0.75}$ & $q_{0.9}$ \\
\hline Delta-Hedged Return & $-0.8 \%$ & $14.9 \%$ & $-14.4 \%$ & $-8.1 \%$ & $4.0 \%$ & $14.2 \%$ \\
Days to Maturity & 49.7 & 2.6 & 47.0 & 50.0 & 51.0 & 52.0 \\
Moneyness (S/K) & 1.00 & 0.06 & 0.94 & 0.97 & 1.03 & 1.06 \\
\hline
\end{tabular}

Panel B: Put Options (359,136 observations)

\begin{tabular}{lcccccc}
\hline & $\mu$ & $\sigma$ & $q_{0.1}$ & $q_{0.25}$ & $q_{0.75}$ & $q_{0.9}$ \\
\hline Delta-Hedged Return & $-0.4 \%$ & $12.1 \%$ & $-12.0 \%$ & $-6.9 \%$ & $3.8 \%$ & $12.4 \%$ \\
Days to Maturity & 49.7 & 2.6 & 47.0 & 50.0 & 51.0 & 52.0 \\
Moneyness (S/K) & 1.01 & 0.06 & 0.94 & 0.97 & 1.04 & 1.07 \\
\hline
\end{tabular}

Panel C: Stock Return Volatilities

\begin{tabular}{|c|c|c|c|c|c|c|}
\hline & $\mu$ & $\sigma$ & $q_{0.1}$ & $q_{0.25}$ & $q_{0.75}$ & $q_{0.9}$ \\
\hline VOL & $46.1 \%$ & $30.5 \%$ & $18.8 \%$ & $26.2 \%$ & $57.0 \%$ & $81.9 \%$ \\
\hline \multicolumn{7}{|l|}{ 1-Factor Model (1F) } \\
\hline IVOL-1F & $39.1 \%$ & $27.6 \%$ & $14.8 \%$ & $21.2 \%$ & $49.0 \%$ & $71.1 \%$ \\
\hline SVOL-1F & $20.7 \%$ & $18.4 \%$ & $4.3 \%$ & $9.0 \%$ & $26.3 \%$ & $41.9 \%$ \\
\hline \multicolumn{7}{|l|}{ 3-Factor Model (3F) } \\
\hline IVOL-3F & $36.0 \%$ & $25.7 \%$ & $13.5 \%$ & $19.4 \%$ & $45.0 \%$ & $65.7 \%$ \\
\hline SVOL-3F & $26.4 \%$ & $20.1 \%$ & $9.0 \%$ & $13.6 \%$ & $32.8 \%$ & $49.8 \%$ \\
\hline \multicolumn{7}{|c|}{ Panel D: Conditioning Variables } \\
\hline & $\mu$ & $\sigma$ & $q_{0.1}$ & $q_{0.25}$ & $q_{0.75}$ & $q_{0.9}$ \\
\hline Expensiveness: IV-HV & $-0.8 \%$ & $16.6 \%$ & $-16.4 \%$ & $-6.6 \%$ & $5.6 \%$ & $13.5 \%$ \\
\hline Option Spread & $27 \%$ & $30 \%$ & $6 \%$ & $10 \%$ & $31 \%$ & $61 \%$ \\
\hline
\end{tabular}

Note: This table shows descriptive statistics of the options and stock data that we use in our empirical study. In particular, it presents the mean $(\mu)$, the standard deviation $(\sigma)$, and different quantiles $\left(10 \%\right.$-quantile $\left(q_{0.1}\right), 25 \%$-quantile $\left(q_{0.25}\right), 75 \%$-quantile $\left(q_{0.75}\right)$, 90\%-quantile $\left.\left(q_{0.9}\right)\right)$. Panel A shows the descriptive statistics for call options. Delta-hedged returns are calculated as given in Equation (4.1). Panel B shows the descriptive statistics for put options. The formula for these delta-hedged returns is given in Equation (4.2). Panel C provides descriptive statistics for historical stock return volatilities. These refer to annualized values from a historical 30-day data window, estimated from daily returns. We distinguish between total volatility (VOL), idiosyncratic volatility (IVOL), and systematic volatility (SVOL). The separation between SVOL and IVOL is either done via a one-factor market model (IVOL-1F, SVOL-1F) or via the three-factor model by Fama and French (1993) (IVOL-3F, SVOL-3F). Panel D presents descriptive statistics of the expensiveness measure, IV-HV, where IV denotes the implied volatility of the options, and $\mathrm{HV}$ is a historical 365-day benchmark volatility. Moreover, Panel D provides descriptive statistics of the quoted option spreads at the beginning of the return period, measured in percent of the mid price. 
Table 4.2: Average Returns of Options Sorted by Stock Volatility and Expensiveness: One-factor Model

Panel A: Delta-hedged call returns

\begin{tabular}{|c|c|c|c|c|c|c|c|}
\hline & \multicolumn{7}{|c|}{ Option Expensiveness (IV-HV) } \\
\hline \multirow{8}{*}{$\stackrel{1}{\circ}$} & & 1-low & 2 & 3 & 4 & 5-high & all \\
\hline & 1-low & $0.3 \%$ & $-0.3 \%$ & $-0.4 \%$ & $-0.7 \%$ & $-1.8 \%$ & $-0.6 \%$ \\
\hline & 2 & $0.6 \%$ & $-0.2 \%$ & $-0.6 \%$ & $-0.8 \%$ & $-2.5 \%$ & $-0.7 \%$ \\
\hline & 3 & $1.1 \%$ & $-0.1 \%$ & $-0.5 \%$ & $-1.0 \%$ & $-2.7 \%$ & $-0.7 \%$ \\
\hline & 4 & $1.0 \%$ & $0.2 \%$ & $-0.5 \%$ & $-1.2 \%$ & $-3.7 \%$ & $-0.8 \%$ \\
\hline & 5-high & $0.7 \%$ & $0.1 \%$ & $-0.5 \%$ & $-1.9 \%$ & $-5.5 \%$ & $-1.4 \%$ \\
\hline & $5-1$ & $0.5 \%$ & $0.4 \%$ & $-0.0 \%$ & $-1.2 \%$ & $-3.7 \%$ & $-0.8 \%$ \\
\hline & t-stat. & 1.1 & 1.2 & -0.1 & -3.8 & -10.0 & -2.4 \\
\hline \multirow{8}{*}{ 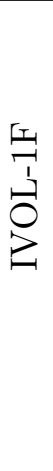 } & & 1-low & 2 & 3 & 4 & 5-high & all \\
\hline & 1-low & $0.4 \%$ & $-0.4 \%$ & $-0.4 \%$ & $-0.6 \%$ & $-1.7 \%$ & $-0.6 \%$ \\
\hline & 2 & $0.6 \%$ & $-0.1 \%$ & $-0.5 \%$ & $-0.8 \%$ & $-2.4 \%$ & $-0.6 \%$ \\
\hline & 3 & $0.9 \%$ & $0.0 \%$ & $-0.4 \%$ & $-0.9 \%$ & $-2.7 \%$ & $-0.6 \%$ \\
\hline & 4 & $1.1 \%$ & $0.2 \%$ & $-0.4 \%$ & $-1.2 \%$ & $-3.8 \%$ & $-0.8 \%$ \\
\hline & 5-high & $0.7 \%$ & $0.1 \%$ & $-0.6 \%$ & $-2.0 \%$ & $-5.8 \%$ & $-1.5 \%$ \\
\hline & $5-1$ & $0.3 \%$ & $0.5 \%$ & $-0.1 \%$ & $-1.3 \%$ & $-4.0 \%$ & $-0.9 \%$ \\
\hline & t-stat. & 0.8 & 1.5 & -0.3 & -4.5 & -11.5 & -3.0 \\
\hline \multirow{8}{*}{$\begin{array}{l}\frac{1}{7} \\
\frac{1}{3} \\
0 \\
\stackrel{8}{8}\end{array}$} & & 1-low & 2 & 3 & 4 & 5-high & all \\
\hline & 1-low & $0.5 \%$ & $-0.3 \%$ & $-0.6 \%$ & $-1.0 \%$ & $-3.3 \%$ & $-0.9 \%$ \\
\hline & 2 & $0.5 \%$ & $-0.1 \%$ & $-0.6 \%$ & $-1.0 \%$ & $-3.2 \%$ & $-0.9 \%$ \\
\hline & 3 & $0.6 \%$ & $-0.1 \%$ & $-0.6 \%$ & $-0.9 \%$ & $-2.9 \%$ & $-0.8 \%$ \\
\hline & 4 & $1.1 \%$ & $-0.1 \%$ & $-0.3 \%$ & $-1.0 \%$ & $-3.1 \%$ & $-0.7 \%$ \\
\hline & 5-high & $1.1 \%$ & $0.0 \%$ & $-0.3 \%$ & $-1.2 \%$ & $-3.8 \%$ & $-0.9 \%$ \\
\hline & $5-1$ & $0.5 \%$ & $0.2 \%$ & $0.3 \%$ & $-0.2 \%$ & $-0.5 \%$ & $0.1 \%$ \\
\hline & t-stat. & 1.7 & 0.8 & 1.1 & -0.9 & -1.3 & 0.3 \\
\hline
\end{tabular}


Panel B: Delta-hedged put returns

\begin{tabular}{|c|c|c|c|c|c|c|c|}
\hline & \multicolumn{7}{|c|}{ Option Expensiveness (IV-HV) } \\
\hline \multirow{8}{*}{0} & & 1-low & 2 & 3 & 4 & 5-high & all \\
\hline & 1-low & $0.4 \%$ & $0.1 \%$ & $0.0 \%$ & $-0.3 \%$ & $-1.4 \%$ & $-0.2 \%$ \\
\hline & 2 & $0.7 \%$ & $0.2 \%$ & $-0.1 \%$ & $-0.4 \%$ & $-1.7 \%$ & $-0.3 \%$ \\
\hline & 3 & $1.0 \%$ & $0.3 \%$ & $-0.1 \%$ & $-0.5 \%$ & $-1.8 \%$ & $-0.2 \%$ \\
\hline & 4 & $1.0 \%$ & $0.5 \%$ & $0.1 \%$ & $-0.7 \%$ & $-2.6 \%$ & $-0.4 \%$ \\
\hline & 5-high & $0.6 \%$ & $0.3 \%$ & $-0.3 \%$ & $-1.4 \%$ & $-3.8 \%$ & $-0.9 \%$ \\
\hline & $5-1$ & $0.2 \%$ & $0.1 \%$ & $-0.3 \%$ & $-1.1 \%$ & $-2.4 \%$ & $-0.7 \%$ \\
\hline & t-stat. & 0.5 & 0.4 & -1.1 & -4.0 & -7.3 & -2.7 \\
\hline \multirow{8}{*}{$\begin{array}{l}1 \\
7 \\
1 \\
0 \\
2\end{array}$} & & 1-low & 2 & 3 & 4 & 5-high & all \\
\hline & 1-low & $0.5 \%$ & $0.1 \%$ & $0.0 \%$ & $-0.3 \%$ & $-1.3 \%$ & $-0.2 \%$ \\
\hline & 2 & $0.8 \%$ & $0.3 \%$ & $-0.1 \%$ & $-0.4 \%$ & $-1.6 \%$ & $-0.2 \%$ \\
\hline & 3 & $1.0 \%$ & $0.3 \%$ & $-0.2 \%$ & $-0.4 \%$ & $-1.9 \%$ & $-0.2 \%$ \\
\hline & 4 & $0.9 \%$ & $0.4 \%$ & $0.0 \%$ & $-0.6 \%$ & $-2.6 \%$ & $-0.4 \%$ \\
\hline & 5-high & $0.5 \%$ & $0.3 \%$ & $-0.4 \%$ & $-1.4 \%$ & $-4.0 \%$ & $-1.0 \%$ \\
\hline & $5-1$ & $0.0 \%$ & $0.2 \%$ & $-0.5 \%$ & $-1.1 \%$ & $-2.7 \%$ & $-0.8 \%$ \\
\hline & t-stat. & 0.1 & 0.6 & -1.9 & -4.2 & -8.9 & -3.5 \\
\hline \multirow{8}{*}{$\begin{array}{l}1 \\
\frac{1}{7} \\
0 \\
0 \\
0 \\
0\end{array}$} & & 1-low & 2 & 3 & 4 & 5-high & all \\
\hline & 1-low & $0.6 \%$ & $0.1 \%$ & $-0.2 \%$ & $-0.4 \%$ & $-2.6 \%$ & $-0.5 \%$ \\
\hline & 2 & $0.5 \%$ & $0.2 \%$ & $-0.1 \%$ & $-0.7 \%$ & $-2.2 \%$ & $-0.5 \%$ \\
\hline & 3 & $0.7 \%$ & $0.1 \%$ & $-0.1 \%$ & $-0.3 \%$ & $-2.2 \%$ & $-0.3 \%$ \\
\hline & 4 & $1.0 \%$ & $0.3 \%$ & $0.1 \%$ & $-0.6 \%$ & $-2.0 \%$ & $-0.2 \%$ \\
\hline & 5-high & $1.0 \%$ & $0.3 \%$ & $0.0 \%$ & $-0.7 \%$ & $-2.7 \%$ & $-0.4 \%$ \\
\hline & $5-1$ & $0.4 \%$ & $0.2 \%$ & $0.2 \%$ & $-0.2 \%$ & $-0.1 \%$ & $0.1 \%$ \\
\hline & t-stat. & 1.6 & 0.9 & 0.9 & -1.0 & -0.3 & 0.5 \\
\hline
\end{tabular}

Note: This table shows average delta-hedged options returns of portfolios sorted by stock volatility and expensiveness (IV-HV). Panel A shows the results for calls and Panel B the results for puts. For each month of the data period January 1996 to August 2015, delta-hedged option returns are sorted by volatility (either VOL, IVOL-1F or SVOL-1F). Within each volatility quintile, option returns are then sorted by expensiveness. The table reports the average delta-hedged returns for each volatility-expensiveness combination, averaged over time. The last column (all) provides averages over all expensiveness categories. The row denoted by 5-1 presents the results for a long-short trading strategy that buys the portfolios with the highest volatilities (5-high) and sells the portfolios with the lowest volatilities (1-low). The t-statistics for the average returns of these portfolios are obtained via Newey-West estimators (Newey and West 1987), which account for heteroskedasticity and autocorrelation of the portfolio returns. 
Table 4.3: Average Returns of Options Sorted by Stock Volatility and Expensiveness: Three-factor Model

Panel A: Delta-hedged call returns

\begin{tabular}{|c|c|c|c|c|c|c|c|}
\hline & \multicolumn{7}{|c|}{ Option Expensiveness (IV-HV) } \\
\hline \multirow{8}{*}{$\stackrel{1}{0}$} & & 1-low & 2 & 3 & 4 & 5-high & all \\
\hline & 1-low & $0.3 \%$ & $-0.3 \%$ & $-0.4 \%$ & $-0.7 \%$ & $-1.8 \%$ & $-0.6 \%$ \\
\hline & 2 & $0.6 \%$ & $-0.2 \%$ & $-0.6 \%$ & $-0.8 \%$ & $-2.5 \%$ & $-0.7 \%$ \\
\hline & 3 & $1.1 \%$ & $-0.1 \%$ & $-0.5 \%$ & $-1.0 \%$ & $-2.7 \%$ & $-0.7 \%$ \\
\hline & 4 & $1.0 \%$ & $0.2 \%$ & $-0.5 \%$ & $-1.2 \%$ & $-3.7 \%$ & $-0.8 \%$ \\
\hline & 5-high & $0.7 \%$ & $0.1 \%$ & $-0.5 \%$ & $-1.9 \%$ & $-5.5 \%$ & $-1.4 \%$ \\
\hline & $5-1$ & $0.5 \%$ & $0.4 \%$ & $0.0 \%$ & $-1.2 \%$ & $-3.7 \%$ & $-0.8 \%$ \\
\hline & t-stat. & 1.1 & 1.2 & -0.1 & -3.8 & -10.0 & -2.4 \\
\hline \multirow{8}{*}{ 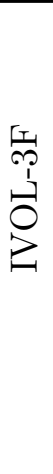 } & & 1-low & 2 & 3 & 4 & 5-high & all \\
\hline & 1-low & $0.3 \%$ & $-0.3 \%$ & $-0.4 \%$ & $-0.7 \%$ & $-1.8 \%$ & $-0.6 \%$ \\
\hline & 2 & $0.8 \%$ & $-0.2 \%$ & $-0.5 \%$ & $-0.8 \%$ & $-2.4 \%$ & $-0.6 \%$ \\
\hline & 3 & $1.0 \%$ & $0.1 \%$ & $-0.4 \%$ & $-0.9 \%$ & $-2.7 \%$ & $-0.6 \%$ \\
\hline & 4 & $1.1 \%$ & $0.1 \%$ & $-0.6 \%$ & $-1.2 \%$ & $-3.8 \%$ & $-0.9 \%$ \\
\hline & 5-high & $0.6 \%$ & $0.2 \%$ & $-0.7 \%$ & $-1.9 \%$ & $-5.7 \%$ & $-1.5 \%$ \\
\hline & $5-1$ & $0.3 \%$ & $0.6 \%$ & $-0.3 \%$ & $-1.2 \%$ & $-3.9 \%$ & $-0.9 \%$ \\
\hline & t-stat. & 0.8 & 1.8 & -0.7 & -4.2 & -11.2 & -3.0 \\
\hline \multirow{8}{*}{ 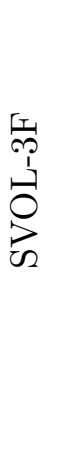 } & & 1-low & 2 & 3 & 4 & 5-high & all \\
\hline & 1-low & $0.5 \%$ & $-0.3 \%$ & $-0.5 \%$ & $-0.8 \%$ & $-2.7 \%$ & $-0.8 \%$ \\
\hline & 2 & $0.4 \%$ & $-0.2 \%$ & $-0.7 \%$ & $-0.9 \%$ & $-2.9 \%$ & $-0.9 \%$ \\
\hline & 3 & $0.7 \%$ & $-0.1 \%$ & $-0.6 \%$ & $-0.9 \%$ & $-3.1 \%$ & $-0.8 \%$ \\
\hline & 4 & $1.1 \%$ & $0.0 \%$ & $-0.6 \%$ & $-1.2 \%$ & $-3.4 \%$ & $-0.8 \%$ \\
\hline & 5-high & $1.0 \%$ & $0.2 \%$ & $-0.2 \%$ & $-1.2 \%$ & $-4.5 \%$ & $-1.0 \%$ \\
\hline & $5-1$ & $0.4 \%$ & $0.5 \%$ & $0.2 \%$ & $-0.4 \%$ & $-1.8 \%$ & $-0.2 \%$ \\
\hline & t-stat. & 1.2 & 1.4 & 0.6 & -1.1 & -5.2 & -0.7 \\
\hline
\end{tabular}


Panel B: Delta-hedged put returns

\begin{tabular}{|c|c|c|c|c|c|c|c|}
\hline & \multicolumn{7}{|c|}{ Option Expensiveness (IV-HV) } \\
\hline \multirow{8}{*}{$\stackrel{7}{\circ}$} & & 1-low & 2 & 3 & 4 & 5-high & all \\
\hline & 1-low & $0.4 \%$ & $0.1 \%$ & $0.0 \%$ & $-0.3 \%$ & $\%$ & $-0.2 \%$ \\
\hline & 2 & $0.7 \%$ & $0.2 \%$ & $-0.1 \%$ & $-0.4 \%$ & $-1.7 \%$ & $-0.3 \%$ \\
\hline & 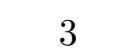 & $1.0 \%$ & $0.3 \%$ & $-0.1 \%$ & $-0.5 \%$ & $-1.8 \%$ & $-0.2 \%$ \\
\hline & 4 & $1.0 \%$ & 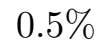 & $0.1 \%$ & -0 . & $-2.6 \%$ & $-0.4 \%$ \\
\hline & 5-high & $0.6 \%$ & $0.3 \%$ & $-0.3 \%$ & $-1.4 \%$ & $-3.8 \%$ & $-0.9 \%$ \\
\hline & $5-1$ & $0.2 \%$ & $0.1 \%$ & $-0.3 \%$ & $-1.1 \%$ & $-2.4 \%$ & $-0.7 \%$ \\
\hline & $\mathrm{t}-$ & 0.5 & 0.4 & -1.1 & -4.0 & -7.3 & -2.7 \\
\hline \multirow{8}{*}{$\begin{array}{l}\frac{1}{1 / 3} \\
\frac{1}{1} \\
0 \\
2\end{array}$} & & 1-low & 2 & 3 & 4 & 5-high & all \\
\hline & 1-low & $0.5 \%$ & $0.2 \%$ & $0.0^{\circ}$ & $-0.3 \%$ & $-1.4 \%$ & $-0.2 \%$ \\
\hline & 2 & $0.8 \%$ & $0.3 \%$ & $-0.1 \%$ & -0 . & $-1.6 \%$ & $-0.2 \%$ \\
\hline & 3 & $1.0 \%$ & $0.5 \%$ & $-0.1 \%$ & $-0.4 \%$ & $-1.9 \%$ & $-0.2 \%$ \\
\hline & 4 & $0.9 \%$ & $.4 \%$ & $-0.1 \%$ & $-0.7 \%$ & $-2.6 \%$ & $-0.4 \%$ \\
\hline & 5-high & $0.5 \%$ & $0.4 \%$ & $-0.5 \%$ & $-1.4 \%$ & $-3.9 \%$ & $-1.0 \%$ \\
\hline & $5-1$ & $0.0 \%$ & $0.2 \%$ & $-0.6 \%$ & $-1.1 \%$ & $-2.5 \%$ & $-0.8 \%$ \\
\hline & t-stat. & 0.1 & 0.6 & -2.3 & -4.2 & -8.5 & -3.5 \\
\hline \multirow{8}{*}{$\begin{array}{l}P_{1} \\
0 \\
0 \\
0\end{array}$} & & $1-1$ & 2 & 3 & 4 & SII & $a$ \\
\hline & 1-low & $0.4 \%$ & $0.2 \%$ & $-0.1 \%$ & $-0.4 \%$ & $-1.9 \%$ & $-0.4 \%$ \\
\hline & 2 & $0.5 \%$ & $0.2 \%$ & $-0.2 \%$ & $-0.4 \%$ & $-2.1 \%$ & $-0.4 \%$ \\
\hline & 3 & $0.8 \%$ & $0.2 \%$ & $0.0 \%$ & $-0.5 \%$ & $-2.1 \%$ & $-0.3 \%$ \\
\hline & 4 & $1.0 \%$ & $0.4 \%$ & $-0.1 \%$ & $-0.7 \%$ & $-2.3 \%$ & $-0.3 \%$ \\
\hline & 5-high & $0.9 \%$ & $0.4 \%$ & $0.1 \%$ & $-0.8 \%$ & $-3.1 \%$ & $-0.5 \%$ \\
\hline & 5 & $0.5 \%$ & $0.2 \%$ & $0.1 \%$ & $-0.4 \%$ & $-1.2 \%$ & $-0.2 \%$ \\
\hline & t-stat. & 1.8 & 0.7 & 0.5 & -1.3 & -4.2 & -0.6 \\
\hline
\end{tabular}

Note: This table shows average delta-hedged options returns of portfolios sorted by stock volatility and expensiveness (IV-HV). Panel A shows the results for calls and Panel B the results for puts. For each month of the data period January 1996 to August 2015, delta-hedged option returns are sorted by volatility (either VOL, IVOL-3F or SVOL-3F). Within each volatility quintile, option returns are then sorted by expensiveness. The table reports the average delta-hedged returns for each volatility-expensiveness combination, averaged over time. The last column (all) provides averages over all expensiveness categories. The row denoted by 5-1 presents the results for a long-short trading strategy that buys the portfolios with the highest volatilities (5-high) and sells the portfolios with the lowest volatilities (1-low). The t-statistics for the average returns of these portfolios are obtained via Newey-West estimators (Newey and West 1987), which account for heteroskedasticity and autocorrelation of the portfolio returns. 
Table 4.4: Regressions of Average Returns of Long-Short (1-5) Portfolios When Expensiveness is High (5-high) on Different Combinations of Factors

Panel A: Calls

\begin{tabular}{|c|c|c|c|c|c|}
\hline & Model 1 & Model 2 & Model 3 & Model 4 & Model 5 \\
\hline Alpha & $\begin{array}{l}3.75 \% \\
(8.85)\end{array}$ & $\begin{array}{l}3.74 \% \\
(10.49)\end{array}$ & $\begin{array}{l}3.96 \% \\
(11.99)\end{array}$ & $\begin{array}{l}3.74 \% \\
(10.53)\end{array}$ & $\begin{array}{c}3.84 \% \\
(8.98)\end{array}$ \\
\hline MKT & $\begin{array}{l}0.255 \\
(3.52)\end{array}$ & & & & $\begin{array}{l}0.063 \\
(0.51)\end{array}$ \\
\hline SMB & $\begin{array}{l}0.145 \\
(1.05)\end{array}$ & & & & $\begin{array}{l}0.046 \\
(0.34)\end{array}$ \\
\hline HML & $\begin{array}{l}-0.281 \\
(-2.69)\end{array}$ & & & & $\begin{array}{l}-0.214 \\
(-2.25)\end{array}$ \\
\hline MOM & $\begin{array}{c}-0.014 \\
(-0.15)\end{array}$ & & & & $\begin{array}{l}0.023 \\
(0.26)\end{array}$ \\
\hline LowVol & $\begin{array}{l}4.362 \\
(0.48)\end{array}$ & & & & $\begin{array}{l}-3.522 \\
(-0.39)\end{array}$ \\
\hline $\begin{array}{l}\text { ZB-STR } \\
\text { Index }\end{array}$ & & $\begin{array}{l}-0.252 \\
(-4.00)\end{array}$ & & $\begin{array}{l}-1.847 \\
(-1.69)\end{array}$ & $\begin{array}{l}-1.420 \\
(-1.30)\end{array}$ \\
\hline dVIX & & & $\begin{array}{l}-0.263 \\
(-4.90)\end{array}$ & & $\begin{array}{l}-0.110 \\
(-1.23)\end{array}$ \\
\hline $\begin{array}{c}\text { ZB-STR } \\
\text { Stocks }\end{array}$ & & & & $\begin{array}{l}-1.836 \\
(-0.85)\end{array}$ & $\begin{array}{l}-0.685 \\
(-0.26)\end{array}$ \\
\hline$R_{a d j}^{2}$ & 0.115 & 0.088 & 0.104 & 0.088 & 0.162 \\
\hline
\end{tabular}


Panel B: Puts

\begin{tabular}{|c|c|c|c|c|c|}
\hline & Model 1 & Model 2 & Model 3 & Model 4 & Model 5 \\
\hline Alpha & $\begin{array}{c}2.54 \% \\
(7.37)\end{array}$ & $\begin{array}{c}2.57 \% \\
(7.81)\end{array}$ & $\begin{array}{c}2.63 \% \\
(8.77)\end{array}$ & $\begin{array}{c}2.57 \% \\
(7.82)\end{array}$ & $\begin{array}{c}2.56 \% \\
(7.48)\end{array}$ \\
\hline MKT & $\begin{array}{l}0.158 \\
(2.25)\end{array}$ & & & & $\begin{array}{l}0.113 \\
(1.14)\end{array}$ \\
\hline SMB & $\begin{array}{l}0.096 \\
(1.01)\end{array}$ & & & & $\begin{array}{l}0.100 \\
(1.01)\end{array}$ \\
\hline HML & $\begin{array}{l}-0.217 \\
(-3.14)\end{array}$ & & & & $\begin{array}{l}-0.209 \\
(-3.18)\end{array}$ \\
\hline MOM & $\begin{array}{l}-0.007 \\
(-0.12)\end{array}$ & & & & $\begin{array}{l}-0.013 \\
(-0.21)\end{array}$ \\
\hline LowVol & $\begin{array}{l}0.629 \\
(0.09)\end{array}$ & & & & $\begin{array}{l}0.441 \\
(0.06)\end{array}$ \\
\hline $\begin{array}{c}\text { ZB-STR } \\
\text { Index }\end{array}$ & & $\begin{array}{l}-0.875 \\
(-1.63)\end{array}$ & & $\begin{array}{l}-1.354 \\
(-1.42)\end{array}$ & $\begin{array}{l}-1.017 \\
(-1.17)\end{array}$ \\
\hline dVIX & & & $\begin{array}{l}-0.139 \\
(-2.66)\end{array}$ & & $\begin{array}{l}-0.053 \\
(-0.77)\end{array}$ \\
\hline $\begin{array}{c}\text { ZB-STR } \\
\text { Stocks }\end{array}$ & & & & $\begin{array}{l}1.310 \\
(0.69)\end{array}$ & $\begin{array}{l}2.305 \\
(1.07)\end{array}$ \\
\hline$R_{a d j}^{2}$ & 0.120 & 0.016 & 0.049 & 0.014 & 0.120 \\
\hline
\end{tabular}

Note: This table shows the results of different regression models that regress the returns of a low-volatility trading strategy on different combinations of factors. Panel A provides the results for calls and Panel B the results for puts. The low-volatility trading strategy holds long positions in a low-volatility portfolio (1-low) and short positions in a high-volatility portfolio (5-high). These portfolios refer to the highest expensiveness quintiles (see Table 4.2) and use IVOL-1F. Based on Fama and French's (1993) model, we consider the market factor (MKT), the value factor (HML) and the size factor (SMB). In addition, we use Carhart's (1997) momentum factor (MOM) and a low-volatility stock market factor (LowVol). Factors referring to the option market are the returns of zero-beta straddles on the S\&P 500 Index (ZB-STR Index), the average returns of zero-beta straddles written on the component stocks of the S\&P 500 Index (ZB-STR Stocks), and changes in the VIX Index (dVIX). The t-statistics (in parentheses) are obtained via Newey-West estimators (Newey and West 1987), which account for heteroskedasticity and autocorrelation. 
Table 4.5: Average Returns and Alphas of Long-Short (1-5) Portfolios When Expensiveness is High (5-high) for Different Periods

Panel A: Calls

\begin{tabular}{ccccc}
\hline & Full Period & excl. Crisis & $\leq 04 / 2003$ & $>04 / 2003$ \\
\hline Average Return & $4.03 \%$ & $4.05 \%$ & $3.17 \%$ & $4.54 \%$ \\
& $(11.48)$ & $(10.76)$ & $(4.26)$ & $(13.55)$ \\
\hline Alpha & $3.84 \%$ & $3.74 \%$ & $2.89 \%$ & $4.60 \%$ \\
(Eight-Factor Model) & $(8.98)$ & $(7.09)$ & $(3.60)$ & $(12.09)$ \\
\hline
\end{tabular}

Panel B: Puts

\begin{tabular}{ccccc}
\hline & Full Period & excl. Crisis & $\leq 04 / 2003$ & $>04 / 2003$ \\
\hline Average Return & $2.67 \%$ & $2.59 \%$ & $1.38 \%$ & $3.43 \%$ \\
& $(8.91)$ & $(7.74)$ & $(2.37)$ & $(14.11)$ \\
\hline Alpha & $2.56 \%$ & $2.28 \%$ & $1.02 \%$ & $3.48 \%$ \\
(Eight-Factor Model) & $(7.48)$ & $(5.23)$ & $(1.61)$ & $(13.86)$ \\
\hline
\end{tabular}

Note: This table shows the average returns and alphas of a low-volatility trading strategy for different time periods. Panel A provides the results for calls and Panel B the results for puts. The low-volatility trading strategy holds a long position in a low-volatility portfolio (1-low) and a short position in a high-volatility portfolio (5-high). These portfolios refer to the highest expensiveness quintiles (see Table 4.2) and use IVOL-1F. Alphas are obtained from the eight-factor model (Model 5) in Table 4.4. The full data period is from January 1996 to August 2015. The crisis period is from June 2007 to December 2009. The t-statistics (in parentheses) are obtained via Newey-West estimators (Newey and West 1987), which account for heteroskedasticity and autocorrelation. 
Table 4.6: Effect of Transaction Costs on Average Returns and Alphas of Long-Short (1-5) Portfolios When Expensiveness is High (5-high)

Panel A: Calls

\begin{tabular}{ccccc}
\hline ESRP/QSPR & MidP & $10 \%$ & $25 \%$ & $50 \%$ \\
\hline Average Return & $4.03 \%$ & $3.30 \%$ & $2.22 \%$ & $0.46 \%$ \\
& $(11.48)$ & $(9.88)$ & $(6.81)$ & $(1.29)$ \\
\hline Alpha & $3.84 \%$ & $3.08 \%$ & $1.96 \%$ & $0.14 \%$ \\
(Eight-Factor-Model) & $(8.98)$ & $(7.42)$ & $(4.80)$ & $(0.34)$ \\
\hline
\end{tabular}

Panel B: Puts

\begin{tabular}{ccccc}
\hline ESRP/QSPR & MidP & $10 \%$ & $25 \%$ & $50 \%$ \\
\hline Average Return & $2.67 \%$ & $2.16 \%$ & $1.39 \%$ & $0.08 \%$ \\
& $(8.91)$ & $(7.49)$ & $(4.98)$ & $(0.28)$ \\
\hline Alpha & $2.56 \%$ & $2.04 \%$ & $1.24 \%$ & $-0.10 \%$ \\
(Eight-Factor-Model) & $(7.48)$ & $(6.16)$ & $(3.90)$ & $(-0.33)$ \\
\hline
\end{tabular}

Note: This table shows the average returns and alphas of a low-volatility trading strategy for different levels of transaction costs. Panel A provides the results for calls and Panel B the results for puts. The low-volatility trading strategy holds long positions in a low-volatility portfolio (1-low) and short positions in a high-volatility portfolio (5-high). These portfolios refer to the highest expensiveness quintiles (see Table 4.2) and use IVOL-1F. Alphas are obtained from the eight-factor model (Model 5) in Table 4.4. The data period is from January 1996 to August 2015. The different transaction cost scenarios refer to different ratios of ESPR to QSPR: $10 \%, 25 \%$, or $50 \%$. As a reference point, the table also includes the case without transaction costs (MidP). The t-statistics (in parentheses) are obtained via Newey-West estimators (Newey and West 1987), which account for heteroskedasticity and autocorrelation. 


\section{Conclusion}

This dissertation studied the behaviour of equity and index option returns in perfect and imperfect markets providing guidance to investors' decision making process when trading highly risky non-linear derivative products.

Chapter 1 provides an introduction and overview of the questions discussed in the main chapters. Chapter 2 analyzes the behaviour of expected and realized S\&P500 option returns in perfect markets under a risk-adjusted option-implied approach and option return volatility in the Black-Scholes model. Chapter 3 presents the derivation of and empirical study on option return volatility in the Black-Scholes model. Chapter 4 investigates the option mispricing puzzle in an imperfect markets setting, where option market makers adjust their quotes based on their own net position and the underlying's idiosyncratic volatility due to hedging costs. This conclusion summarizes the findings of the three main chapters 2 - 4 and provides an outlook on further research questions.

\section{Summary on Findings in Main Chapters}

Chapter 2 applied the option-implied risk-adjusted approach by Brinkmann and Korn (2018) to predict mean realized S\&P500 index option returns in perfect markets. The approach is highly flexible and dynamic as it instantly adjusts to changes in current option market prices and can be equipped with arbitrary risk-averse preferences. As shown through an option return prediction test, the approach well explained realized S\&P500 put option returns under CRRA risk preferences, while S\&P500 call returns were unexplainable due to the empirically U-shaped pricing kernel.

Chapter 3 studied option return volatility in a Black-Scholes world providing analytical expressions for option return volatility over instantaneous, before-expiration and hold-toexpiration time periods. The cross-sectional option volatility sensitivities to the option parameters are illustrated: At-the-money Black-Scholes call volatility over finite holding 
periods increases with time to maturity, underlying volatility, underlying physical drift and dividend yield, and decreases with the risk-free rate and moneyness. At-the-money BlackScholes put volatility over finite holding periods decreases with time to maturity, underlying physical drift, dividend yield and moneyness, can increase and decrease with underlying volatility, and increases with the risk-free rate. Option volatilities under the Black-Scholes model behave similarly when held to maturity or sold prior to maturity, but differences exist for the instantaneous holding period where at-the-money call volatility decreases with time-to-maturity, and both call and put volatility are independent of the physical drift rate. An empirical test on realized S\&P500 option volatilities against the Black-Scholes model shows that Black-Scholes option volatilities were rejected with respect to realized call volatilities over finite and instantaneous holding periods, while put volatilities were not rejected for finite and instantaneous holding periods except instantaneous out-of-money put volatilities; this result connects well with chapter 2 where mean realized put returns but not call returns were explainable by the implied risk-adjusted approach.

Chapter 4 investigates the conditional low-volatility effect in option markets, where the negative relation between underlying volatility and delta-hedged option returns is found to be conditional on option expensiveness being high. For cheap options, the effect can be even reversed but is only weakly significant. Hereby option expensiveness was used as a proxy for market makers' net positions in options and IVOL as a proxy for market imperfections induced by hedging costs. The hedging of long positions in options is less risky as the loss of the holder is capped at the option premium, while a short position in options can cause potentially infinite losses. The asymmetry of the conditional low-volatility effect in option markets further leads to an observed net unconditional low-volatility effect. These findings demonstrate the importance of market imperfections, where investors in options markets can potentially gain alpha from the observed conditional low-volatility effect in option prices which is three to four times stronger than the unconditional one and cannot be explained by common factor risks in the stock and option market. 


\section{Research Outlook}

As shown in Chapters 2 and 3 of this thesis, S\&P500 put returns can be well explained by the option-implied risk-adjusted approach and even the standard Black Scholes model. However, none of the tested models were able to explain the mean negative realized call returns. As discussed in Chapter 2, the realization of negative call returns when the underlying return is positive could only be explained by risk-seeking preferences in the region above the current stock price. As the explanation of put returns however requires risk-averse behaviour in the region below the current stock price, the overall utility function required to fit both call and put returns should reflect a U-shaped pricing kernel. However, none of the known standard utility functions contain reflect such property which therefore represents a question for future research in order to explain realized call returns in perfect markets. Another related question in an imperfect markets setting is whether the shorting of S\&P500 call options could still lead to significant excess returns given the high spreads and margin requirements involved in such strategies.

Chapter 4 explores the conditional low volatility effect in individual stock options revealing an asymmetry in market makers' option quoting: When market makers are net short in options due to positive end-user demand pressure, they tend to sell further options only at a significant premium when hedging error is high due to high idiosyncratic volatility of the underlying. When market makers are net long, the effect tends to reverse but not statistically significant. Therefore further research may explore the determinants of option quotes where market makers being net long. The study further uses sorted option portfolios based on the IV-HV measure as a proxy for market makers' position, while the true position being unknown. It may hence be important to reconfirm the above results using end-user option demand data or other records on market maker positions where possible. 


\section{Bibliography}

Ang, A., R. J. Hodrick, Y. Xing, and X. Zhang (2006). The cross section of volatility and expected returns. Journal of Finance 61(1), 259-299.

Ang, A., R. J. Hodrick, Y. Xing, and X. Zhang (2009). High idiosyncratic volatility and low returns: International and further U.S. evidence. Journal of Financial Economics $91(1)$, $1-23$.

Bakshi, G., N. Kapadia, and D. Madan (2003). Stock return characteristics, skew laws, and the differential pricing of individual equity options. The Review of Financial Studies 16(1), 101-143.

Bakshi, G., D. Madan, and G. Panayotov (2010). Returns of claims on the upside and the viability of u-shaped pricing kernels. Journal of Financial Economics 97, 130-154.

Bali, T. G., S. J. Brown, S. Murray, and Y. Tang (2017). A lottery-demand-based explanation of the beta anomaly. Journal of Financial and Quantitative Analysis 52(6), 2369-2397.

Bali, T. G., N. Cakici, and R. F. Whitelaw (2011). Maxing out: Stocks as lotteries and the cross-section of expected returns. Journal of Financial Economics 99(2), 427-446.

Bates, D. S. (2000). Post-' 87 crash fears in the s\&p 500 futures option market. Journal of Econometrics 94(1-2), 181-238.

Benko, M., M. Fengler, W. Härdle, and M. Kopa (2007, Dec). On extracting information implied in options. Computational Statistics 22(4), 543-553.

Black, F. (1975). Fact and fantasy in the use of options. Financial Analysts Journal 31(4), pp. $36-41+61-72$.

Black, F. and M. Scholes (1973). The pricing of options and corporate liabilities. Journal of Political Economy 81(3), 637-654. 
Bollen, N. P. B. and R. E. Whaley (2004). Does net buying pressure affect the shape of implied volatility functions? The Journal of Finance 59(2), 711-753.

Bondarenko, O. (2014). Why are put options so expensive? Quarterly Journal of Finance $04(1450015)$.

Boyer, B. and K. Vorkink (2014). Stock options as lotteries. The Journal of Finance 69(4).

Brinkmann, F., A. Kempf, and O. Korn (2014). Forward-looking measures of higher order dependencies with an application to portfolio selection. SSRN eLibrary 2385228.

Brinkmann, F. and O. Korn (2018). Risk-adjusted option-implied moments. Review of Derivatives Research 21, 149-173.

Broadie, M., M. Chernov, and M. Johannes (2009). Understanding index option returns. The Review of Financial Studies 22(11), 4493-4529.

Brown, D. P. and J. C. Jackwerth (2012). The Pricing Kernel Puzzle: Reconciling Index Option Data and Economic Theory, pp. 155-183. Book Series: Contemporary Studies in Economic and Financial Analysis AND Emerald Group Publishing Limited.

Byun, S.-J. and D.-H. Kim (2016). Gambling preference and individual equity option returns. Journal of Financial Economics 122, 155-174.

Cao, J. and B. Han (2013). Cross section of option returns and idiosyncratic stock volatility. Journal of Financial Economics 108(1), 231 - 249.

Carhart, M. M. (1997). On persistence in mutual fund performance. Journal of Finance 52(1), 57-82.

Chambers, D. R., M. Foy, J. Liebner, and Q. Lu (2014). Index option returns: Still puzzling. The Review of Financial Studies.

Christoffersen, P., M. Fournier, and K. Jacobs (2018). The factor structure in equity options. Review of Financial Studies 31(2), 595-637.

Christoffersen, P., R. Goyenko, K. Jacobs, and M. Karoui (2014, July). Illiquidity premia in the equity options market. Working Paper. 
Christoffersen, P., S. Heston, and K. Jacobs (2013). Capturing option anomalies with a variance-dependent pricing kernel. The Review of Financial Studies 26(8), 1963-2006.

Coval, J. D. and T. Shumway (2001). Expected option returns. The Journal of Finance $56(3), 983-1009$.

Driessen, L., P. J. Maenhout, and G. Vilkov (2009). The price of correlation risk: Evidence from equity options. The Journal of Finance 64(3), 1377-1406.

Fama, E. F. and K. R. French (1993). Common risk factors in the returns on stocks and bonds. Journal of Financial Economics 33(1), 3-56.

Figlewski, S. (1989). Options arbitrage in imperfect markets. The Journal of Finance 44(5), 1289-1311.

Figlewski, S. (2010). Estimating the implied risk neutral density for the u.s. market portfolio. Volatility and Time Series Econometrics: Essays in Honor of Robert F. Engle.

Frazzini, A. and L. H. Pedersen (2014). Betting against beta. Journal of Financial Economics 111(1), 1-25.

Garleanu, N., L. H. Pedersen, and A. M. Poteshman (2009). Demand-based option pricing. The Review of Financial Studies 22(10), 4259-4299.

Goyal, A. and A. Saretto (2009). Cross-section of option returns and volatility. Journal of Financial Economics 94(2), 310 - 326.

Goyenko, R., C. Ornthanalai, and S. Tang (2014, September). Trading cost dynamics of market making in equity options. Rotman School of Management Working Paper No. 2492506 .

Heston, S. L. (1993). A closed-form solution for options with stochastic volatility with applications to bond and currency options. Review of Financial Studies 6(2), 327-343.

Hitzemann, S., M. Hofmann, M. Uhrig-Homburg, and C. Wagner (2018). Margin requirements and equity option returns. Working paper, Rutgers University, Karlsruhe Institute of Technology (KIT) and WU Vienna. 
Hu, G. and K. Jacobs (2016). Volatility and expected option returns. Working Paper.

Huang, D. and I. Shaliastovich (2014, September). Volatility-of-volatility risk. Working Paper.

Kanne, S., O. Korn, and M. Uhrig-Homburg (2018). Stock illiquidity and option returns. Working paper, Karlsruhe Institute of Technology (KIT) and University of Goettingen.

Karakaya, M. (2014, January). Characteristics and expected returns in individual equity options. Working Paper.

Menezes, C. F. and D. L. Hanson (1970). On the theory of risk aversion. International Economic Review 11(3), 481-487.

Merton, R. C. (1973). An intertemporal capital asset pricing model. Econometrica 41(5).

Mohrschladt, H. and J. C. Schneider (2018). The idiosyncratic volatility puzzle and its interplay with sophisticated and private investors. Working paper, University of Muenster.

Muravyev, D. (2016). Order flow and expected option returns. Journal of Finance 71(3), $673-708$.

Newey, W. K. and K. D. West (1987). A simple, positive semi-definite, heteroskedasticity and autocorrelation consistent covariance matrix. Econometrica 55(3), 703-708.

Ni, S. X. (2009). Stock option returns: A puzzle. Working Paper.

Ni, S. X., J. Pan, and A. M. N. Poteshman (2008). Volatility information trading in the option market. The Journal of Finance 63(3), 1059-1091.

Pratt, J. W. (1964). Risk aversion in the small and in the large. Econometrica 32(1/2), 122-136.

Rubinstein, M. (1976). The valuation of uncertain income streams and the pricing of options. The Bell Journal of Economics 7(2), pp. 407-425. 
Santa-Clara, P. and A. Saretto (2009). Option strategies: Good deals and margin calls. Journal of Financial Markets 12(3), 391 - 417.

Schürhoff, N. and A. Ziegler (2011, February). Variance risk, financial intermediation, and the cross-section of expected option returns. CEPR Discussion Paper No. DP8268.

Shu, J. and J. E. Zhang (2012). Causality in the VIX futures market. Journal of Futures Markets 32(1), 24-46.

Simon, D. P. and J. Campasano (2014). The VIX futures basis: Evidence and trading strategies. Journal of Derivatives 21(3), 54-69. 


\section{Ph.D. program in Economics \\ Declaration for admission to the doctoral examination}

I confirm

1. that the dissertation "Analysis of option returns in perfect and imperfect markets" that I submitted was produced independently without assistance from external parties, and not contrary to high scientific standards and integrity,

2. that I have adhered to the examination regulations, including upholding a high degree of scientific integrity, which includes the strict and proper use of citations so that the inclusion of other ideas in the dissertation are clearly distinguished,

3. that in the process of completing this doctoral thesis, no intermediaries were compensated to assist me neither with the admissions or preparation processes, and in this process,

- no remuneration or equivalent compensation were provided

- no services were engaged that may contradict the purpose of producing a doctoral thesis

4. that I have not submitted this dissertation or parts of this dissertation elsewhere,

5. that my own contribution to each cumulative part of this dissertation was as follows: Chapter 2 (100\%), Chapter 3 (100\%), Chapter 4 (33\%).

I am aware that false claims and the discovery of those false claims now, and in the future with regards to the declaration for admission to the doctoral examination can lead to the invalidation or revoking of the doctoral degree.

Place, Date

David Salazar Volkmann 